UNIVERSIDADE DE BRASÍLIA

FACULDADE DE TECNOLOGIA

DEPARTAMENTO DE ENGENHARIA MECÂNICA

\author{
DESENVOLVIMENTO DE UM SENSOR DE VISÃO PARA \\ MONITORAÇÃO DOS PARÂMETROS GEOMÉTRICOS DA POÇA \\ DE SOLDA NO PROCESSO GTAW PULSADO
}

FILIPE FRAGA PAULA SILVA

ORIENTADOR: Dr. GUILHERME CARIBÉ DE CARVALHO

DISSERTAÇÃO DE MESTRADO EM SISTEMAS MECATRÔNICOS

BRASÍLIA/DF, 31 DE AGOSTO DE 2016 
UNIVERSIDADE DE BRASÍLIA

FACULDADE DE TECNOLOGIA

DEPARTAMENTO DE ENGENHARIA MECÂNICA

\author{
DESENVOLVIMENTO DE UM SENSOR DE VISÃO PARA \\ MONITORAÇÃO DOS PARÂMETROS GEOMÉTRICOS DA POÇA \\ DE SOLDA NO PROCESSO GTAW PULSADO
}

FILIPE FRAGA PAULA SILVA

DISSERTAÇÃO SUBMETIDA AO DEPARTAMENTO DE ENGENHARIA MECÂNICA DA FACULDADE DE TECNOLOGIA DA UNIVERSIDADE DE BRASÍLIA COMO PARTE DOS REQUISITOS NECESSÁRIOS PARA A OBTENÇÃO DO GRAU DE MESTRE EM SISTEMAS MECATRÔNICOS.

APROVADO POR

Prof. Dr. Guilherme Caribé de Carvalho, (ENM-UnB) (Orientador)

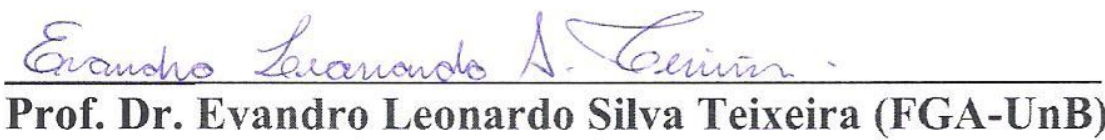
(Examinador Externo ao PPMEC)

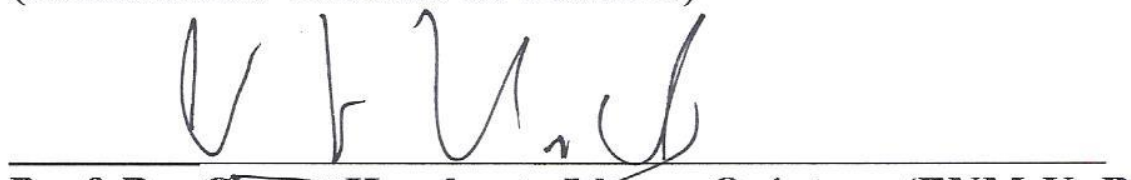

Prof. Dr. Cåros Humberto thanos Quintero (ENM-UnB) (Examinador Interno) 


\section{FICHA CATALOGRÁFICA}

SILVA. P. F. FILIPE.

Desenvolvimento de um sensor de visão para monitoramento dos parâmetros geométricos da poça de solda no processo GTAW pulsado. [Distrito Federal] 2016.

107p. 297mm (ENM/FT/UnB, Mestre, Sistemas Mecatrônicos, 2016). Dissertação de Mestrado - Universidade de Brasília. Faculdade de Tecnologia. Dissertação de Mestrado - Universidade de Brasília. Faculdade de Tecnologia.

Departamento de Engenharia Mecânica.

1. Poça de solda

3. Soldagem

I. ENM/FT/UnB
2. Sensor de Visão

4.Soldagem TIG

II. Título (série)

\section{REFERÊNCIA BIBLIOGRÁFICA}

SILVA. P. F FILIPE. (2016). Desenvolvimento e um sensor de visão para monitoramento dos parâmetros geométricos da poça de solda no processo GTAW pulsado. Dissertação de Mestrado em Sistemas Mecatrônicos, Publicação ENM.DM-110/16, Departamento de Engenharia Mecânica,

Universidade de Brasília, Brasília, DF, 107p.

\section{CESSÃO DE DIREITOS}

AUTOR: Filipe Fraga Paula Silva.

TÍTULO: Desenvolvimento e um sensor de visão para monitoramento dos parâmetros geométricos da poça de solda no processo GTAW pulsado.

GRAU: Mestre

ANO: 2016

É concedida à Universidade de Brasília permissão para reproduzir cópias desta dissertação de mestrado e para emprestar ou vender tais cópias somente para propósitos acadêmicos e científicos. O autor reserva outros direitos de publicação e nenhuma parte dessa dissertação de mestrado pode ser reproduzida sem autorização por escrito do autor.

Filipe Fraga Paula Silva 


\section{DEDICATÓRIA}

Dedico esse trabalho a Deus, minha família (pais e irmãos), minha querida irmã Leopoldina e minha amada esposa Franciele. 


\section{AGRADECIMENTO}

Começo minha lista de agradecimentos citando a misericórdia e o amor de Deus, que tornou tudo isso possível dando-me forças para finalizar todas etapas propostas neste trabalho. Agradeço em especial minha família pelos esforços as vezes sobre humano com propósito de ajudar a prosseguir minha carreira acadêmica, suas orações e amor incondicional. Agradeço minha esposa Franciele, por sua paciência na espera da conclusão deste trabalho e pela força em se empenhar a realização do mesmo, você foi um dos motivos de almejar algo mais. Não poderia deixar de citar a minha querida irmã Leopoldina que durante minha estadia em Brasília me recebeu em sua casa como filho e como tal fui tratado, minhas orações são para que Deus possa multiplicar grandemente em sua vida e família.

Agradeço também ao professor Guilherme Caribé e a turma do laboratório GRACO pelos conhecimentos compartilhados que possibilitaram a conclusão do projeto. 


\section{EPIGRAFE}

Ora, àquele que é poderoso para vos guardar de tropeçar, e apresentar-vos irrepreensíveis, com alegria, perante a sua glória. Ao único Deus sábio, Salvador nosso, seja glória e majestade, domínio e poder, agora, e para todo o sempre. Amém. 


\title{
DESENVOLVIMENTO DE UM SENSOR DE VISÃO PARA MONITORAMETO DOS PARÂMETROS GEOMÉTRICOS DA POÇA DE SOLDA NO PROCESSO GTAW PULSADO
}

\author{
Autor: Filipe Fraga Paula Silva \\ Orientador: Dr. Guilherme Caribé de Carvalho \\ Programa de Pós-graduação em Sistemas Mecatrônicos
}

\section{Brasília, Agosto de 2016}

Este trabalho apresenta o desenvolvimento de um sensor para monitoramento geométrico da poça de fusão em um processo GTAW pulsado utilizando uma câmera de alta velocidade CMOS para aquisição das imagens. A configuração da câmera é tal que o seu eixo óptico é paralelo ao eixo longitudinal da tocha e a imagem da poça de solda é transmitida por meio de um conjunto de espelhos planos. Afim de reduzir o efeito da luz causada pela emissão do arco, um filtro passa alta com corte na região do infravermelho é utilizado de tal modo que a emissão do arco no espectro visível e ultravioleta são eliminados. A configuração do sensor permite a redução do tamanho da estrutura de fixação do conjunto óptico, pois utiliza as leis da reflexão para direcionar a imagem desejada até a câmera. A estrutura de sustentação dos aparatos ópticos foi projetada com a finalidade de minimizar o efeito de vibração na câmera ocasionada pelo movimento robótico e na perda de graus de orientação da tocha no processo de soldagem robotizado. Com a configuração proposta, é possível obter imagens consistentes e de qualidade da poça de fusão permitindo extrair seus dados geométricos. Neste trabalho a principal característica geométrica desejada é a largura da poça de fusão, uma vez que é fortemente correlacionada à largura do cordão resultante. Por se tratar de um processo no qual o arco está constantemente aberto, um software para sincronização das imagens baseado na análise do brilho do arco foi proposto, mostrando eficiência na seleção das imagens com menor interferência luminosa. A integração da estrutura óptica com os softwares proporcionou imagens consistentes para análise de parâmetros que futuramente podem ser usadas nos métodos de controle.

Palavras chaves: Poça de Solda, Sensor de Visão, Soldagem, Soldagem TIG, Detecção de borda. 


\begin{abstract}
DEVELOPMENT OF A VISION SENSOR FOR MONITORING OF GEOMETRIC PARAMETERS OF WELD POOL IN PULSED GTAW
\end{abstract}

Author: Filipe Fraga Paula Silva

Supervisor: Dr. Guilherme Caribé de Carvalho

Mechatronic Systems Post-graduation Program

Brasília, August th2016

This work presents the development of a sensor for monitoring weld pool geometry in a pulsed GTAW process using a high-speed CMOS camera for image acquisition. The configuration of the camera is such that its optical axis is parallel to the longitudinal axis of the torch and the weld pool image is transmitted through a set of plane mirrors. In order to reduce the effect caused by the emission of light from the arc, a long wave pass filter with cutoff in the infrared region is used such that the emission of the arc in the UV and visible spectra are eliminated. The proposed sensor configuration enabled the reduction in size of the optical assembly structure because it uses the laws of reflection to direct the desired image to the camera. The bearing structure of the optical apparatus is designed in order to minimize the effect of camera vibration caused by robotic movement and loss of degrees orientation of the robot torch at the welding process. With the proposed configuration, it is possible to obtain consistent quality images of the weld pool, allowing extract their geometric data. At this work, the main geometrical feature desired is the weld pool width, once it is strongly correlated the resulting bead width. Because it is a process in which the arch is constantly open, one software for synchronization based on the analysis of the arc brightness was proposed showing efficiency in the selection of images with less light interference. The integration of optical structure with the proposed software provided consistent images for analysis of parameters that can be used in future control methods.

Key words: Weld Pool, Sensor Vision, Welding, TIG Welding, Edge Detection. 


\section{LISTA DE FIGURAS}

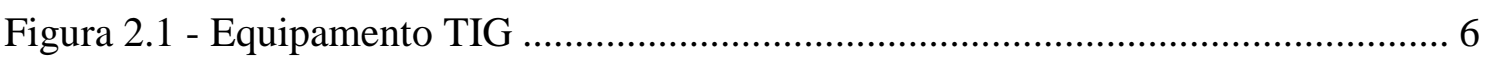

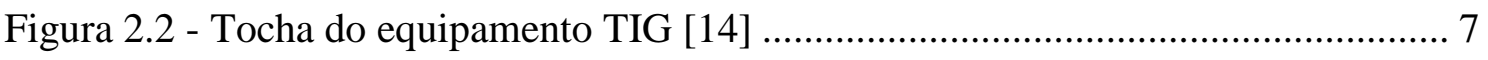

Figura 2.3 - Característica da soldagem GTAW relacionadas com o tipo da polaridade e

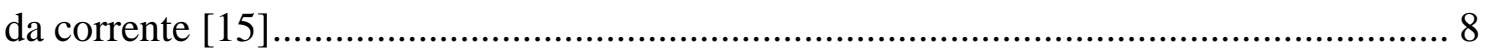

Figura 2.4 - Processo de soldagem TIG com metal de adição [15] ................................. 9

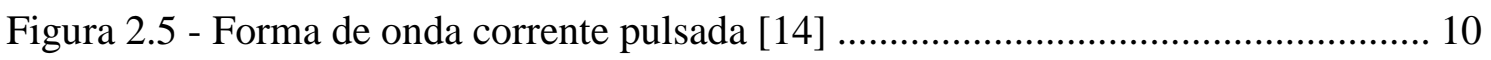

Figura 2.6 - Efeito da forma de onda pulsada sobre o cordão de solda [16] ................... 10

Figura 2.7 - Ilustração dos parâmetros característicos da poça de solda [17], [20]........ 12

Figura 2.8 - Formato do arco elétrico no processo TIG ............................................... 13

Figura 2.9 - Ilustrativo de parcelas que compõem a emissão luminosa do arco de solda

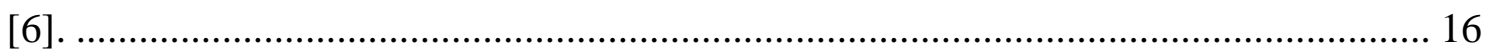

Figura 2.10 - Principio da perfilografia aplicado a soldagem [41][26] …..................... 17

Figura 2.11 - Esquemático de montagem sensor visão passiva...................................... 17

Figura 2.12 - (a) Estrutura utilizada por Koike e (b) Esquemático Bauchspiess............ 18

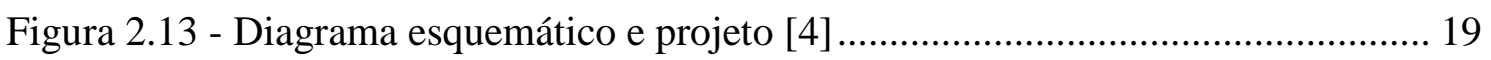

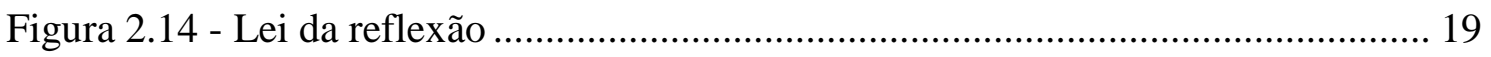

Figura 2.15 - Formação da imagem refletida no espelho plano [42] ............................. 20

Figura 2.16 - Formação do campo de visão [42] ........................................................ 21

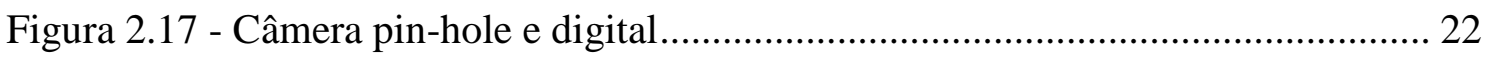

Figura 2.18 - Responsividade espectral da câmera DS-21 1M150-SA fabricante Dalsa

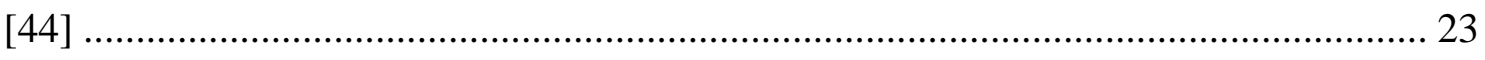

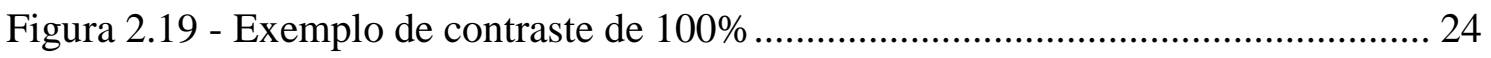

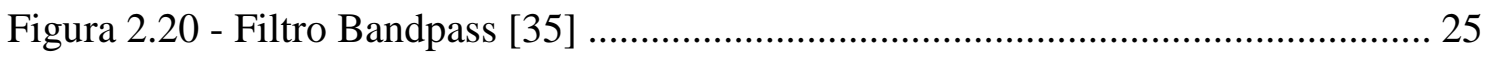

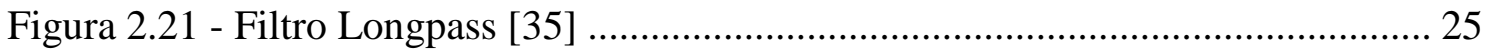

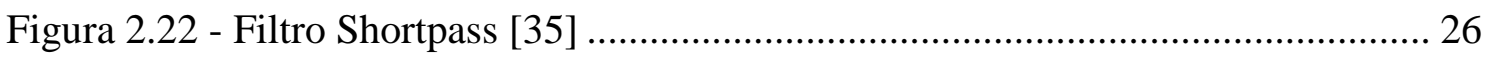

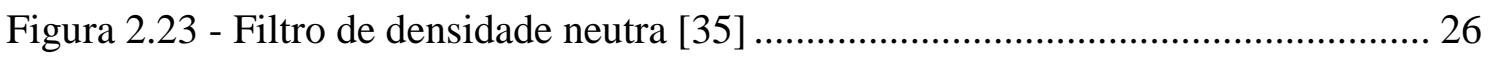

Figura 2.24 - Esquemático de modo de transferência por curto-cucurito ...................... 28

Figura 2.25 - Passos fundamentais em processamento de imagens digitais [36] ........... 29

Figura 2.26 - Visão geral detecção de borda ............................................................. 30

Figura 2.27 - Detecção de borda por operadores de derivação; (a) faixa clara sobre o fundo escuro (b) faixa escuro sobre um fundo claro[36] ............................................ 32 


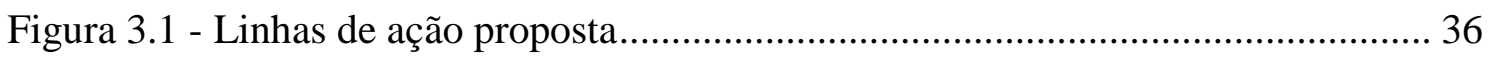

Figura 3.2 - Característica do espectro do Argônio [47] ................................................ 38

Figura 3.3 - Câmera DALSA modelo DS-21-001M150 …............................................ 39

Figura 3.4 - Diagrama esquemático da trajetória da luz de uma poça solda utilizando espelhos planos

Figura 3.5 - (A) é a câmera utilizada, (B) é o suporte dos filtros e (C) são os espelhos

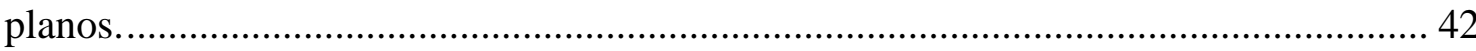

Figura 3.6 - Estrutura de fixação da Câmera, filtros e espelhos..................................... 42

Figura 3.7 - Imagem capturada pela câmera................................................................. 43

Figura 3.8 - Diagrama de montagem da mesa linear [1] ........................................... 44

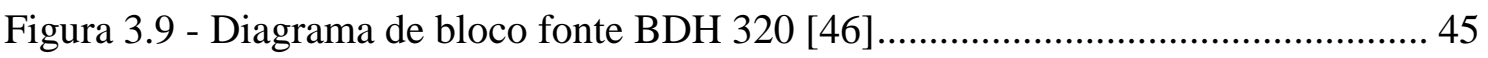

Figura 3.10 - (A) é a fonte de soldagem Migatrônic BDH 320; (B) Tocha do

equipamento com eletrodo de tungstênio; (C) tanque de gás argônio para proteção. .... 46

Figura 3.11 - Esquemático da bancada experimental ................................................... 47

Figura 3.12 - Efeito da mudança na taxa de amostragem............................................ 48

Figura 3.13 - Exemplificação da imagem integral ........................................................ 50

Figura 3.14 - Pontos da imagem, região de interesse. .................................................. 51

Figura 3.15 - Característica da imagem saturada pela interferência do arco.................. 51

Figura 3.16 - Resultado do algoritmo "integral da imagem" ........................................ 52

Figura 3.17 - Parte A do gráfico sobre integral da imagem ......................................... 53

Figura 3.19 - Parte $\mathrm{C}$ sobre o resultado da integral da imagem ................................... 55

Figura 3.18 - Parte B sobre o resultado da integral da imagem ................................... 54

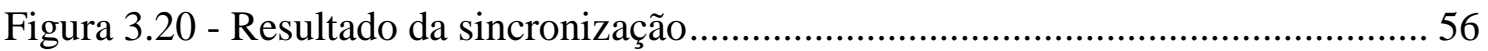

Figura 3.21 - Gráfico da sincronização por meio de análise dos pontos de pico ........... 57

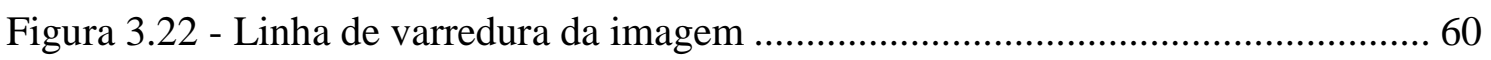

Figura 3.23 - Aplicação da primeira derivada na linha de pixel determinada................ 60

Figura 3.24 - Aplicação da primeira derivada na linha de pixel determinada................ 61

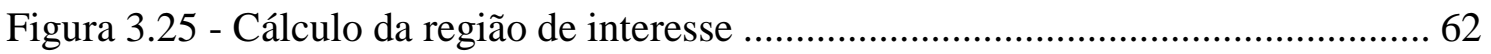

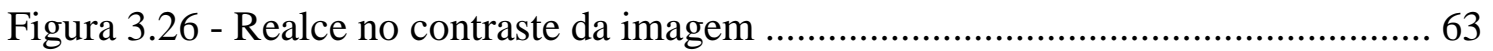

Figura 3.27 - Largura da poça em pixel encontrada durante experimento ...................... 64

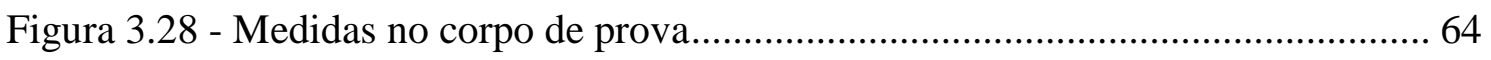

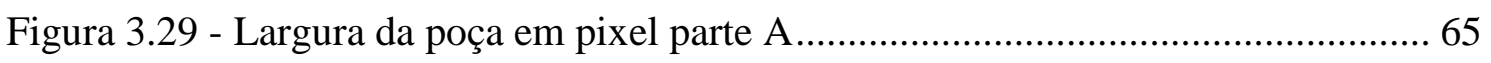

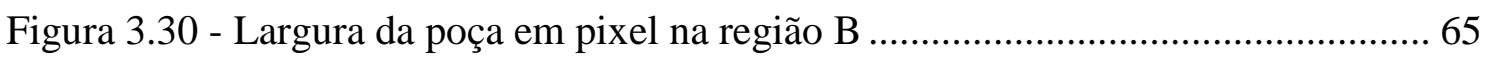

Figura 3.31 - Largura da poça em pixel em outra parte da região B .............................. 66 


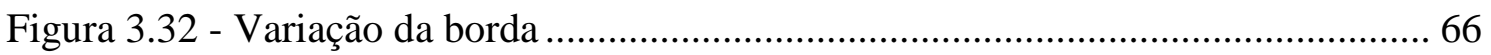

Figura 8.1 - Aparato para suporte dos periféricos do sensor ....................................... 89

Figura 8.2 - Montagem da estrutura no robô IRB2000 ................................................ 90

Figura 8.3 - Imagem adquirida utilizando um Endoscópio ........................................ 90 


\section{LISTA DE TABELAS}

Tabela 1 - Picos de emissão dos átomos excitados presente nos gases de proteção NITS [19] 15

Tabela 2 - Parâmetros do processo de soldagem TIG pulsado......................................... 46

Tabela 3 - Tabela Comparativa de Sincronizações ............................................................ 58 


\section{LISTA DE SIMBOLOS, NOMENCLATURAS E ABREVIAÇÕES.}

GMAW: Gas metal arc welding.

GTAW: Gas Tungsten arc welding.

CMOS: Complementary metal oxide semiconductor.

CCD: Charged coupled device.

GRACO: Grupo de automação e controle.

FPGA: Field programmable gate arrays.

USB: Universal serial bus.

TIG: Tungsten inert gas.

ATA: Advanced technology attachment.

PCI: Peripheral component interconnect.

API: Application programming interface.

RAM: Random access memory.

ROI: Regions of interest.

UnB: Universidade de Brasília.

$t_{p}$ : Tempo de Pulso.

$t_{b}:$ Tempo de base.

$I_{p}:$ Corrente de pico.

$I_{b}$ : Corrente de base.

F : Frequência de Pulso.

$I_{\text {max }}$ : Maior luminosidade do pixel possível.

$I_{\text {min }}$ : Menor luminosidade do pixel possível.

$\lambda_{c}$ : Comprimento de onda de borda.

$\lambda_{s}$ : Limite inferior da faixa de passagem.

$\lambda_{p}$ : Limite de faixa de passagem.

$\nabla_{f}:$ Vetor na posição $(x, y)$. 
$G_{x}$ : Gradiente em $x$

$G_{y}$ : Gradiente em y.

$\alpha(x, y)$ : Ângulo na direção do vetor $\nabla_{f}$.

Fps: Frame per second.

RI: Raio incidente.

RR: Raio Refletido.

$N$ : Normal.

CP: Campo de visão.

E1: Espelho 01.

E2: Espelho 02.

I(x,y): Imagem integral.

Hz: Hertz.

$\varphi:$ Diâmetro.

l/min: litros por minuto

GAP: Abertura da junta.

Vx: Varredura em $X$.

Vy: Varredura em y. 


\section{SUMÁRIO}

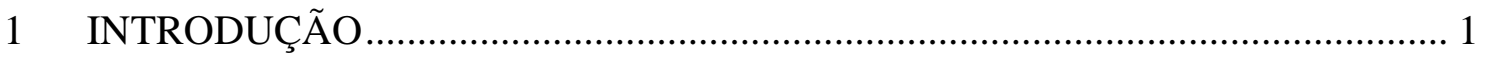

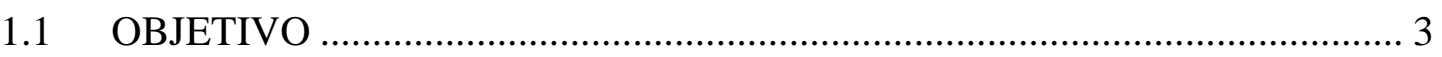

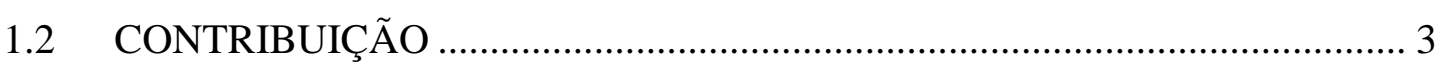

1.3 ORGANIZAÇÃO DO TEXTO .................................................................... 4

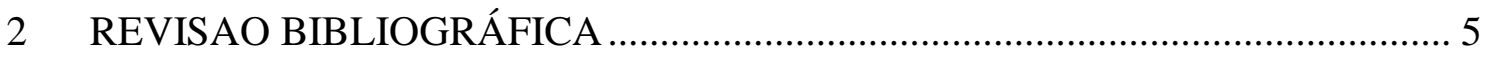

2.1 PROCESSO DE SOLDAGEM TIG ….................................................... 5

2.1.1 TECNICAS CONEXAS NA SOLDAGEM TIG .................................... 7

2.1.2 SOLDAGEM TIG PULSADA (CORRENTE PULSADA)...................... 9

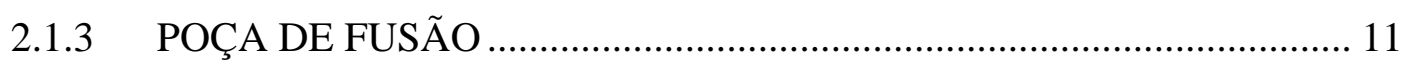

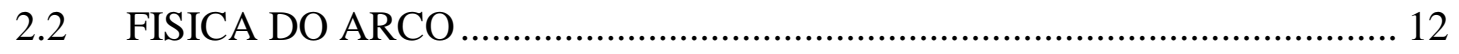

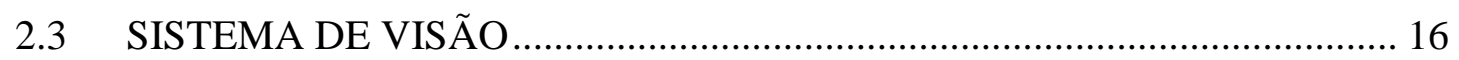

2.3.1 VISUALIZAÇÃO DIRETA E INDIRETA DA POÇA DE FUSÃO ....... 18

2.3.2 FORMAÇÃO DAS IMAGENS DIGITAIS ....................................... 21

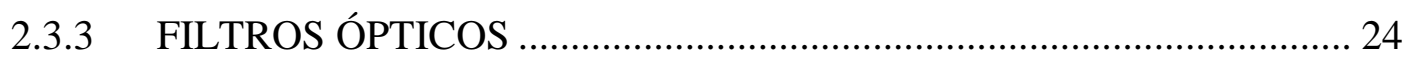

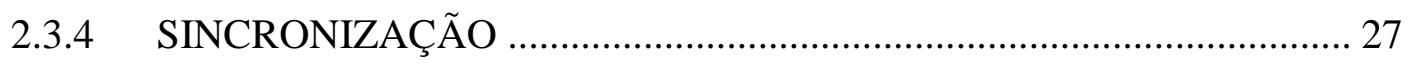

2.4 PROCESSAMENTO DE IMAGEM …....................................................... 28

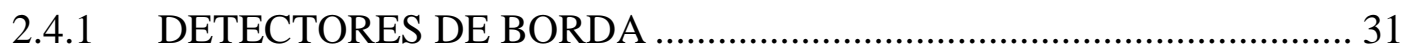

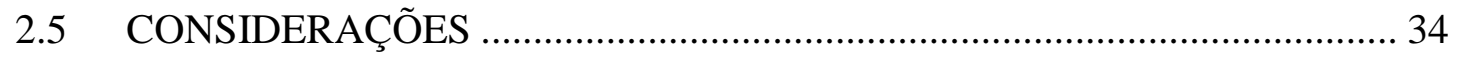

3 METODOLOGIA E MONTAGEM EXPERIMENTAL ......................................... 35

3.1 ESPECIFICAÇÃO DA BANCADA EXPERIMENTAL …........................... 37

3.1.1 FILTROS ÓPTICOS ......................................................................... 37

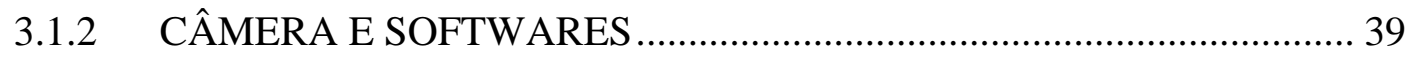

3.1.3 VISUALIZAÇÃO DA POÇA ............................................................ 40

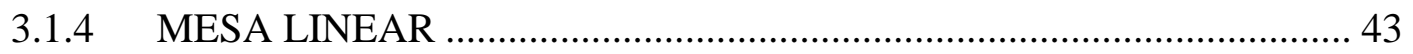

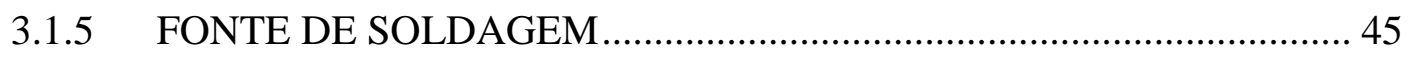

3.2 PROCEDIMENTO EXPERIMENTAL ......................................................... 47

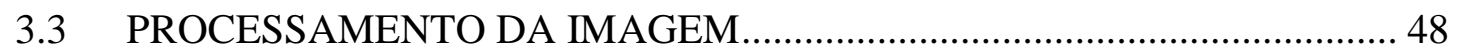

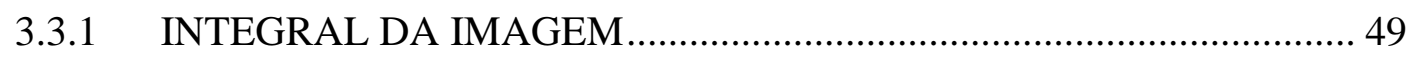

3.3.2 ANALISE E SINCRONIZAÇÃO DA IMAGEMO ............................... 51

3.3.3 DETECTORES DE BORDA PARA MEDIÇÃO DA LARGURA DA

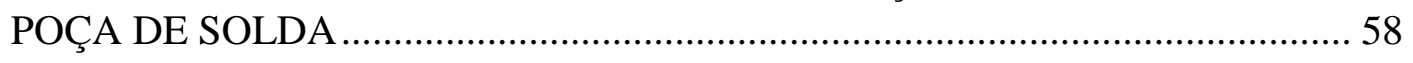

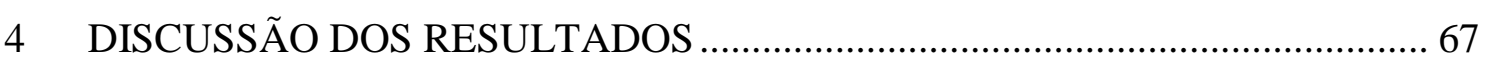

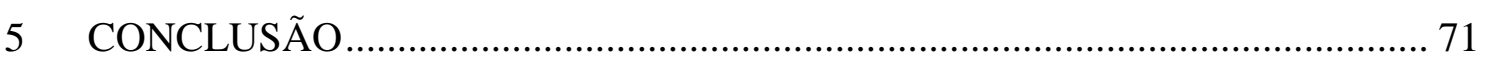




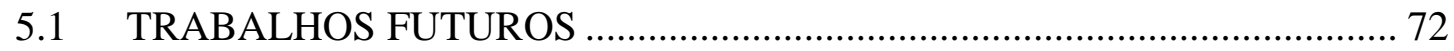

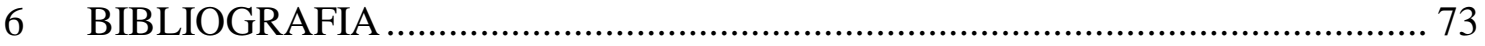

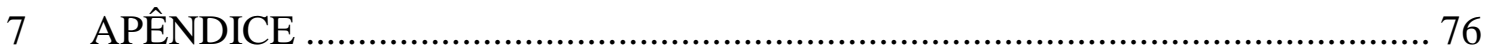

7.1 OPERADOR SOBEL IMAGEM OFFLINE …................................................ 76

7.2 OPERADOR SOBER CAPTURA LIVRE.................................................... 81

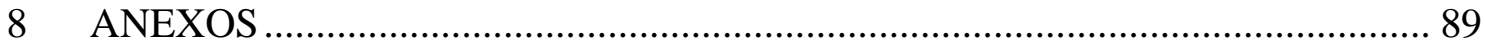

8.1 PROJETO INICIAL COM UM ENDOSCÓPIO CMOS ............................... 89 


\section{INTRODUÇÃO}

A soldagem a arco com eletrodo de tungstênio e proteção gasosa (GTAW) é um processo no qual a união de peças metálicas é produzida pelo aquecimento e fusão através de um arco elétrico estabelecido entre um eletrodo de tungstênio, não consumível, e as peças a unir. A proteção da poça de fusão e do arco contra a contaminação pela atmosfera é feita por uma nuvem de gás inerte ou mistura de gases inertes. A soldagem pode ou não ser feita com adição de metal e, quando usada, é feita diretamente na poça de fusão. A soldagem TIG é usada principalmente na união de metais difíceis de serem soldados por outros processos, em situações em que é necessário um controle rigoroso no calor concedido à peça e principalmente em situações em que a qualidade da junta produzida é mais importante que seu custo de produção.

Um operador de soldagem qualificado, utilizando seus conhecimentos é capaz detectar desvios de qualidade no cordão soldado e atuar no processo. A correção é feita mudando os parâmetros de soldagem, ou a orientação da tocha [1]. A demanda por maior produtividade, a escassez de mão de obra especializada e ambientes insalubres, tem promovido um aumento significativo na utilização de métodos automáticos (Máquinas de soldagem, Robôs e etc.) nos processos de soldagem por resistência e a arco [2]. Geralmente os sistemas robóticos de soldagem na produção, reproduzem comandos ensinados sem o controle em tempo real dos parâmetros do cordão soldado, portanto, não é capaz de atender requisitos de qualidade, uma vez que robôs não possuem capacidade de adaptação as mudanças de circunstâncias e distúrbios incertos que ocorrem durante o processo de soldagem [3].

O controle em malha aberta na soldagem robotizada confia que o sistema robótico ou automático repita a operação sem erro, e que a peça a se trabalhar apresente consistência dimensional e posicional. O controle em malha fechada possibilita a correção de desvios de qualidade, em tempo de soldagem, simulando os procedimentos de um soldador experiente. Para esse fim, sensores são utilizados com a função de coletar dados, compará-los com parâmetros de qualidade pré-estabelecidos inicialmente e enviá-los ao controlador que produzirá as saídas necessárias para qualidade da solda [1].

As técnicas de controle atualmente aplicadas envolvem medição durante a soldagem de diferentes sinais, tais como, variações de corrente, tensão, nível de 
luminosidade do arco, perfil óptico ou acústico da poça de fusão etc. Estes sinais são processados, interpretados em termos de características do processo e enviados para o sistema de controle.

Sistemas de monitoração são usados para garantir que a qualidade das soldas produzidas esteja em conformidade com padrões pré-estabelecidos, cuja características, satisfaçam requisitos de continuidade, dimensões e estéticos. É importante para a soldagem automática e robotizada a habilidade de se ajustar a variações que ocorrem na execução da solda e, nesse contexto, os sensores de visão estão sendo empregados em várias pesquisas para monitoramento dos parâmetros geométricos do cordão [4], [5].

A utilização da tecnologia de detecção visual nos processos de soldagem é interessante devido ao fato do sensor de visão não tocar ou interferir no processo durante monitoração da poça de fusão, que contêm informações abundantes sobre a dinâmica da solda. O sensor de visão ideal tem que ser apto a verificar a dinâmica da poça de fusão (geometria, distribuição de temperatura, e etc.). Porém a visualização da poça é prejudicada pela alta intensidade de emissão do arco elétrico. A principal tarefa ao projetar o sensor está em eliminar a interferência do arco, para melhoria do grau de contraste das imagens [6].

Atualmente os sensores de visão são divididos em dois tipos, de acordo com a da fonte emissora de luz: A visão ativa, ou método ativo, tem a fonte emissora de luz acoplada ao próprio sistema, a passiva utiliza a luz emanada pela própria região visualizada, como exemplo o arco elétrico na soldagem [5]. Alguns autores utilizando um sistema de visão passiva conseguiram capturar a borda da poça de fusão e extrair informações através do processamento das imagens adquiridas [3], [4].

Afim de minimizar o efeito causado pelo arco elétrico, esse trabalho propõe o estudo de técnicas que reduzem ou minimizam sua interferência na imagem, por meio de um sistema de visão computacional e, posteriormente, a construção de um sensor capaz de medir parâmetros da poça de solda utilizando métodos algorítmicos disponíveis na literatura. Propõe ainda um método de sincronização das imagens com menor interferência do arco por análise da soma integral em uma filmagem livre. 


\subsection{OBJETIVO}

O trabalho tem por objetivo o desenvolvimento de um sensor para monitoramento geométrico da poça de fusão em um processo GTAW pulsado utilizando uma câmera de alta velocidade CMOS para aquisição das imagens. Para atingir os objetivos, os seguintes objetivos específicos deverão ser alcançados.

- Estudo das características de um processo GTAW e o comportamento do arco elétrico para escolhas dos filtros adequados;

- $\quad$ Projeto de uma estrutura para fixação da câmera e dos filtros na tocha de soldagem, com o propósito de minimizar os efeitos de orientação e vibração na soldagem robotizada;

- $\quad$ Sincronização via métodos computacionais;

- Aplicar técnicas de processamento de imagem disponíveis na literatura com finalidade de analisar os parâmetros geométricos da poça de solda.

\subsection{CONTRIBUIÇÃO}

Dentre as principais contribuições que este trabalho propõe estão:

- Desenvolvimento da metodologia para visualização da poça de solda baseado nas leis da reflexão e formação da imagem;

- Uma nova opção para sincronização das imagens com menor interferência do arco, baseado em técnicas computacionais denominada integral da imagem;

- Estrutura para fixação da câmera e dos aparatos ópticos na tocha de soldagem afim de minimizar o efeito de vibração e orientação numa soldagem robotizada;

- Aplicação do operador SOBEL para extração de dados da poça. 


\subsection{ORGANIZAÇÃO DO TEXTO}

O capítulo 1, a introdução, apresenta um texto introdutório, a motivação para execução desse trabalho, além disso apresenta os objetivos a serem atingidos e a contribuição para trabalhos futuros

O capítulo 2, apresenta a revisão bibliográfica, onde são abordados: os temas básicos de um processo de soldagem GTAW, a monitoração tradicional do processo de soldagem, além disso são apresentados temas relacionados a visão computacional como: a captura e formação de imagens; análise de imagem da poça de solda; técnicas desenvolvidas para detecção de borda.

O capítulo 3, apresenta a montagem experimental do projeto: elaboração do suporte de fixação da câmera, bem como justificativa na utilização da estrutura como maneira de minimizar os efeitos de orientação da tocha; a realização dos experimentos básicos, os problemas e soluções encontradas, desenvolvimento de algoritmos de detecção de borda e extração de geometrias.

No capítulo 4 os experimentos e resultados do projeto são demonstrados.

No capítulo 5, a conclusão, apresenta o desenvolvimento, os problemas, as soluções e resultados desse trabalho, além disso, propõe alguns trabalhos futuros, a partir do desenvolvimento desse trabalho. 


\section{REVISAO BIBLIOGRÁFICA}

\subsection{PROCESSO DE SOLDAGEM TIG}

A soldagem é um dos principais processos de fabricação utilizados na indústria para a união de materiais, principalmente os metais, sendo cada vez mais necessário e mais empregado. Tendo isso em vista, a necessidade da garantia de qualidade e produtividade dos processos envolvidos nesta tarefa está em constante crescimento. Sendo um processo especial, com parâmetros interdependentes, muitos trabalhos de pesquisa são desenvolvidos com o intuito de alcançar um melhor entendimento dos fenômenos envolvidos [6]. A técnica de soldagem por Tungstênio Inerte Gás (TIG) foi desenvolvida na década de 1940 e, desde o início, é amplamente aplicada na indústria e é uma tecnologia continuamente melhorada [7].

O arco elétrico atualmente é a fonte de calor mais usada nos processos de soldagem por fusão de materiais metálicos, pois apresenta uma ótima combinação de características que incluem uma concentração adequada de energia para fusão localizada no metal de base, facilidade de controle, baixo custo relativo de equipamento e um nível de risco aceitável à saúde dos seus operadores [8].

No processo de soldagem TIG, um arco é estabelecido entre o eletrodo não consumível de tungstênio puro - ou composto com outros metais, ou óxidos - e a peça, por meio de emissão termiônica, formando a coluna de plasma a partir da ionização de parte do gás de proteção (geralmente argônio) [9], [10]. É muito usado na soldagem de materiais mais sofisticados, incluindo aços inoxidáveis e ligas de metais reativos, e quando um bom acabamento e uma elevada qualidade das soldas são requeridos [11].

O equipamento utilizado na soldagem TIG é composto por uma fonte de energia elétrica, uma tocha de soldagem refrigerada por ar ou água, gás de proteção, um dispositivo para abertura de arco, cabos e mangueiras. A Figura 2.1, mostra o esquemático do equipamento utilizado para soldagem TIG. 


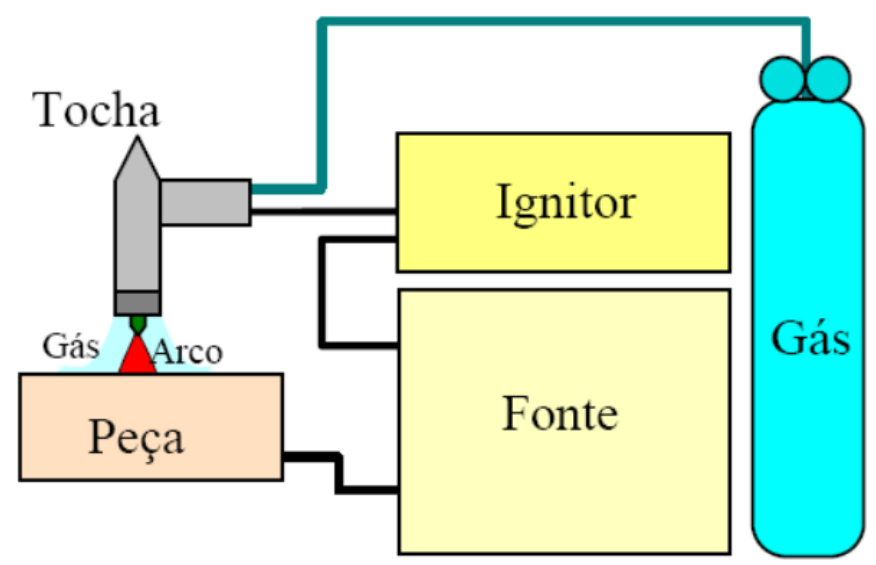

Figura 2.1 - Equipamento TIG

Os controles geralmente disponíveis no equipamento são: (a) Intensidade e tipo de corrente em alta frequência; (b) temporizadores, para que ocorra fluxo de gás antes do arco iniciar e após a corrente ter sido interrompida; (c) vazão do fluxo de gás. Para a soldagem TIG pulsada são adicionados, ainda, regulagem para as correntes de base, de pico e da frequência com que as mesmas atuam, assim como ciclo de trabalho no caso de fontes de corrente AC.

Há algumas desvantagens na utilização na soldagem TIG, dentre elas se destacam: (a) sua capacidade de penetração é relativamente baixa, especialmente em operações de soldagem com passagem única; (b) alta sensibilidade na qualidade do cordão de solda na variação química do material de base; (c) baixa produção [10].

O custo dos equipamentos necessários e dos consumíveis usados é alto, e a produtividade ou rendimento do processo é baixo, quando comparados à soldagem MIG/MAG, o que limita a sua aplicação a situações em que a qualidade da solda produzida seja mais importante que a produtividade ou o custo da operação.

O processo manual de soldagem TIG é considerado um dos mais difíceis de todos os processos comuns utilizados pela indústria devido à necessidade de destreza do operador para manter um pequeno arco elétrico e prevenir que o eletrodo não encoste na peça de trabalho [12]. Por esse motivo, sistemas automatizados de soldagem estão sendo criados para garantir que a qualidade do cordão soldado esteja em conformidade ao pré-estabelecido. 


\subsubsection{TECNICAS CONEXAS NA SOLDAGEM TIG}

Os eletrodos geralmente são de tungstênio puro ou com adição de óxido de tório, lantânio ou zircônio, e servem para conduzir corrente até o arco elétrico. A faixa de corrente utilizável para um eletrodo depende de seu tipo, diâmetro e do tipo de polaridade da corrente de soldagem.

A tocha sustenta e energiza o eletrodo de tungstênio e direciona o gás de proteção para região de soldagem. Ela pode ser resfriada a ar (para até $150 \mathrm{~A}$ ) ou a água, sendo que, neste caso, pode ser usado um sistema de refrigeração de circuito fechado. A tocha usualmente possui um gatilho para início e término da soldagem para operações manuais. A forma da ponta do eletrodo pode ser uma variável importante, particularmente na soldagem mecanizada ou automática, pois pode influir no formato do cordão de solda.

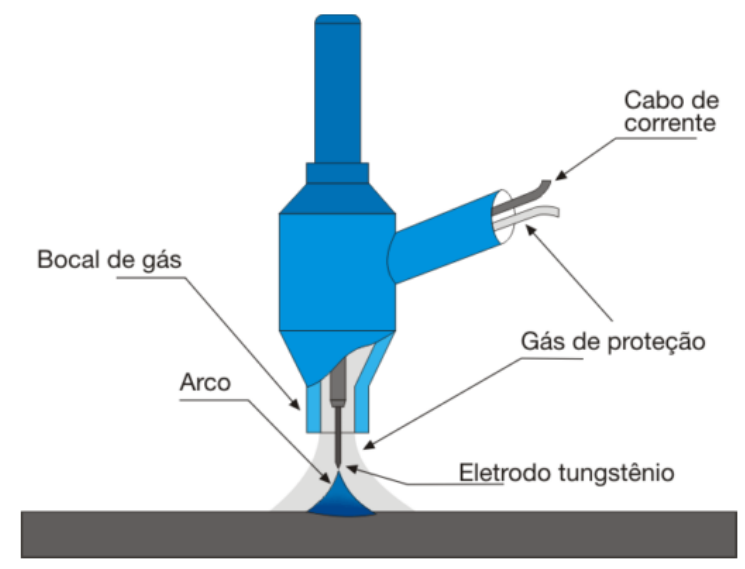

Figura 2.2 - Tocha do equipamento TIG [14]

O tipo de corrente e, se for o caso, a sua polaridade influenciam a distribuição de calor no eletrodo e na peça, a estabilidade do processo e a sua capacidade de remoção de óxidos da superfície da peça. A forma mais usual de soldagem é a CC com eletrodo negativo. Nesta condição o processo apresenta uma maior estabilidade e o calor é transferido com maior intensidade para a peça [12].

Nas fontes CC com eletrodo negativo os elétrons são emitidos pelo terminal negativo (cátodo) e obtidos pela ionização dos átomos do gás. Estes elétrons são atraídos ao terminal positivo (ânodo) onde geram a maior parte do calor total do arco. Uma parcela menor da corrente do arco é carregada pelos íons positivos do gás, que são atraídos ao terminal negativo onde geram aproximadamente $30 \%$ do calor do arco. O cátodo perde 
calor pela emissão dos elétrons e esta energia é transferida à peça quando os elétrons colidem com o ânodo. Esta é a principal razão do porquê uma quantidade significativamente maior de calor é desenvolvida no ânodo [13].

A configuração CC com polaridade positiva no eletrodo, consequentemente negativa na peça de trabalho, não é tradicionalmente utilizada em virtude do eletrodo de tungstênio apresentar-se fortemente agredido pelo calor do arco. Isto é resultante do fato de que, neste caso, o eletrodo de tungstênio permanece sujeito aos efeitos de aquecimento promovido pelo choque dos elétrons ao invés da peça de trabalho. Entretanto, nesta polaridade têm-se o efeito de limpeza da peça de trabalho (limpeza catódica) [14].

Para soldagem de metais e ligas que apresentam uma camada superficial de oxido refratário, é comum o uso de corrente CA. Quando a peça fica ligada ao polo negativo do circuito elétrico, o arco é capaz de remover a camada de óxido da região que está sendo soldada e, assim, garantir melhores condições para a formação da solda. Como a polaridade se inverte periodicamente, o uso de corrente alternada evita que o eletrodo seja superaquecido [15].

Um resumo dos tipos de fonte pode ser visto na Figura 2.3:

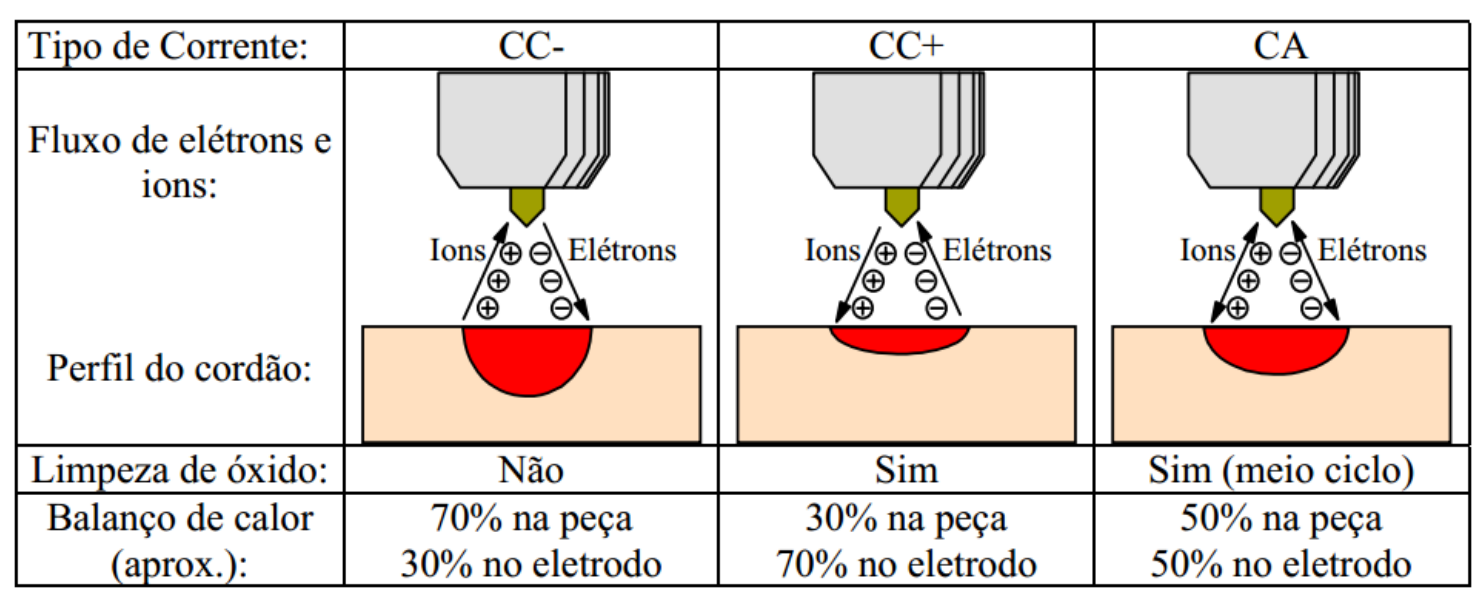

Figura 2.3 - Característica da soldagem GTAW relacionadas com o tipo da polaridade e da corrente [15]

O cordão de solda é obtido de duas formas nos processos se soldagem TIG: (a) pela fusão do material de base, neste caso não necessita do material de adição, (b) pela adição de algum material: essa condição depende da forma e do tamanho da junta, além da finalidade da solda realizada. Em casos específicos, este metal de adição é usado 
apenas como material de enchimento para recompor áreas com excessivo desgaste [13]. A Figura 2.4 representa um processo de soldagem TIG com adição de material.

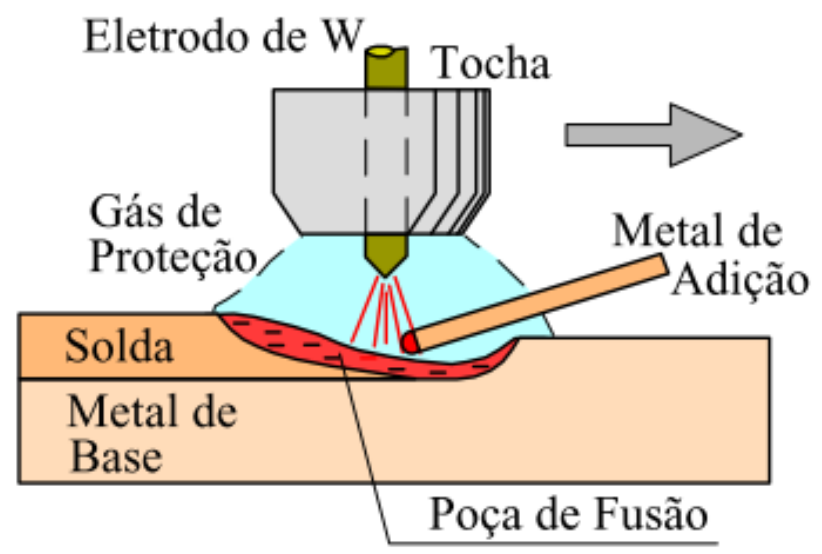

Figura 2.4 - Processo de soldagem TIG com metal de adição [15]

\subsubsection{SOLDAGEM TIG PULSADA (CORRENTE PULSADA)}

Em corrente pulsada, a fonte de soldagem fornece uma corrente em forma de onda retangular que pulsa ciclicamente entre dois níveis. As variáveis de regulagem são: $\left(t_{p}\right)$ tempo de pulso, $\left(t_{b}\right)$ tempo de base, $\left(I_{p}\right)$ corrente de pico, $\left(I_{b}\right)$ corrente de base, $\left(F_{p}\right)$ frequência de pulso e velocidade de soldagem. A Figura 2.5 mostra uma representação esquemática da corrente pulsada. Os valores $t_{s}$ e $t_{d}$ são tempo de subida e descida respectivamente.

A corrente de pulso $\left(I_{p}\right)$ e o tempo de pulso $\left(t_{p}\right)$ são ajustados para fundir o material de base, de maneira a fornecer a penetração desejada. Por outro lado, a corrente de base $\left(I_{b}\right)$ e o tempo de base $\left(t_{b}\right)$ são ajustados visando à redução da corrente média ou eficaz, de maneira a diminuir o aporte térmico, o que resulta no melhor controle sobre a poça de fusão [16]. 


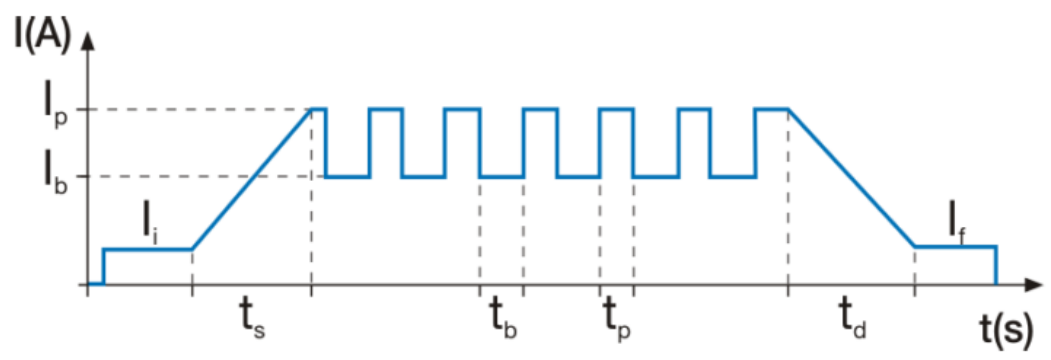

Figura 2.5 - Forma de onda corrente pulsada [14]

Os efeitos dessa forma de onda (Figura 2.6), sobre o cordão de solda, é um cordão escamado, que pode ser comparado a um cordão constituído por vários pontos de solda, alinhados, onde os pontos são formados por pulso de corrente [16].

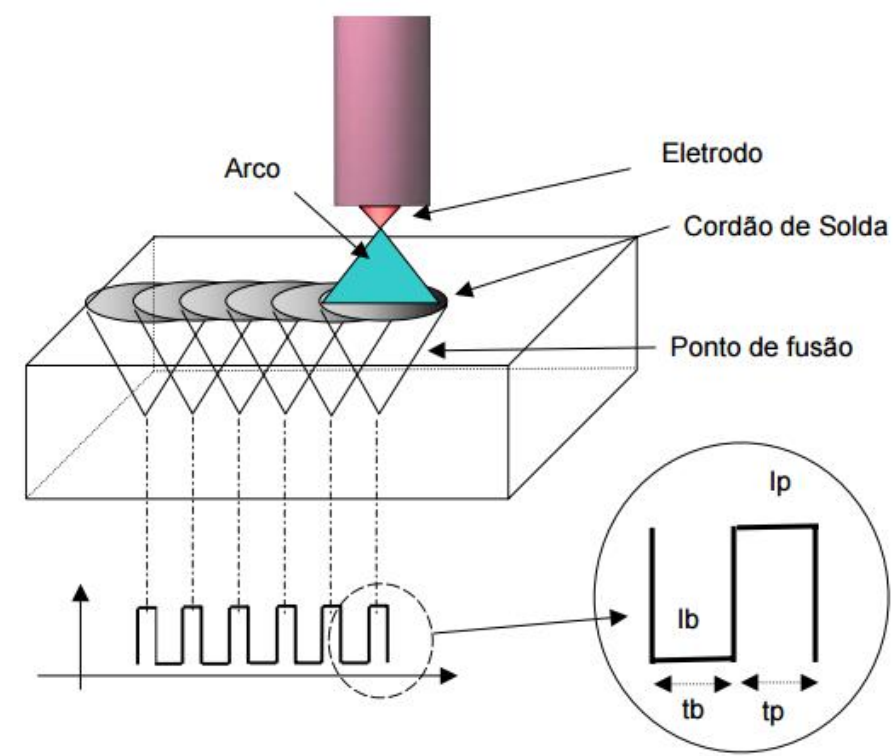

Figura 2.6 - Efeito da forma de onda pulsada sobre o cordão de solda [16]

As vantagens em utilizar o TIG pulsados são [13]:

a) Redução do aporte térmico;

b) Maior controle da poça de fusão e da penetração;

c) Menor distorção;

d) Redução da zona termicamente afetada

e) A agitação da poça de fusão minimiza a ocorrência de porosidade

f) Redução da susceptibilidade a trincas quentes

g) Maior controle sobre a microestrutura

h) Possibilidade de uma estrutura de solidificação mais refinada 
i) Maior controle sobre o cordão de solda e a geometria

\subsubsection{POÇA DE FUSÃO}

A capacidade de controle da superfície da poça de solda é considerada essencial nas máquinas de solda automáticas. Essa informação é real pelo fato de que um soldador qualificado pode inferir o status de penetração da solda baseado em sua observação e controlar certos parâmetros de soldagem de acordo sua dinâmica [17], um processo de soldagem automático baseia-se nas técnicas usadas por um soldador profissional. A observação da poça de solda utiliza de algumas técnicas de sensoriamento, incluindo estudos da oscilação da poça, detecção ultrassônica, sensoriamento infravermelho, e o método de detecção baseado em visão [17][18].

Entre todos os tipos de informações que podem ser extraídos da poça de solda, a geometria da poça fornece informações valiosas sobre o estado do processo de soldagem. Informações importantes, como defeitos no processo e penetração estão contidos na deformação da superfície da poça solda [18].

Vilarinho conclui que a observação e o controle da poça, e suas principais características, resulta na penetração da solda em uma junta e em propriedades mecânicas desejadas [19]. Além disso, a aplicação de um sistema de auxílio visual vai muito além do controle da penetração em um processo de soldagem.

A Figura 2.7 apresenta os parâmetros de caracterização da geometria da poça de solda. Os parâmetros de caracterização incluem os seguintes dados: largura (W), o comprimento (L) e convexidade (C) da poça de solda. Especificamente, a convexidade é definida como a altura média da poça de solda ao longo da direção longitudinal, isto é, a área total de cima da peça de trabalho $(\mathrm{S})$ dividida pelo comprimento L (mostrado na Figura 2.7, à esquerda). Estes parâmetros são usados como as saídas nos sistemas de controle. Entre todas as entradas do processo de solda, um aumento na corrente de soldagem e uma diminuição na velocidade de soldagem irá aumentar significativamente a entrada de calor, influenciando assim a geometria da superfície da poça de solda consideravelmente. 
Dentre os principais problemas que influenciam a qualidade da solda, três principais se destacam [21]:

- Preparação da junta a ser soldada;

- Posicionamento da junta;

- Combinação inadequada dos parâmetros de soldagem.
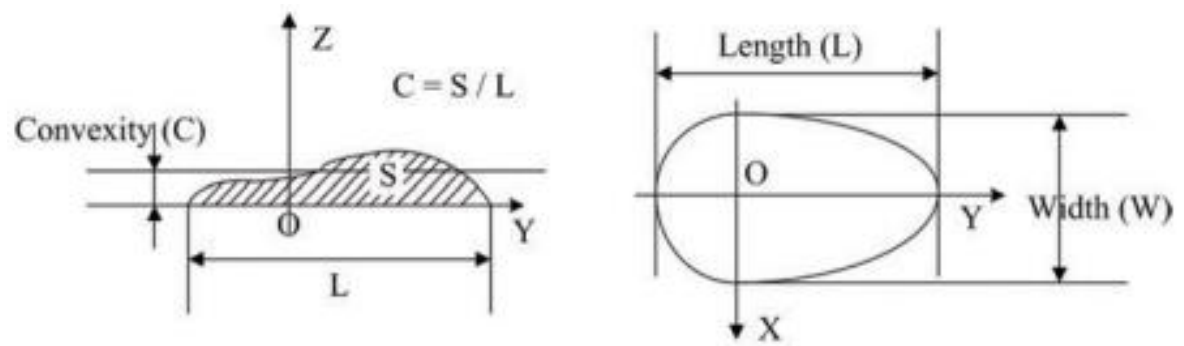

Figura 2.7 - Ilustração dos parâmetros característicos da poça de solda [17], [20]

Por meio da monitoração da poça de solda durante o processo, pode-se identificar a presença destes problemas, gerando-se sinais que podem ser utilizados para corrigir desvios de qualidade antes que possam comprometer o cordão de solda [22].

A formação da poça de fusão é de extrema importância para a qualidade do cordão de solda, especialmente no caso de solda em chapas finas, em que as tolerâncias do processo são menores. Devido à dificuldade de se monitorar todas as variáveis do processo e relacioná-las à geometria da poça, a correlação entre a geometria da poça e as características da solda resultante ainda são objeto de estudo.

\subsection{FISICA DO ARCO}

O funcionamento de um sistema de visão computacional consiste na união de um conjunto de equipamentos a fim de que seja possível a captura, transmissão e processamento digital de uma imagem [23]. A aplicação de sensores ópticos envolvem estudos físicos do comportamento do arco elétrico que emite radiação luminosa visível em praticamente todos os comprimentos de onda, incluindo a radiação ultravioleta e infravermelha [6].

A intensidade da radiação produzida pelo arco de solda é uma função do próprio processo de soldagem e de suas variáveis. As fontes de radiação visíveis no arco de solda 
são as seguintes: a coluna de arco (importante para escolha do filtro de atenuação), as regiões próximas do eletrodo, o metal líquido transportado através do arco de soldagem, a poça de fusão, a região aquecida do material de base em torno da poça de fusão e a extremidade aquecida eletrodo [24].

O arco elétrico de soldagem compreende a uma região relativamente pequena do espaço caracterizada por temperaturas elevadas (similares ou mesmo superiores à do superfície do sol), forte radiação luminosa, fluxo intenso da matéria e grandes gradientes de propriedades físicas [8]. No processo TIG o arco parece cobrir toda a superfície da ponta do eletrodo e a coluna do arco tem o formato de um cone truncado ou de um sino, dependendo do formato da ponta do eletrodo (Figura 2.8).

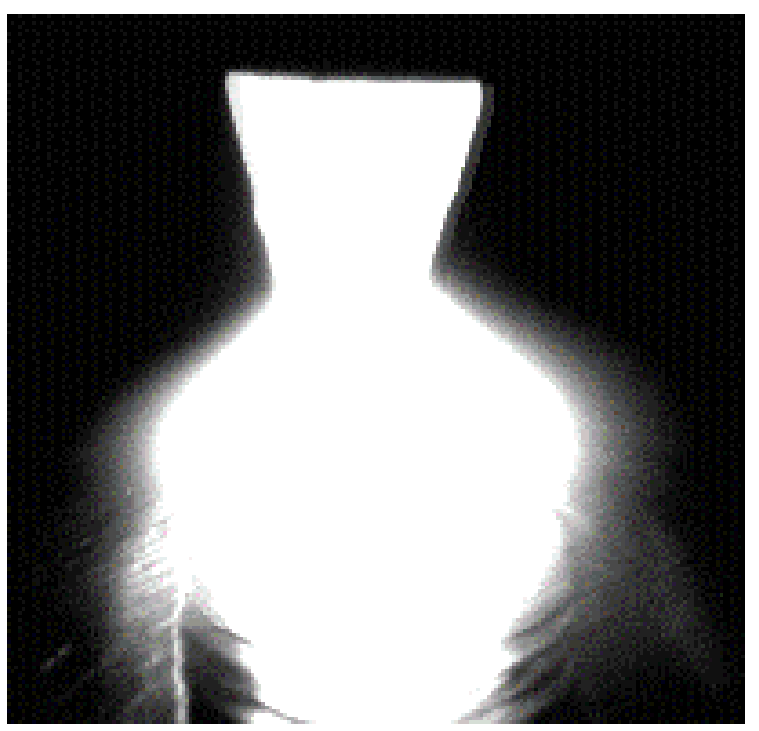

Figura 2.8 - Formato do arco elétrico no processo TIG

Algumas técnicas de monitoração indireta (onde não há interferência na propriedade final do arco formado) são importantes para estudo. Medições e a análise do espectro da radiação visível do arco de solda são aplicadas em investigações sobre o processo de soldagem, para fins diversos, tais como medição da temperatura no arco, para detecção e medição de quantidade de hidrogênio gasoso na blindagem do arco de solda. As investigações sobre a radiação visível nos métodos de soldagem GMAW ajudam também a controlar a maneira na qual o metal é transferido através do arco, particularmente durante a transferência de pulsada. As técnicas também são aplicados para verificar o comprimento de onda emitido do arco nos processos de soldagem GMAW e TIG [24]. 
O plasma é considerado o quarto estado da matéria, é um estado distinto que contém um número significativo de partículas eletricamente carregadas. É constituído por um conjunto quase neutro de partículas eletricamente carregadas formado pela ionização de átomos e moléculas por excitação energética de radiações eletromagnéticas, como calor (radiação térmica), micro-ondas e etc. Este processo faz com que haja a formação de íons que durante a recombinação de seus elétrons emitem radiação visível ou não.

Para produzir um plasma é preciso liberar elétrons que se encontram ligados ao átomo. Um gás parcialmente ionizado pode ser afetado por campos elétricos ou magnéticos aplicados intensamente e podem conduzir corrente elétrica. Os íons e elétrons servem como portadores de cargas, onde os campos das partículas carregadas do gás ionizado produzirão consequências de efeito coletivo. Este efeito coletivo constitui a principal característica do plasma. A medição quantitativa do gás pode ajudar na observação da distância entre a partícula carregada e o campo elétrico. Quando o gás é ionizado pela influência de campo elétrico intenso gerado por uma corrente é chamado de plasma de corrente contínua. Isso é o que acontece quando se efetua a solda TIG. Aplica-se uma corrente em um eletrodo a uma certa distância da peça a ser soldada, liberase o gás de proteção, esse é ionizado e ocorre a formação do plasma. Por isso, pode-se considerar que esse processo de soldagem é uma fonte do plasma para análise espectroscópica [25].

O ensaio de espectroscopia consiste em aplicar o plasma na amostra desejada e observar os comprimentos de onda emitidos. Após o ensaio, faz-se a comparação das linhas espectrais obtidas com um banco de dados, e determinam-se quais elementos estão presentes naquela amostra em estudo.

O espectro adquirido na região ao redor do arco é composto pela radiação térmica de corpo negro, devido à alta temperatura atingida, e corresponde à área inferior do espectro obtido e pelo espectro de emissão atômica, quando um elétron pertencente a um átomo excitado libera energia ao retornar à sua posição de origem, correspondente aos picos presentes [19]. De acordo com National Institute of Standards and Technology (NIST) [43], os átomos excitados presentes nos diferentes gases utilizados (argônio, carbono e oxigênio), possuem picos de emissão na faixa de comprimentos de onda filtrados, e são, portanto, responsáveis pelos picos presentes nos espectros adquiridos, a Tabela 1 mostra os picos de emissão dos átomos excitados presente nos gases de proteção. 
Tabela 1 - Picos de emissão dos átomos excitados presente nos gases de proteção NITS [19]

Comprimento de

Elemento

Átomo excitado onda observada Ar

( $\mathrm{nm})$

\begin{tabular}{|l|c|c|c|}
\multirow{3}{*}{ Argônio } & Ar I & 912,2967 & $100 \%$ \\
\cline { 2 - 4 } Carbono & & 909,483 & $45,00 \%$ \\
\multirow{2}{*}{ Oxigênio } & C I & 911,180 & $30,00 \%$ \\
\cline { 2 - 4 } & O I & 915,601 & $23,5 \%$ \\
\hline
\end{tabular}

O formato do espectro adquirido fornece informações importantes sobre o arco de soldagem. Seus picos indicam a composição da proteção gasosa utilizada e a temperatura atingida influencia na emissão de corpo negro. A soma dessas duas parcelas caracteriza a emissão total do arco, como pode ser visto na Figura 2.9, do trabalho da Carolina Matos sobre o Estudo da emissão de raios infravermelho próximo em processos de soldagem a arco [19]. Com base nos resultados obtidos nos ensaios, é possível dimensionar um filtro de atenuação para sobreposição do arco durante a aquisição das imagens.

A principal tarefa ao projetar um sensor de visão é eliminar a interferência de arco afim de melhorar o grau de contraste das imagens. O ideal para o projeto de construção do sensor é utilizar sistemas ópticos de filtragem espectral na faixa continua do espectro do arco, no caso da Figura 2.9, o ideal seria de $890 \mathrm{~nm}-900 \mathrm{~nm}$ ou acima de 920nm, nessa região a interferência do arco na imagem é menor. Casos específicos para soldagem TIG serão vistos posteriormente. 


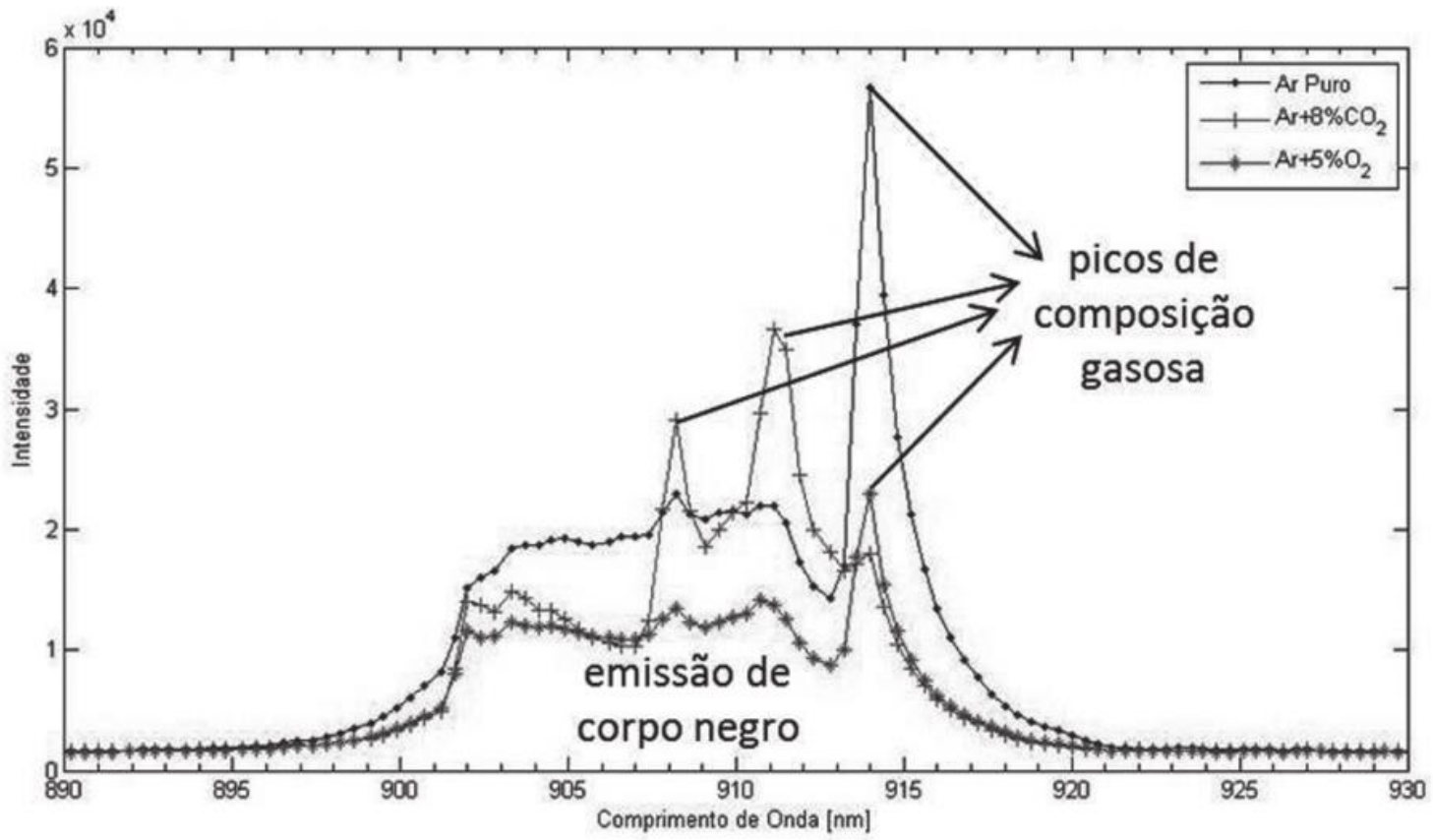

Figura 2.9 - Ilustrativo de parcelas que compõem a emissão luminosa do arco de solda [6].

\subsection{SISTEMA DE VISÃO}

O uso de câmeras, pode fornecer diversas informações úteis, que não são possíveis de se obter com a monitoração dos sinais elétricos usuais, como a corrente ou a tensão. Diferentes sistemas de visão podem fornecer informações específicas sobre o processo em andamento: a técnica de perfilografia ou back-lighting - projeção da sombra de elementos na região da solda em uma superfície plana - visualiza as gotas em transferência como forma de estudar à transferência metálica [26], enquanto novos sistemas de visão têm como o objetivo a visualização direta do metal fundido e da junta propriamente dita, com uma gama de aplicações indo de estudo dos fenômenos na poça até seguidores de junta ou controladores online de parâmetros do processo [6].

Atualmente o sistema de visão é dividido em dois, de acordo com a fonte emissora de luz: A visão ativa, ou método ativo, tem a fonte de luz acoplada ao próprio sistema e a passiva utiliza da fonte de luz do alvo monitorado, como exemplo o arco elétrico na soldagem, para captação da imagem [5]. 
Machado [6], utilizou em seu estudo a iluminação do processo com luz na faixa do infravermelho próximo, e a utilização de filtros de interferência (Passa-Faixa), em torno deste mesma faixa de comprimentos de onda durante a aquisição de imagem para diminuir o efeito do arco. Esta técnica é conhecida como perfilografia, e faz parte da visão ativa, e pode ser observado na Figura 2.10.

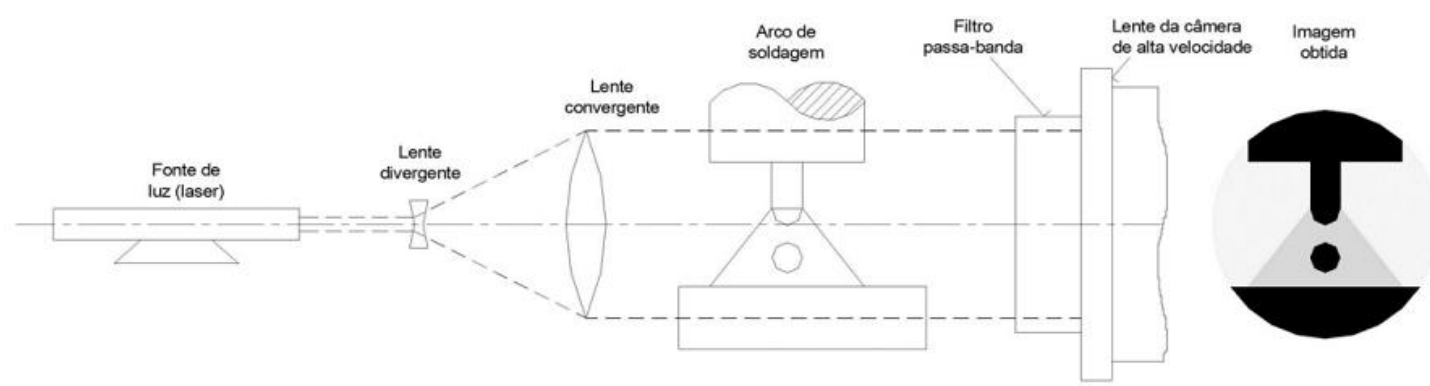

Figura 2.10 - Principio da perfilografia aplicado a soldagem [41][26]

O sistema de visão passiva geralmente é composto por um filtro primário Passa Faixa, em torno de um comprimento de onda determinado, um filtro neutro para diminuir o brilho do arco, uma câmera CMOS ou CCD [27]. A visão passiva é utilizada geralmente para visualização da poça de solda. Um comprimento de onda particular não passa através do filtro primário, que usa o espectro contínuo da luz do arco para observar a poça de solda, o esquemático de montagem pode ser visto na Figura 2.11.

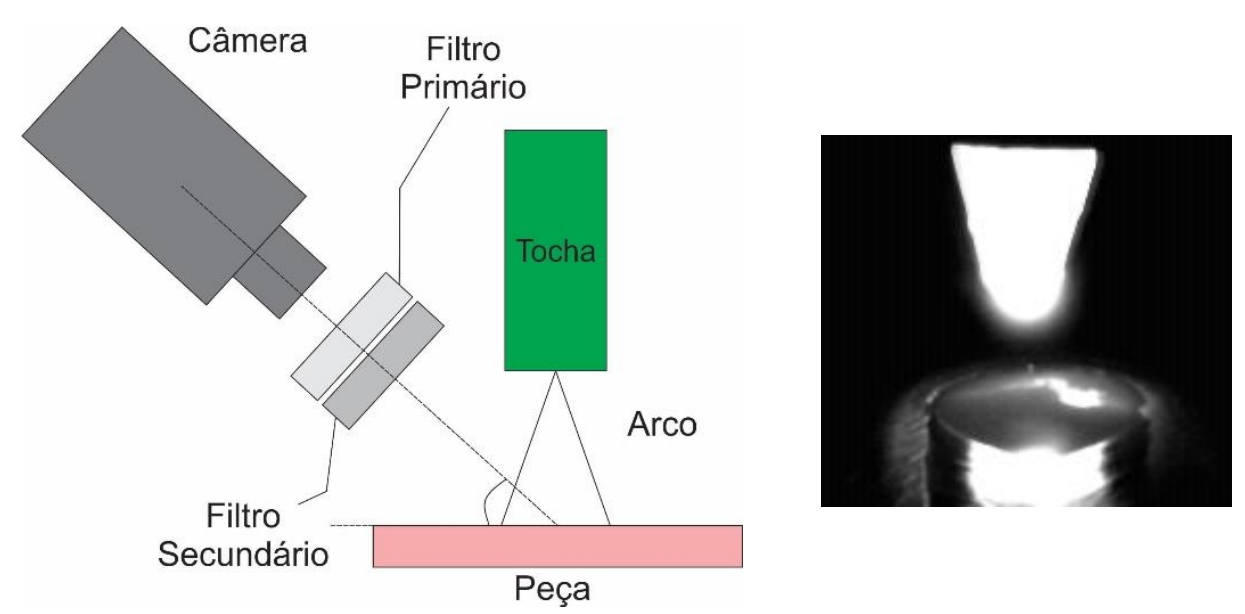

Figura 2.11 - Esquemático de montagem sensor visão passiva

Chen [3], utilizando um sistema de visão passiva conseguiu capturar claramente a borda e a poça de solda, e comprovou que a utilização de métodos algoritmos aplicados no processamento da imagem capturada pela câmera é eficiente para o controle da qualidade do cordão. O método utilizado foi alterar velocidade de alimentação do arame 
verificando a variação da abertura da junta (GAP). Chen também utilizou anteriormente um sistema de visão com técnicas baseadas em algoritmos neurais em tempo real para monitoramento da poça de solda durante o processo de soldagem, o estudo foi feito utilizando uma célula robótica e a câmera foi acoplada à tocha de soldagem [4]. Outros trabalhos, [28], [29], [30], [31], [32], utilizaram do mesmo princípio.

\subsubsection{VISUALIZAÇÃO DIRETA E INDIRETA DA POÇA DE FUSÃO}

A visualização direta confia que o objeto monitorado estará dentro do campo visual da câmera. Koike et al. [48] utilizou de um sistema de visualização direta para monitoramento da largura da poça, a largura da abertura da raiz e a distância do arame ao eixo da junta. A posição considerada mais apropriada para realizar esta visualização foi a frontal e a estrutura foi instalada no corpo do robô (vide Figura 2.12). O mesmo método também foi empregado no trabalho de Bauchspiess et al. [49].
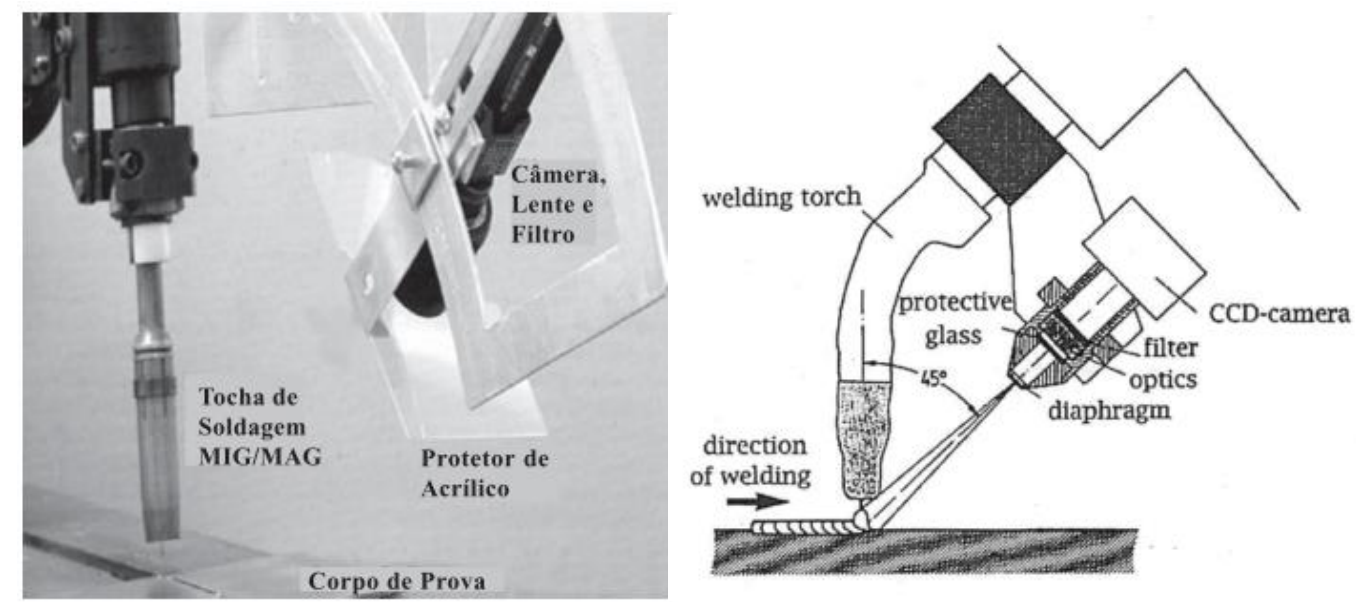

Figura 2.12 - (a) Estrutura utilizada por Koike e (b) Esquemático Bauchspiess

A visualização indireta usa técnicas de transmissão e direcionamento da imagem com finalidade de visualizar um ponto fora do campo visual direto da câmera. Chen [4], verificou que o método de reflexão utilizando espelhos planos, e instalação da estrutura na ferramenta de soldagem minimiza os distúrbios ocasionados pela vibração e o movimento do robô. O diagrama esquemático do projeto pode ser visto na Figura 2.13: 

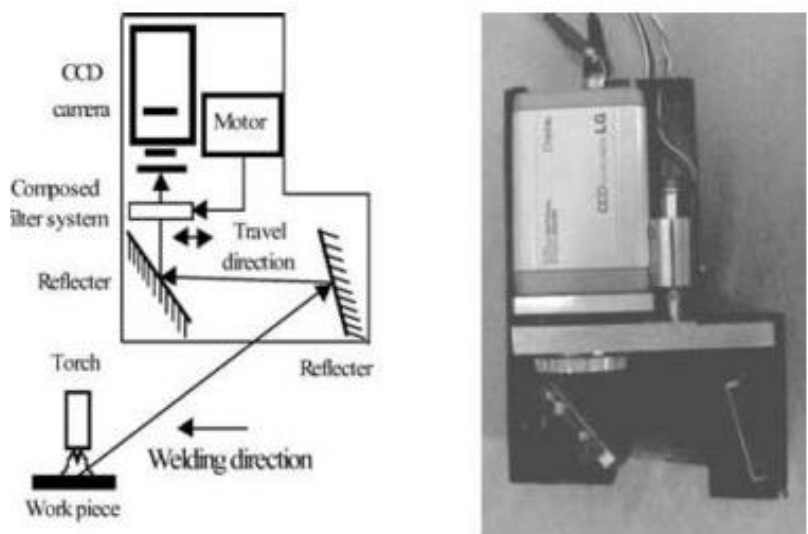

Figura 2.13 - Diagrama esquemático e projeto [4]

Para compreensão do diagrama esquemático da Figura 2.173, dois fenômenos físicos precisam ser compreendidos. O primeiro fenômeno físico é a reflexão, ou seja, quando um raio de luz incide em uma superfície de separação entre dois meios diferentes, parte da energia da radiação pode retornar e se propagar no mesmo meio em que estava.

O raio de luz que incide em certa superfície plana, ou raio incidente (RI), após incidir em um ponto na superfície, a luz é refletida, seguindo uma trajetória, definida pelo raio refletido (RR), conforme mostrado na Figura 2.14.

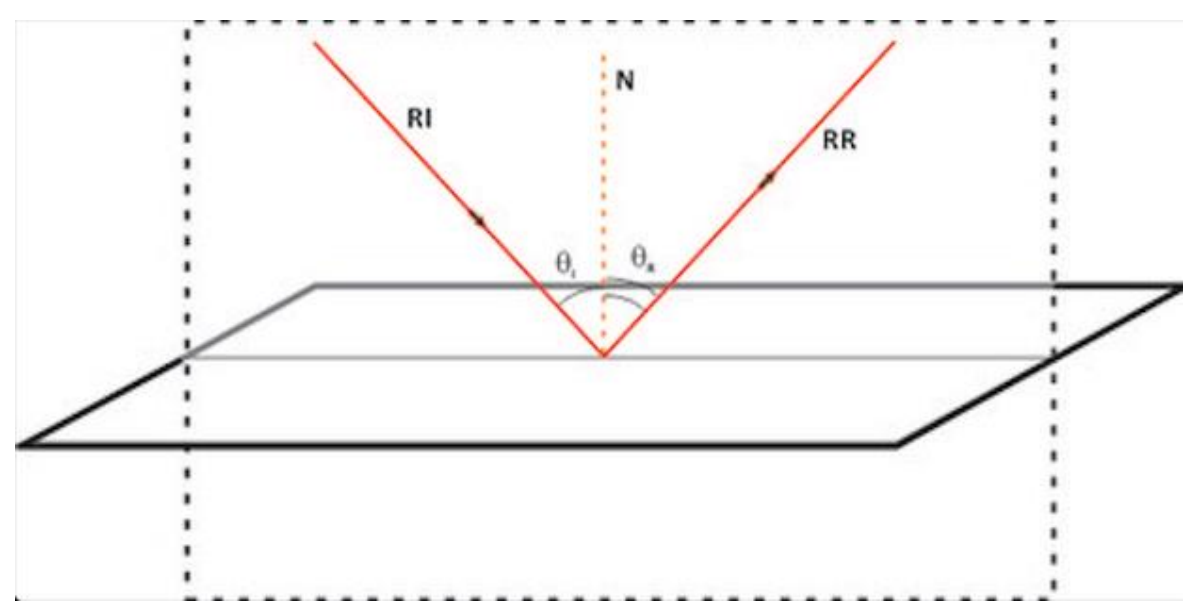

Figura 2.14 - Lei da reflexão

A letra N (Figura 2.14) representa a normal ao plano da superfície do espelho. Assim as leis da reflexão são regidas pelas seguintes regras: 
- O raio incidente, RI, a reta normal à superfície no ponto de incidência, $\mathrm{N}$, e o raio refletido, RR, são coplanares, ou seja, pertencem ao mesmo plano, chamado de plano de incidência.

- O ângulo de incidência $\theta_{\mathrm{I}}$, entre o raio incidente e a reta normal, é igual ao ângulo de reflexão $\theta_{R}$, entre o raio refletido e a reta normal: $\theta_{I}=\theta_{R}$

O segundo fenômeno físico é formação da imagem em um espelho plano. Espelho plano é definido como uma superfície lisa e plana que reflete a luz de maneira regular. Seja P um ponto luminoso ou iluminado colocado na frente de um espelho plano. Considere dois raios luminosos que incidem no espelho e são refletidos posteriormente, como mostrado na Figura 2.15.

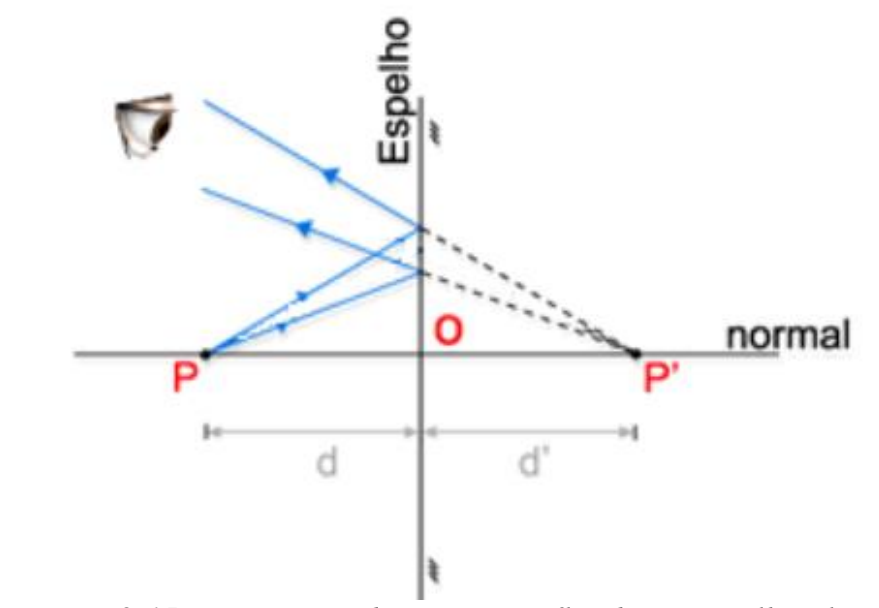

Figura 2.15 - Formação da imagem refletida no espelho plano [42]

O ponto $\mathrm{P}$, definido pela interseção efetiva dos raios incidentes sobre o espelho, é o objeto real. O ponto $\mathrm{P}^{\prime}$ definido pela interseção dos prolongamentos dos raios emergentes (refletidos), é uma imagem virtual. De um modo geral:

- Real: Interseção efetiva dos raios luminosos;

- Virtual: Interseção efetiva dos prolongamentos de raios luminosos.

A imagem formada pelos espelhos planos possui como características:

- $\quad$ O objeto e a imagem são equidistantes do espelho; 
- $\quad$ O objeto e a imagem têm natureza contrárias: se o objeto é real, a imagem é virtual e vice-versa.

Outra variável importante no projeto de construção do sistema de visualização da poça por meio de reflexão utilizando espelhos planos de Chen [4], é o campo de visão. Este compreende a região possível de ser observada por algum sistema em frente a um espelho, ou seja, todos os pontos que estiverem compreendidos na região delimitada pelas retas que ligam o' (imagem do observador) às extremidades do espelho, conforme mostra a Figura 2.16.

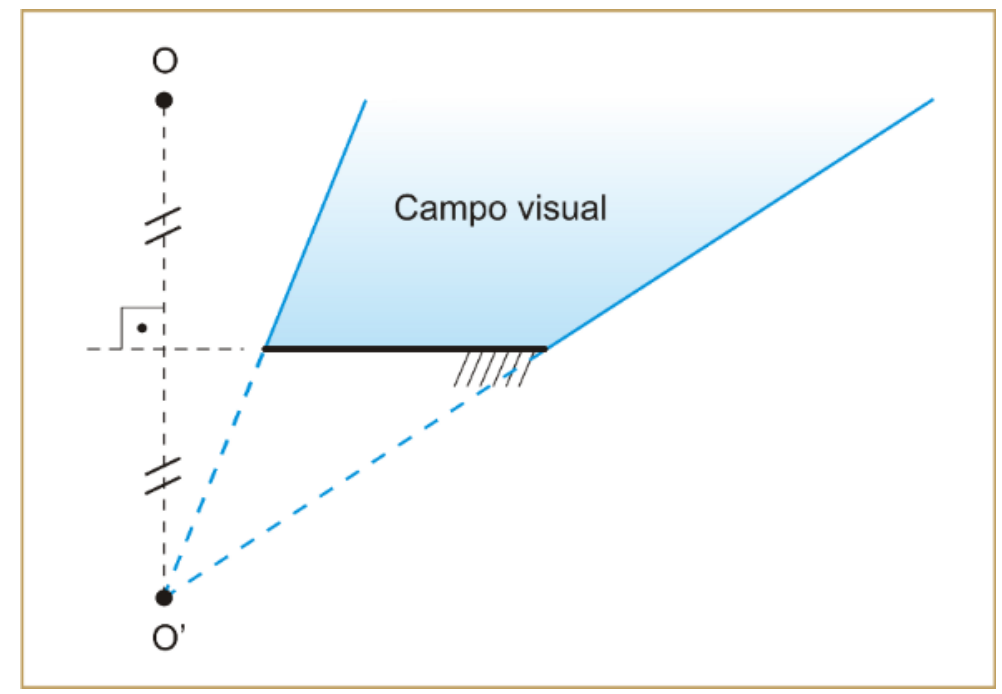

Figura 2.16 - Formação do campo de visão [42]

\subsubsection{FORMAÇÃO DAS IMAGENS DIGITAIS}

O termo imagem, refere-se à função bidimensional de intensidade de luz $f(x, y)$, em que $\mathrm{x}$ e y denotam as coordenadas espaciais e o valor de $f$ em qualquer ponto $(x, y)$ é proporcional ao brilho da imagem naquele ponto. Uma imagem digital é uma imagem $f(x, y)$ discretizada tanto em coordenadas espaciais quanto em brilho. Pode ser considerada uma matriz cujos índices de linhas e de colunas identificam um ponto na imagem. O correspondente valor do elemento da matriz identifica o nível de brilho naquele ponto. Os elementos dessa matriz digital são chamados de elementos da imagem, elementos de figura, "pixel" ou "pels", sendo que os dois últimos são abreviações de Picture elements, (elementos de figura). 
O funcionamento de uma câmera digital possui o mesmo princípio básico da clássica câmera "pin-hole ", (Figura 2.17). Ao compará-la a uma câmera digital, fica evidente que foi inserida uma objetiva para obter e concentrar mais a luz e o anteparo que possuía um filme fotossensível foi substituído por um sensor de imagens fotoelétrico [1].

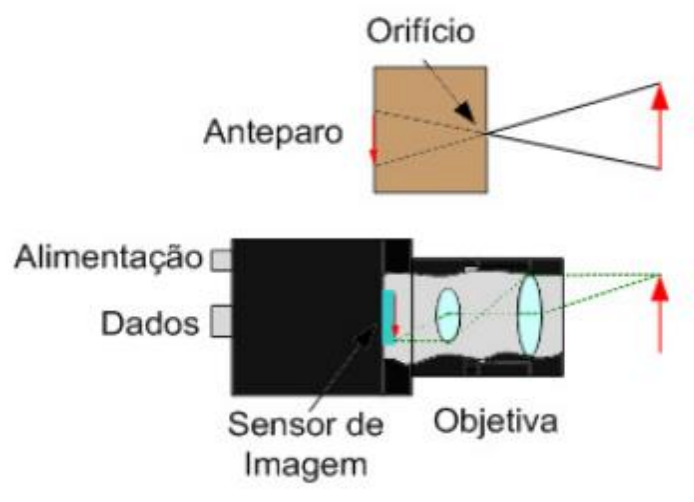

Figura 2.17 - Câmera pin-hole e digital

O sensor de imagem é um dispositivo que pode contar com dezenas de milhões e transdutores fotossensíveis, cada um deles capaz de converter a energia luminosa de um ponto da imagem em carga elétrica para ser lida ou gravada posteriormente na forma de imagem digitalizada em valores numéricos. Um sensor de imagem responde de forma eficiente a uma certa faixa de comprimentos de onda geralmente a faixa do visível (350 a 700nm), e responde com menor intensidade a comprimentos acima ou abaixo dessa faixa [1]. O gráfico de responsividade espectral da câmera fornece essa faixa em que melhor ela atua, a Figura 2.18 corresponde ao gráfico da câmera do fabricante Dalsa, modelo DS-21 1M150-SA.

Duas tecnologias principais competem para a construção de sensores de imagem: a CCD (charge-coupled device) e a CMOS (complementary metal-oxide semiconductor).

Em um dispositivo CCD, a carga é, na verdade, transportada ao longo do dispositivo e lida em um canto da matriz [33]. Um conversor analógico para digital transforma cada valor de pixel em um valor digital. Na maioria dos dispositivos CMOS, há vários transistores em cada pixel que amplificam e movem a carga usando fios mais tradicionais. A abordagem CMOS é mais flexível porque cada pixel pode ser lido individualmente [34], e essas características definem a câmera CMOS como aplicável a 
monitoração do processo de soldagem. As principais diferenças entre os dispositivos são [12]:

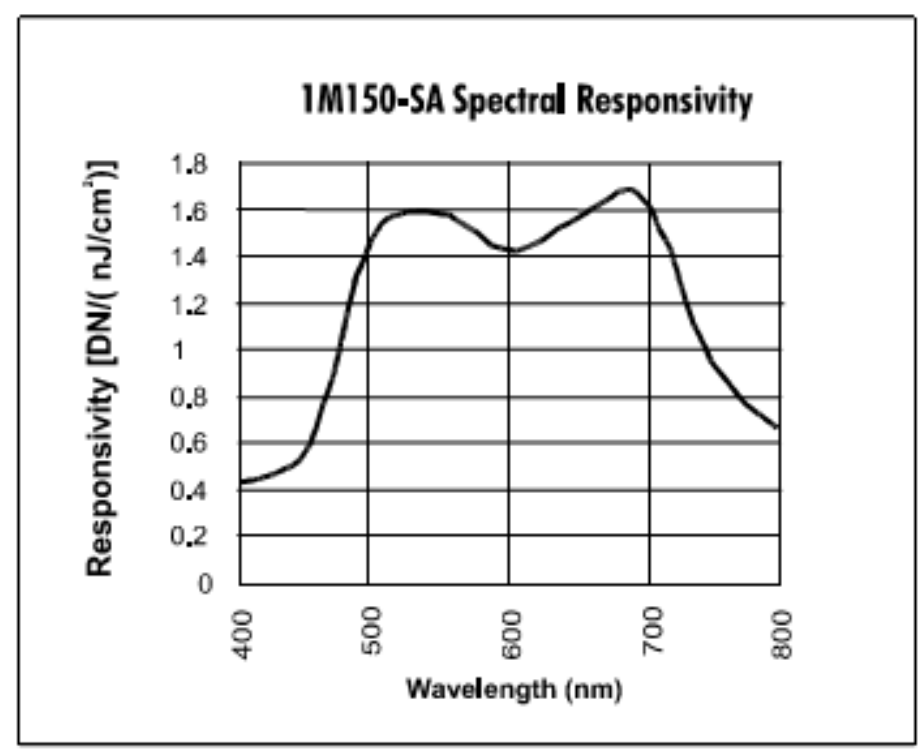

Figura 2.18 - Responsividade espectral da câmera DS21 1M150-SA fabricante Dalsa [44]

- $\quad$ Os sensores CCD criam imagens de alta qualidade e baixo "ruído". Os sensores CMOS são tradicionalmente mais suscetíveis ao ruído;

- Como há vários transistores próximos de cada pixel, a sensibilidade à luz de um dispositivo CMOS tende a ser menor. Muitos dos fótons que atingem o dispositivo colidem com os transistores em vez de atingir o fotodiodo;

- A tecnologia CMOS tradicionalmente consome menos energia.

Na tecnologia CMOS cada fotosensor possui intensidade luminosa independente e o conjunto deles agrupados formam uma matriz chamada sensor de imagens [34]. Cada elemento unitário da matriz formada é chamado de pixel e seu conjunto define a qualidade da imagem. A câmera utilizada neste trabalho possui 1024 linhas e 1024 colunas e sua resolução é de 1 megapixel, a resolução é calculada utilizando a formula abaixo:

$$
\text { Resolução }=\frac{N \text { o de linhas } * N \text { o de colunas }}{10^{6}}=\text { megapixels }
$$

O contraste de uma imagem é a diferença de tom calculada entre duas regiões vizinhas de uma imagem, ou diferença de intensidade de carga entre um pixel e outro, e é dado pela formula abaixo: 


$$
\operatorname{Contraste}(\%)=\frac{I_{1}-I_{2}}{I_{\max }-I_{\min }} * 100
$$

Em que $I_{1}$ e $I_{2}$ representam a luminosidade da região mais clara e mais escura respectivamente, $I_{\max }$ é a maior luminosidade possível (branco total) e $I_{\min }$ é a menor luminosidade possível (preto total). Em imagens de 8 bits, $I_{\min }$ vale 0 e $I_{\max }$ vale 255 . A Figura 2.19 apresenta um exemplo de contraste de $100 \%$ entre uma região branca e uma região preta. Neste caso, $\mathrm{I}_{1}=255$ e $\mathrm{I}_{2}=0$.

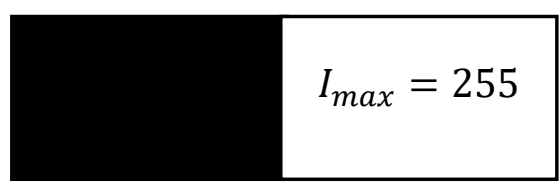

Figura 2.19 - Exemplo de contraste de $100 \%$

À medida em que a diferença de tom entre as duas regiões é reduzida, o valor do contraste também diminui. Quanto menor o contraste, mais difícil torna-se a diferenciar as regiões vizinhas.

\subsubsection{FILTROS ÓPTICOS}

A forma mais simples de melhoria de imagem em um processo de soldagem é o uso de filtros ópticos físicos que podem atenuar, impedir ou filtrar determinados comprimentos de onda que são recebidos por um sensor de imagens de uma câmera. $O$ uso de filtros ópticos na faixa do infravermelho reduzem o brilho do arco de elétrico e exibem a poça de solda incandescente [22].

Filtros ópticos transmitem seletivamente a luz em um determinado intervalo de comprimentos de onda, enquanto bloqueia a parte restante. São divididos em:

- Filtros bandpass: filtros de banda apenas transmitem todos os comprimentos de onda em um intervalo, e bloqueia outros fora do intervalo; 


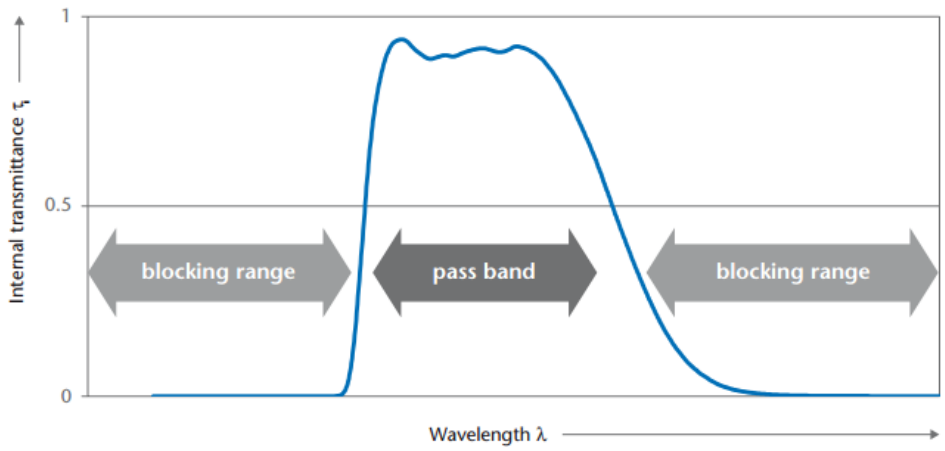

Figura 2.20 - Filtro Bandpass [35]

- Filtro longpass: Um filtro passa alta é caracterizada pelo fato de uma gama de baixa transmissão (gama de bloqueio) na região de comprimento de onda curto é unida a uma área de alta transmissão (faixa de passagem) na região de comprimento de onda longo;

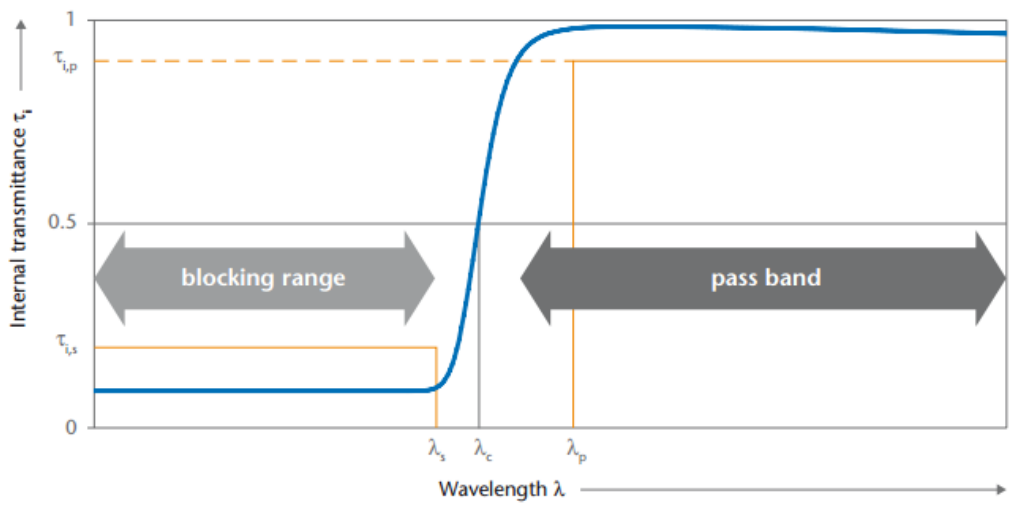

Figura 2.21 - Filtro Longpass [35]

Em que:

$\lambda_{c}$ : Comprimento de onda de borda ou comprimento de onda de corte no ponto em que a transmitância espectral interna tem um valor de 0,5 .

$\lambda_{s}:$ O limite inferior da faixa de bloqueio. Abaixo deste comprimento de onda, a transmitância interna tem um valor inferior $\tau$ i, s para uma determinada região espectral.

$\lambda_{p}$ : O limite da faixa de passagem. Acima deste comprimento de onda, a transmitância espectral interna não atinge valores inferiores $\tau i, p$ dentro de uma certa faixa espectral. 
- Filtros shortpass: Comprimentos de onda mais curtos podem passar através de um filtro passa baixa, enquanto que comprimentos de onda longos são bloqueados;

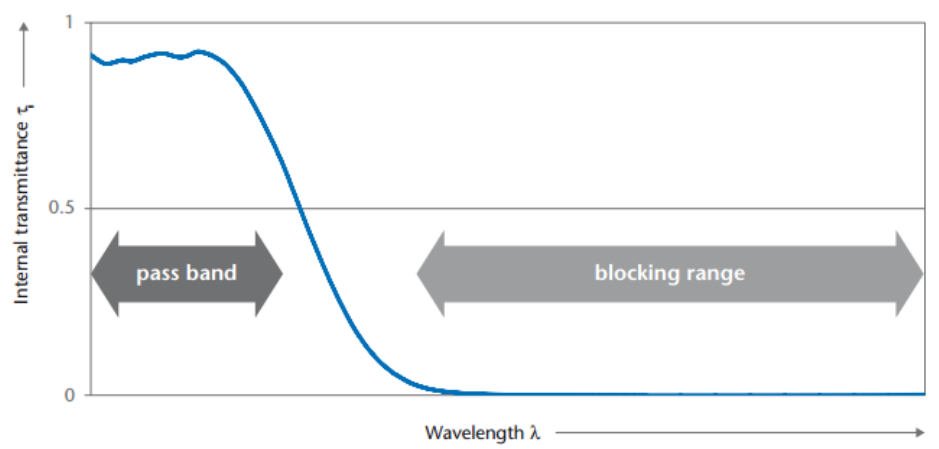

Figura 2.22 - Filtro Shortpass [35]

- Filtros de densidade neutra: Os filtros de densidade neutros apresentam transmitância espectral quase constante no intervalo da luz visível;

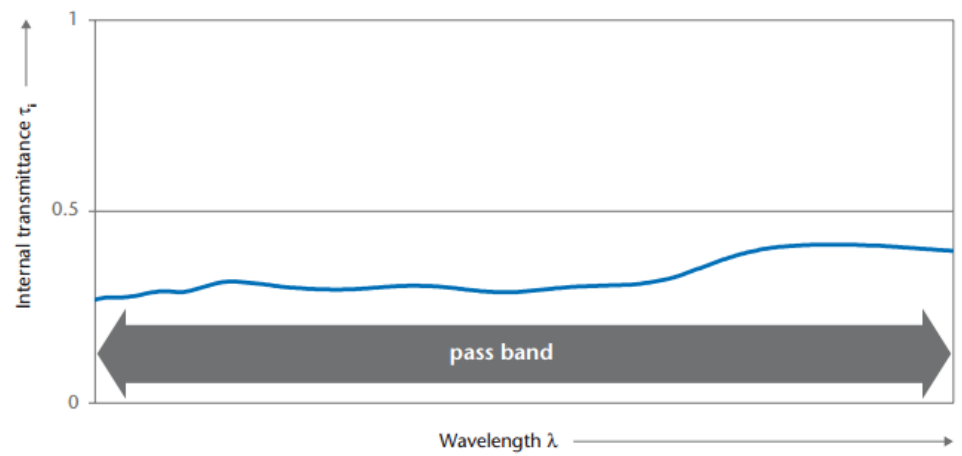

Figura 2.23 - Filtro de densidade neutra [35]

- Polarizadores: Bloquear ou transmitir a luz de acordo com a sua polarização.

Geralmente os filtros são implementados com vidro plano ou dispositivos de plástico e são descritos por sua resposta a frequência, que especifica como a magnitude e a fase de cada componente de um sinal de entrada de frequência é alterada pelo filtro.

Os filtros longpass são usados em aplicações de espectroscopia de precisão como separadores de banda. Em aplicações de fotometria filtros longpass e shortpass são usadas como ordem de classificação ou filtros de bloqueio, que são aplicados à janela de 
um detector para eliminar qualquer distorção de segunda e de terceira ordem. Filtros longpass e shortpass também são frequentemente utilizados em espectroscopia Raman [45].

Os filtros são comumente usados em fotografia (onde alguns filtros de efeitos especiais são usados ocasionalmente, como filtros de absorção), e em muitos instrumentos óticos [35].

\subsubsection{SINCRONIZAÇÃO}

Uma ferramenta que vem a complementar os estudos experimentais de transferência metálica é a sincronização das imagens obtidas na filmagem com sinais de corrente, tensão ou de outro tipo de sensor que sejam adquiridas durante a soldagem [50]. Sincronização dos sistemas de visão visa selecionar imagens aptas para processamento, ou seja, imagens com o mínimo de interferência luminosa causada pelo arco elétrico. Os métodos utilizados estão relacionados principalmente ao tipo de transferência metálica aplicado ao processo e, consequentemente, aos níveis variáveis de luminosidade produzida pela coluna de plasma.

Segundo Adolfsson [51], o melhor período para captura da imagem em um processo com transferência por curto-circuito, ocorre quando o arame toca a peça de soldagem. Neste momento o arco é extinto deixando somente o brilho da poça de soldagem fundida. Duarte [1], desenvolveu um sistema de medição e monitoração da tensão do arco de soldagem a fim de capturar a poça nos pontos de curto circuito.

A transferência por curto-circuito acontece com relativamente baixos valores de tensão e corrente, se comparados por exemplo ao modo de transferência por spray. Naquela transferência metálica, quando a gota de metal fundido entra em contato com o metal de base, as forças de tensão superficial do metal líquido causam o deslocamento do metal fundido da ponta do eletrodo para poça. Devido ao aumento da corrente de soldagem decorrente do curto circuito, surgem forças magnéticas compressivas (direção radial) que causam a estricção da ponte de metal liquido. A consequente redução da área de passagem da corrente elétrica causa o aumento da resistência do condutor liquido 
produzindo aquecimento Joule que evapora o metal da ponte, gerando a reabertura do arco e recomeçando o ciclo (Figura 2.24). Durante o período do curto circuito, a inexistência do arco elétrico torna possível a captura de imagens iluminadas somente pela emissão proveniente da poça incandescente.

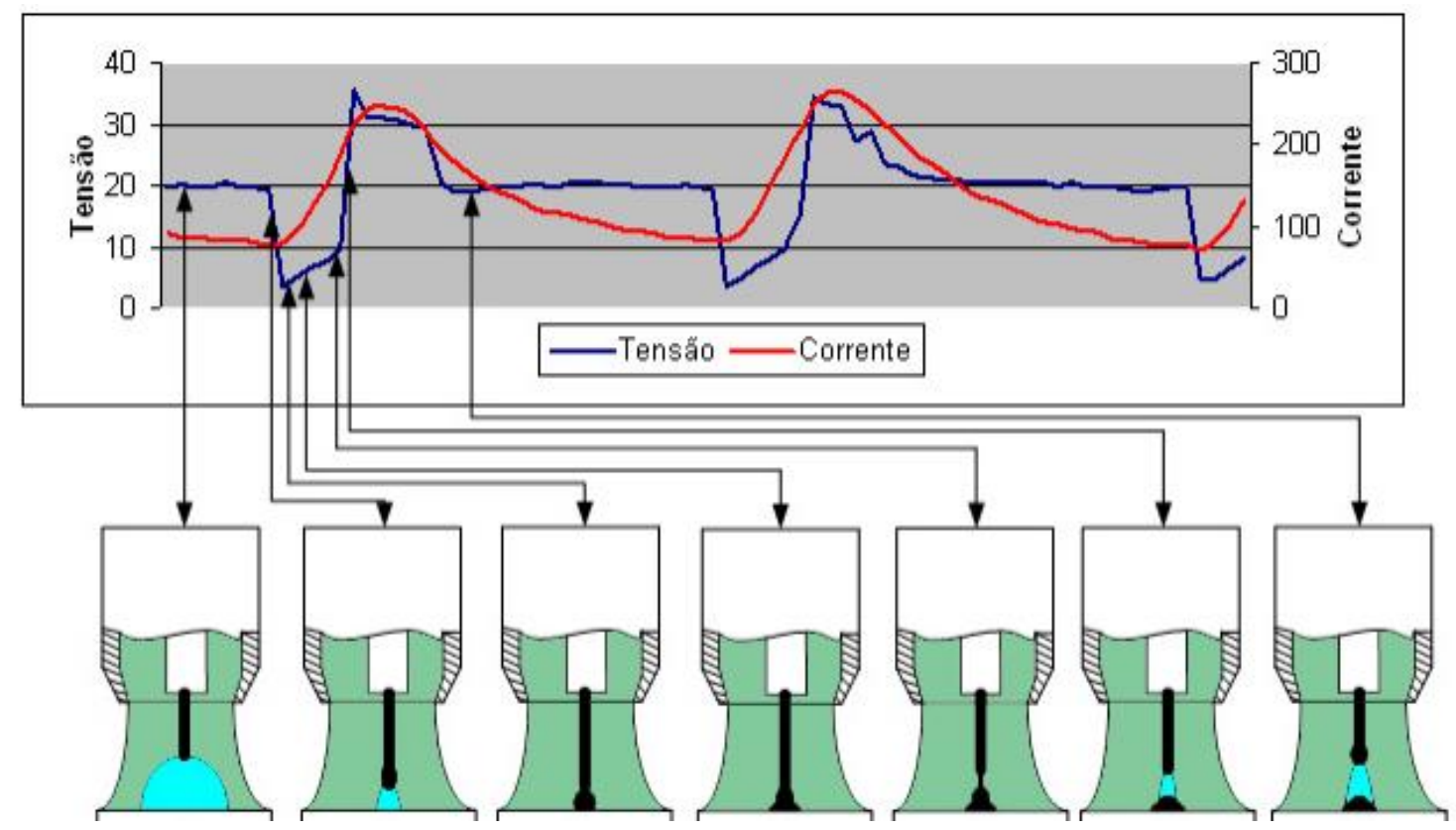

Figura 2.24 - Esquemático de modo de transferência por curto-cucurito

A sincronização por monitoramento dos sinais elétricos também pode ser usado nos processos onde há pulsação dos níveis da corrente elétrica, principal fator relacionado ao brilho do arco elétrico. De acordo com Chen [47], a intensidade luminosa do arco é alta nos pontos que predominam os picos de corrente e mínima nos pontos de corrente de base, ou seja, a técnica de sincronização utilizada nesses processos monitora os pontos de corrente de base para abertura e captura da câmera. Como mencionado no Tópico 2.1.2, a corrente de base é utilizada somente para manutenção do arco. Nestes pontos não há fusão do material e, consequentemente, a interferência do arco é menor.

\subsection{PROCESSAMENTO DE IMAGEM}

O interesse em métodos de processamento de imagens digitais decorre de duas áreas principais de aplicação: (a) melhoria na informação visual para interpretação 
humana e (b) processamento de dados de cenas para percepção automática através de máquinas [36]. A Figura 2.25 mostra que o objetivo global do processamento de imagens é produzir um resultado a partir do domínio do problema por meio de processamento de imagem.

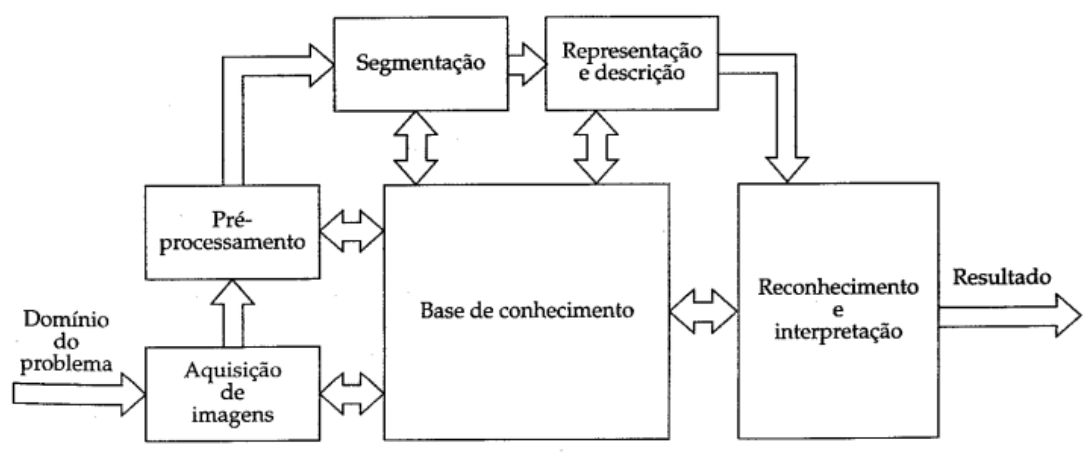

Figura 2.25 - Passos fundamentais em processamento de imagens digitais [36]

A primeira fase no processamento consiste na aquisição da imagem, ou seja, adquirir uma imagem digital. Nessa etapa é necessário o sensor de imagem (CCD ou CMOS) e a capacidade de digitalizar o sinal produzido pelo sensor, ou seja, um conversor de sinal.

Tendo a imagem, o próximo passo seria o pré-processamento. Nesta etapa, técnicas de melhoria são aplicadas para aumentar a chance de sucesso nos outros processos. O pré-processamento geralmente envolve o realce do contraste da imagem, isolamento de região e eliminação de ruídos.

A segmentação divide uma imagem em partes ou objetos constituintes. A saída do processo de segmentação é constituída por dados em forma de pixels, correspondentes tanto à fronteira de uma região como todos os pontos dentro do mesmo. Torna-se necessária, em ambos os casos, a conversão dos dados para uma forma adequada ao processamento computacional.

A escolha da representação é apenas parte da solução para transformar os dados iniciais numa forma adequada para posteriormente o processamento computacional. $\mathrm{O}$ processo de descrição extrai características que resultem em alguma informação quantitativa e de interesse ao processamento. 
O reconhecimento é um processo que atribui um rótulo a um objeto, baseado na informação fornecida pelo seu banco de dados, e a interpretação envolve a atribuição de um significado a um conjunto de objetos reconhecidos [36].

Os passos se encaixam em qualquer tipo de processamento de imagem, e estão diretamente ligados aos detectores de bordas conhecidos. Em uma visão geral, a detecção de borda em soldagem segue os seguintes passos, (Figura 2.26):

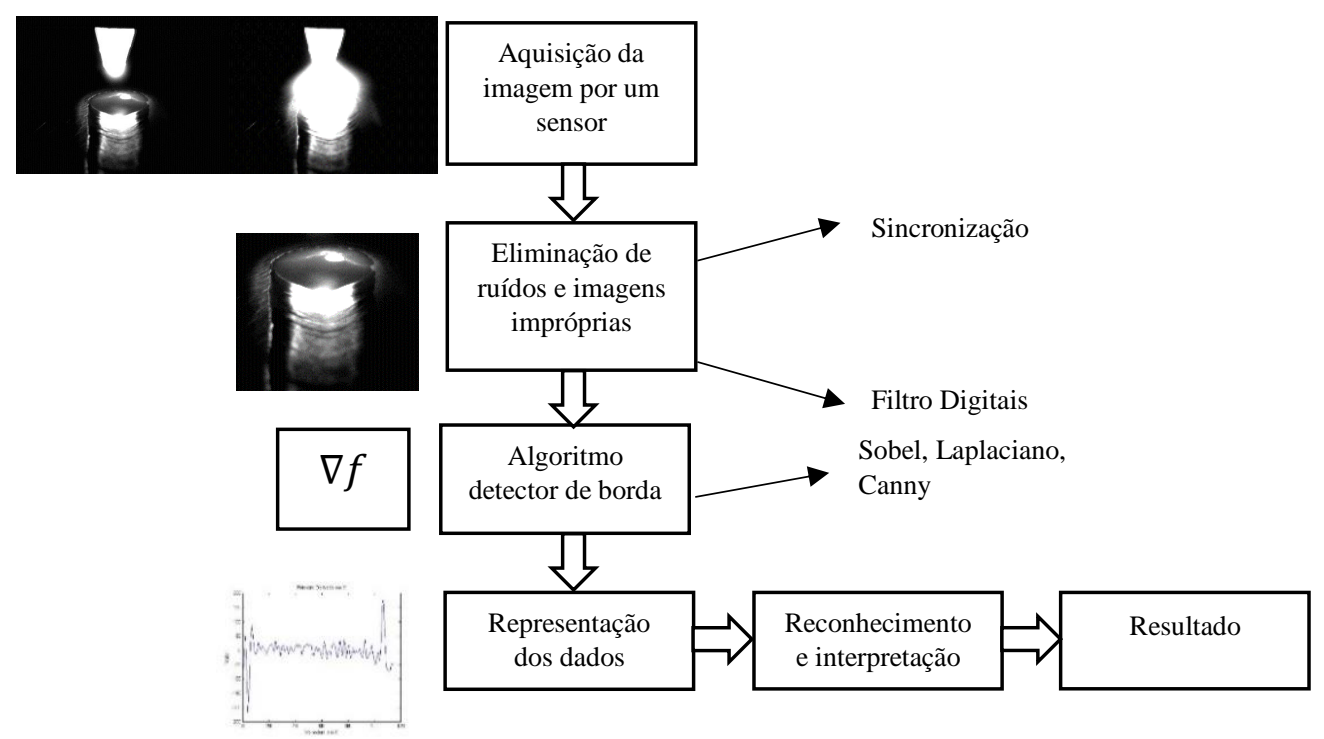

Figura 2.26 - Visão geral detecção de borda

A detecção de borda é uma importante técnica para monitoração da poça de solda. Alguns autores utilizam esse método para medição da largura da poça e da junta [3], [4] e [37], com o fim de controle da penetração total da solda.

Um dos principais problemas encontrados na detecção de bordas são os ruídos. Sendo assim, uma solução seria a filtragem das imagens ruidosas antes da extração de suas bordas. Para isso, necessita-se encontrar um método que elimine os ruídos das imagens, preservando as bordas, para posteriormente, extrair os resultados com mais precisão.

Os filtros para eliminação de ruídos são conhecidos como passa baixa, uma vez que as frequências altas que correspondem as transições são atenuadas. 


\subsubsection{DETECTORES DE BORDA}

Muitos detectores de bordas foram desenvolvidos recentemente, tais como Robot, Prewitt, Kirsch, Sobel, Laplaciano, Canny e assim por diante. A detecção de bordas é essencialmente a operação de detectar mudanças locais significativas na imagem. Em geral, uma borda está associada com um pico local na primeira derivada [38].

Uma borda é o limite entre duas regiões com propriedades distintas de nível de cinza. Basicamente, a ideia por traz da maioria das técnicas para detecção de borda é a operação de um operador local diferencial. A magnitude da primeira derivada pode ser usada na detecção da presença de uma borda em uma imagem, enquanto que o sinal da segunda derivada pode ser usado para determinar se um pixel da borda se localiza no lado escuro ou no claro da imagem, Figura 2.27.

O processo de detecção de borda consiste em três categorias [36]:

- $\quad$ Redução do ruído: como a primeira e a segunda derivada são extremamente sensíveis, é recomendado usar técnicas de suavização da imagem.

- Detecção do ponto de borda: Operadores locais que respondem fortemente às bordas e fracamente em outro lugar são aplicadas à imagem, resultando uma imagem de saída cujos pixels brilhantes são candidatos a se tornarem pontos de borda.

- $\quad$ Localização da borda: Os resultados de detecção de bordas são pós processados, pixels espúrios são removidos e as bordas quebradas são transformadas em linhas significativas e limites.

A primeira derivada em qualquer ponto da imagem é obtida usando-se a magnitude do gradiente naquele ponto, a segunda é obtida similarmente utilizando o Laplaciano. O gradiente de uma imagem $f(x, y)$ na posição $(\mathrm{x}, \mathrm{y})$ é dado pelo vetor:

$$
\nabla f=\left[\begin{array}{l}
G_{x} \\
G_{y}
\end{array}\right]=\left[\begin{array}{l}
\frac{\partial f}{\partial x} \\
\frac{\partial f}{\partial y}
\end{array}\right]
$$


(a)

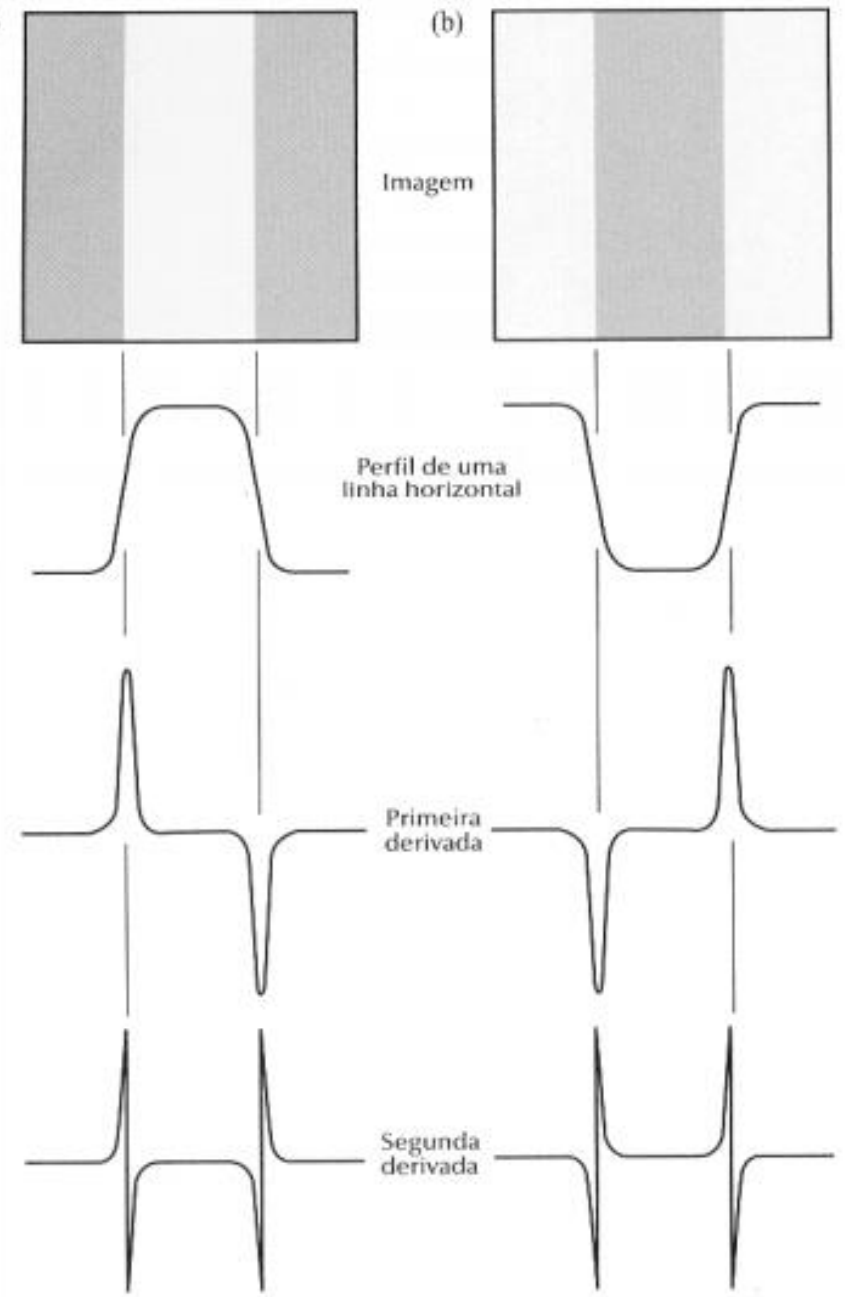

Figura 2.27 - Detecção de borda por operadores de derivação; (a) faixa clara sobre o fundo escuro (b) faixa escuro sobre um fundo claro[36]

A partir da análise vetorial, sabe-se que o vetor gradiente aponta na direção de mudança mais rápida de $f$ na posição $(\mathrm{x}, \mathrm{y})$. Em detecção de bordas, a magnitude desse vetor é uma quantidade importante, chamada simplesmente de gradiente:

$$
\begin{gathered}
\nabla f=\operatorname{mag}(\nabla f)=\left[G_{x}^{2}+G_{y}^{2}\right]^{1 / 2} \\
\nabla f=\left|G_{x}\right|+\left|G_{y}\right|
\end{gathered}
$$

A direção do vetor gradiente é também uma quantidade importante. Seja $\alpha(x, y)$ $\mathrm{o}$ ângulo da direção do vetor $\nabla f$ na posição $(\mathrm{x}, \mathrm{y})$. Então, a partir da análise vetorial, temse que: 


$$
\alpha(x, y)=\operatorname{tang}^{-1}\left(\frac{G_{x}}{G_{y}}\right)
$$

Em que o ângulo é medido em relação ao eixo x.

A partir das equações (2.1) e (2.2), o cálculo do gradiente de uma imagem baseiase na obtenção das derivadas parciais na posição de cada pixel. As derivadas podem ser implementadas de diferentes formas, porém, os operadores SOBEL possuem a vantagem de fornecer, a um só tempo, os efeitos de diferenciação e suavização [36]. Uma vez que a derivação aumenta o ruído, o efeito de suavização é uma característica particularmente atrativo dos operadores SOBEL [39].

Em resumo, o operador Sobel possui as seguintes características [36]:

- $\quad$ O operador Sobel é um operador de diferenciação discreta. Ele calcula uma aproximação do gradiente de uma função de intensidade de imagem; - $\quad$ O operador Sobel combina suavização e diferenciação de Gauss;

- $\quad$ O operador gradiente de Sobel tem a propriedade de realçar linhas verticais e horizontais mais escuras que o fundo, sem realçar pontos isolados;

- $\quad$ A detecção de bordas é obtida pela limiarização da magnitude do gradiente.

O Laplaciano de uma função bidimensional, $f(x, y)$, é uma derivada de segunda ordem definida por:

$$
\nabla^{2} f=\frac{\partial^{2} f}{\partial x^{2}}+\frac{\partial^{2} f}{\partial y^{2}}
$$

Como indicado anteriormente, o Laplaciano responde a transições na intensidade, ele é raramente usado na prática de detecção de borda, por vários motivos. Por ser uma derivada de segunda ordem, o Laplaciano é tipicamente sensível a ruído de maneira inaceitável [36]. Além disso, o Laplaciano produz bordas duplas, sendo incapaz de detectar a direção da borda. Por essas razões, o Laplaciano usualmente cumpre papel secundário como um detector para estabelecer se um pixel está no lado claro ou escuro de uma borda. 
Outro detector de borda usado em alguns casos para extrair dados da poça de solda [3], é conhecido como CANNY EDGE DETECTOR. O detector de borda Canny foi desenvolvido por John F. Canny em 1986 [38]. Também conhecido por muitos como o detector ideal, o algoritmo Canny visa satisfazer três critérios principais:

- $\quad$ Baixa taxa de erro: Significando uma boa detecção de apenas bordas existentes.

- Boa localização: A distância entre a borda dos pixels detectados e a real borda tende a ser minimizada.

- $\quad$ Resposta mínima: Apenas uma resposta do detector por aresta.

Porém sua aplicação aos processos de soldagem não é simples, pois depende de um valor limiar estabelecido inicialmente, que pode ser difícil de estabelecer em condições reais de soldagem. O método geralmente é usado em operações off-line, e posteriormente, com um limiar estabelecido, em operações on-line.

\subsection{CONSIDERAÇÕES}

A visão computacional conjunta a sistemas de soldagem é uma importante ferramenta para monitoração dos parâmetros de solda, porém sua aplicação ao processo é uma tarefa árdua, que abrange conhecimentos de todos tópicos citados anteriormente neste capítulo. O sensor de visão ideal tem que ser apto a verificar a dinâmica da poça de fusão, para isso um conjunto de fatores como equipamento (câmera e fonte de soldagem) e periféricos (lentes, filtros, estrutura) devem trabalhar em conjunto afim de se obter uma imagem nítida, para processamento e obtenção de dados essenciais para controle do processo.

Os tópicos seguintes tratarão da metodologia usada para elaboração de um sensor capaz de detectar esses parâmetros da poça de solda em um processo TIG pulsado sem alimentação de arame, e as respostas ao modelo implementado. Os operadores de detecção de borda implementados são os operadores SOBEL e Laplaciano, e suas respostas ao problema serão mostrados posteriormente. 


\section{METODOLOGIA E MONTAGEM EXPERIMENTAL}

Conforme já explicitado no item 1.1, esta pesquisa foca no desenvolvimento de um sensor de visão para visualização da poça de fusão em um processo GTAW pulsado, em que ocorre pulsação da corrente de soldagem entre dois níveis de intensidade. As etapas componentes da metodologia adotada são baseadas em três linhas de ações:

- Dimensionamento do conjunto de filtros ópticos usados com o propósito de eliminar a interferência do arco, para melhoria do contraste das imagens;

- Escolha da câmera que melhor se adapta ao processo de soldagem proposto;

- Elaboração do projeto de fixação da câmera na tocha de soldagem, utilizando espelhos planos para reflexão da imagem.

Um problema na utilização do sensor de visão aplicado a robótica é concernente a sua instalação no robô. Em muitos casos, sua aplicação é inviabilizada devido à perda de graus de orientação da ferramenta (tocha). O objetivo do projeto de construção do sensor é minimizar os efeitos nessa orientação, com finalidade de utilizar futuramente a estrutura em células robóticas. Para isso foi construído um sistema de visualização da poça de soldagem baseado nas leis da reflexão e posteriormente a estrutura foi instalada na tocha de soldagem.

Outro problema a ser resolvido relaciona-se à redução ou eliminação da influência do arco elétrico nas imagens. Para isso, buscaram-se aliar dois métodos de redução de luminosidade: (a) combinação de filtros ópticos e (b) processamento computacional. $\mathrm{O}$ último método consiste em estudar uma forma eficiente de selecionar, para fins de processamento, somente as imagens que possuem baixa interferência do arco. Após selecionadas, as imagens escolhidas são processadas de modo a se extraírem informações geométricas da poça.

O processo GTAW possui em suas características a permanência do arco aberto em todo processo. Esse aspecto torna a utilização de uma câmera como sensor de visão um obstáculo, pois o brilho excessivo proveniente do arco elétrico limita a qualidade das imagens capturadas, saturando-as na região de maior luminosidade.

No entanto, no caso do processo GTAW pulsado, há alguns momentos em que a interferência do arco é menor. A fonte de soldagem fornece uma onda retangular que 
pulsa ciclicamente entre dois valores de corrente, denominados como corrente de pico e corrente de base. Na corrente de base a interferência luminosa é menor, pois é utilizado um nível baixo de corrente apenas para manutenção do arco elétrico entre o eletrodo e a peça, momento em que não ocorre fusão do material. Esse período é ideal para obtenção da imagem. No contexto da seleção de quadros propícios via processamento computacional, a primeira linha de estudo é sincronizar, via métodos computacionais, a seleção das imagens aos instantes em que a interferência do arco é mínima. O software a ser implementado deve ser capaz de separar as imagens em que o nível de interferência luminosa é menor, a partir do conjunto de imagens adquiridas em uma filmagem livre, baseado na análise do brilho do arco.

O próximo passo consiste em implementar um método algorítmico de medição da poça fundida nas imagens selecionadas, utilizando os detectores de bordas. O objetivo é formar um registro temporal, mostrando a evolução das características geométricas extraídas da poça durante a formação do cordão de solda.

Um resumo das etapas constituintes deste trabalho pode ser visto na Figura 3.1:

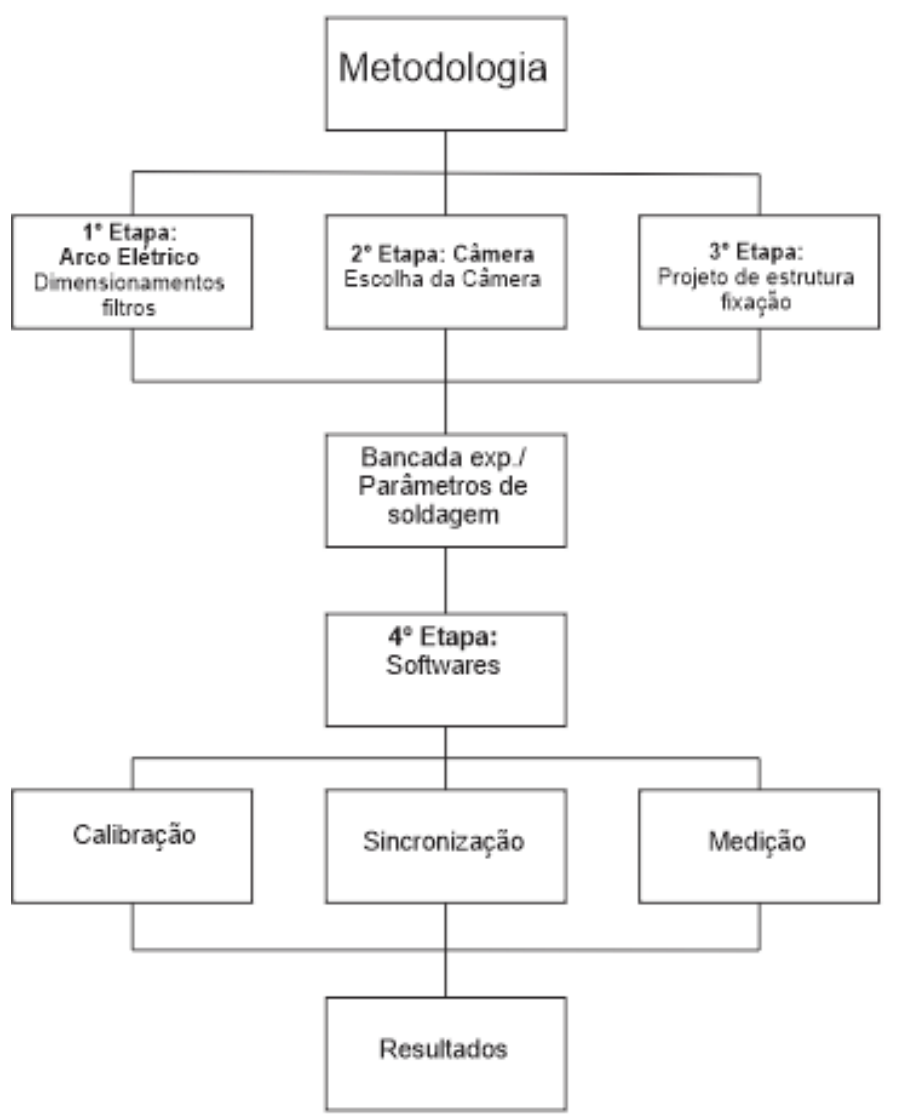

Figura 3.1 - Linhas de ação proposta 
Para atingir os objetivos propostos foi necessário estudar, criar e analisar uma infraestrutura física e lógica, a qual inclui:

- Especificação da geometria de visualização (direta ou indireta) de modo a se ter um aparato que interfira pouco com a acessibilidade da tocha e propicie proteção aos elementos sensíveis (câmera e lente);

- Especificação do conjunto de filtros ópticos a serem utilizado no sistema com objetivo de realçar as bordas da poça e reduzir o efeito do arco;

- Parametrização da fonte de soldagem: Visa-se obter um processo pulsado;

- Sincronização das imagens: Desenvolvimento de software para seleção das imagens com menor interferência luminosa provocada pelo arco;

- Extração das características desejadas da poça fundida por meio de métodos computacionais dispostos na literatura.

\subsection{ESPECIFICAÇÃO DA BANCADA EXPERIMENTAL}

\subsubsection{FILTROS ÓPTICOS}

Devido à alta intensidade de emissão de arco, a imagem da poça de fusão é fortemente interferida. A principal tarefa do projeto do sensor, está em reduzir a interferência de arco, para melhoria do contraste das imagens. Os filtros ópticos são ideais nesta tarefa, pois permitem que apenas uma faixa do espectro alcance a câmera, melhorando a qualidade para fins de processamento.

A escolha do filtro ideal deve ser baseada nos espectros de emissão tanto da poça quanto do arco. Considerando que no TIG, o plasma é formado a partir da ionização do argônio, deve-se buscar em seu espectro regiões em que a intensidade de luminosa do arco seja baixa, quando comparada ao espectro de emissão da poça e à sensibilidade do sensor da câmera. A Figura 3.2 mostra a distribuição característica do espectro do Argônio. 
Chen [47], com base na experiência e na análise dos resultados relacionados à soldagem com gás Argônio, determinou os parâmetros do conjunto de filtros ópticos para o projeto do sensor, sendo eles: o filtro primário é um filtro passa faixa (bandpass) de 560-700 nm, ou seja, apenas o espectro de comprimento de onda maior do que $560 \mathrm{~nm}$ ou menor do que $700 \mathrm{~nm}$ podem passar através dele. $\mathrm{O}$ brilho foi atenuado utilizando um filtro de densidade neutra de $30 \%$.

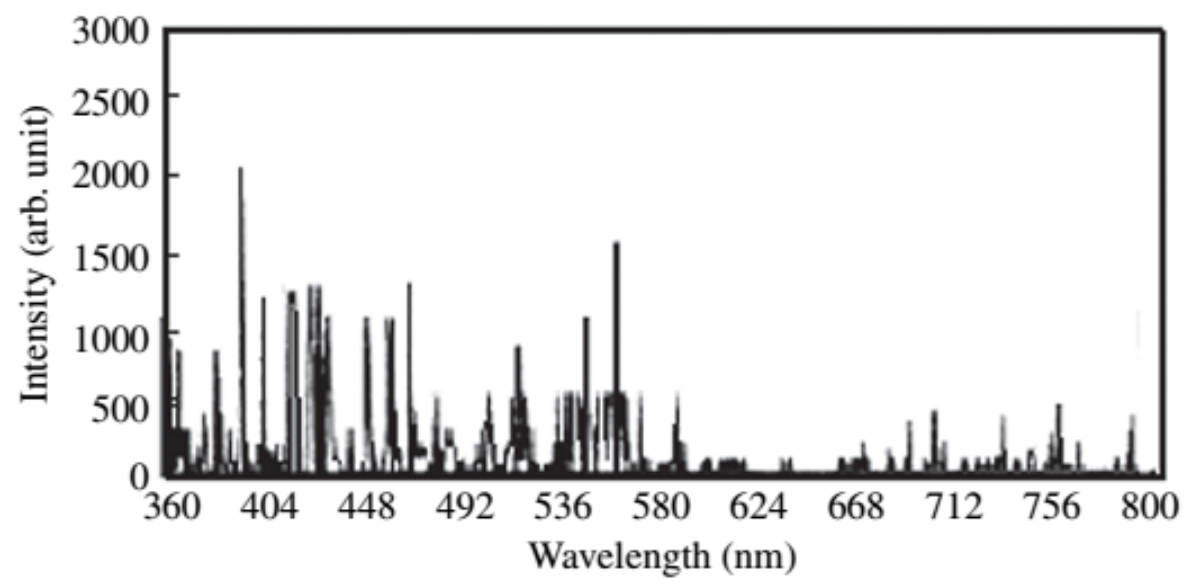

Figura 3.2 - Característica do espectro do Argônio [47]

No entanto, o laboratório de soldagem robotizada do GRACO não possui o filtro passa faixa com a especificação encontrada por Chen [47], tornando necessária a adaptação do trabalho para os filtros que se encontram a disposição. Outra possibilidade seria utilizar filtro de passa alta na região do infravermelho (long wave pass filter), caso que foi estudado por Mota [40]. Em seus testes de espectrometria, ela verificou que na região acima de $920 \mathrm{~nm}$ a interferência do arco também era pequena. No projeto foi utilizado um filtro de comprimento de onda de corte na região do infravermelho próximo (900nm). O limite superior é determinado pela responsividade espectral do sensor da câmera, que sendo de silício responde até $1000 \mathrm{~nm}$.

Em conjunto com o filtro de passa alta, foi utilizado um filtro neutro com $30 \%$ de atenuação, formando assim um aparato óptico para os experimentos de processamento da imagem. 


\subsubsection{CÂMERA E SOFTWARES}

Para filmagem da poça de solda foi utilizada uma câmera CMOS com saída de 8 bits, fabricante DALSA, modelo DS-21-001M150 (Figura 3.3), com taxa de aquisição de $150 \mathrm{fps}^{1}$ a uma resolução de $1024 \times 1024$, mas podendo atingir maior taxa de quadros por meio de técnicas de janelamento, ou seja, diminuindo a resolução da imagem. O equipamento trabalha em conjunto com o programa CamExpert e PFRemote:

- CamExpert, em que são testadas e definidas as características no processo de captura da imagem, como região de interesse (ROI) e sincronismo;

- PFRemote: programa freeware por meio do qual se ajusta o tempo de exposição da câmera.

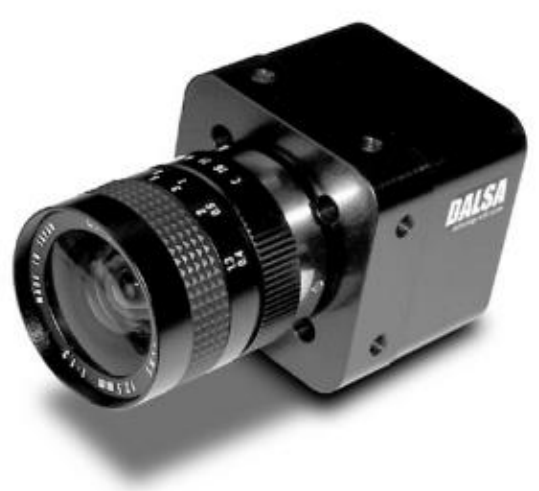

Figura 3.3 - Câmera DALSA modelo DS21-001M150

O programa CamExpert possui em sua base de dados informações intrínsecas sobre câmeras de diversos fabricantes (tipo de câmera, definição), incluído a câmera utilizada neste trabalho. Após selecionada e reconhecida a câmera pelo programa, podese iniciar a exibição de imagens coletadas bastando clicar no botão GRAB. Para finalizar a captura, deve-se clicar no botão Freeze na janela Display do programa. Na janela Parameters, o usuário pode ajustar os parâmetros de aquisição da câmera para adaptá-los à necessidade do experimento como, por exemplo, a região de interesse para aquisição da imagem.

${ }^{1}$ frames por segundo. 
As alterações dos parâmetros da câmera no CamExpert podem ser salvas em arquivos de configuração de câmera conhecidos pela extensão “.ccf”. Este pode ser utilizado em conjunto com a API SAPERA LT para o desenvolvimento de programas, pois evita que o código fonte tenha que ser adaptado a uma série de parâmetros da câmera.

O programa PFRemote comunica de forma serial com a câmera utilizando o padrão CAMERA LINK. Esse programa permite que sejam configurados diretamente na câmera parâmetros como ROI ou múltiplas janelas ROI, correção de iluminação, diferentes formas de sincronismo, calibração, taxa de amostragem e o tempo de exposição do sensor. Uma vantagem desse programa é a possibilidade de gravar esses detalhes diretamente na memória flash da câmera, para que as características definidas se tornem padrão.

Um pequeno tutorial para manuseio desses programas foi feito por Duarte [1], em que se mostra como é feita a integração da câmera com os softwares e métodos de calibração e sincronização de parâmetros pré-estabelecidos.

\subsubsection{VISUALIZAÇÃO DA POÇA}

Com a compreensão dos fenômenos citados no tópico 2.3.1, é possível projetar um sistema de visão capaz de visualizar a poça de fusão indiretamente. Esse método foi implementado por alguns autores em suas pesquisas [2], [3] e [4]. Sua vantagem está principalmente no projeto final da estrutura, pois a visualização indireta da poça permite a construção de algo mais compacto e capaz de ser fixado na tocha de soldagem. A construção da estrutura será comentada posteriormente, inicialmente o objetivo é entender como o sistema de reflexão da imagem irá funcionar.

Conforme mostra a Figura 3.4, a câmera com um campo de visão (CP) cumpre o papel do observador e o objeto imagem é a poça fundida. O caminho da reflexão inicia na imagem real, ou seja, na poça de solda em linha reta em todas direções. Tomando uma dessas linhas como base, considerando que ela parte do ponto central da poça de solda, e usando o fenômeno de reflexão em espelhos planos, é possível direcionar a imagem virtual para a câmera variando o ângulo de inclinação do espelho. Na Figura 3.4 é possível ver essa trajetória do ponto central da poça fundida pelas linhas vermelhas. O feixe 
luminoso incide no espelho E1 com um ângulo a a, em relação a sua normal no ponto de incidência, e é refletido com um ângulo $\mathrm{a}_{1}=\mathrm{a}_{2}$ em relação à mesma normal. Após a primeira reflexão, o feixe atinge o espelho E2 com ângulo de incidência $t_{2}$, em relação à normal a E2 no ponto de incidência, e é refletido com ângulo $t_{1}=t_{2}$, em relação à mesma normal, seguindo em direção à câmera. $\mathrm{O}$ conjunto de linhas verdes representa o campo de visão que a câmera consegue observar, e é medida por $\mathbf{d} 3$ na região da poça. $\mathrm{O}$ valor de $\mathbf{d} 2$ representa a distância entre eixos dos espelhos, e d1 a distância do primeiro espelho à lente da câmera.

A mesma trajetória pode ser feita utilizando apenas um espelho, variando a distância d1 e o ângulo do eixo de inclinação daquele. O projeto construtivo da estrutura de fixação depende, em sua maior parte, das características da câmera utilizada, como o campo de visão, distância focal e dimensão. Apesar de ser possível implementar uma estrutura utilizando apenas um espelho, e consequentemente diminuir o aparato de sustentação, a configuração da câmera utilizada não permitiu, devido ao parâmetro de distância focal. Distância focal é o ponto onde os raios de luz se convergem para formar uma imagem nítida.

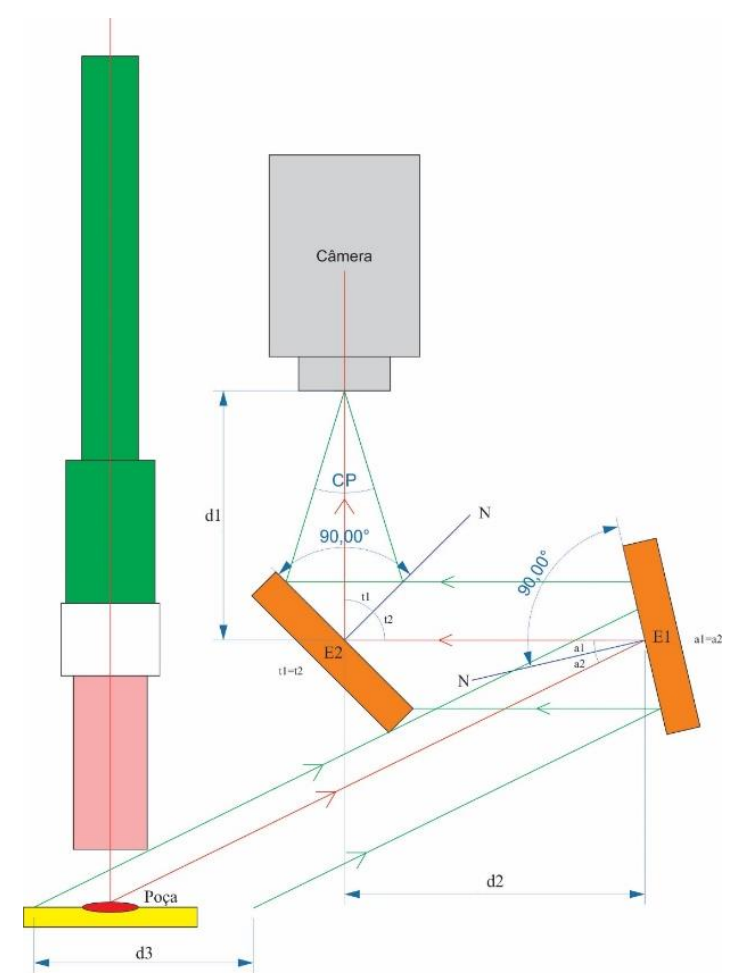

Figura 3.4 - Diagrama esquemático da trajetória da luz de uma poça solda utilizando espelhos planos 
A compreensão dos aspectos da câmera e dos fenômenos envolvidos na reflexão de um objeto imagem tornou possível o projeto de uma estrutura capaz de visualizar a poça de fusão. A estrutura pode ser vista na Figura 3.5:

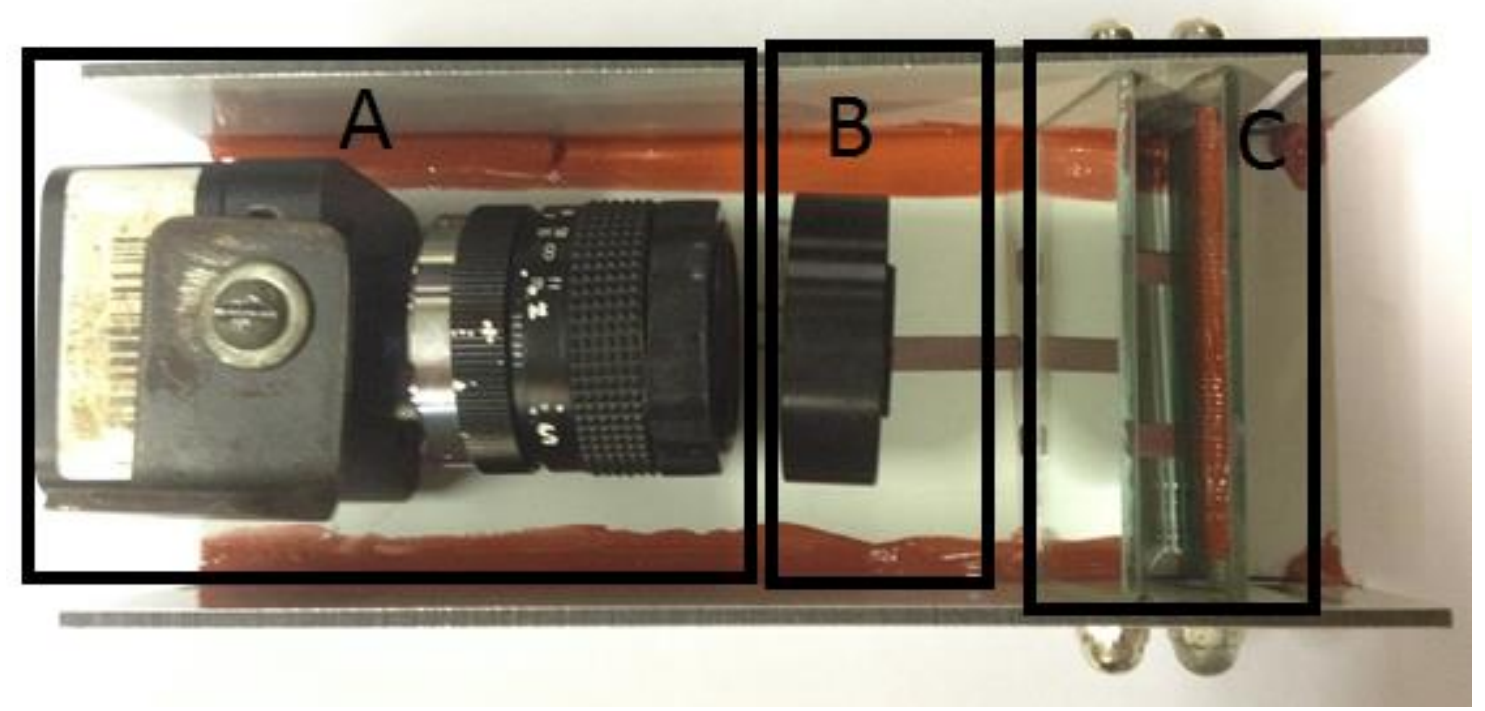

Figura 3.5 - (A) é a câmera utilizada, (B) é o suporte dos filtros e (C) são os espelhos planos.

A estrutura elaborada bem como sua instalação na tocha de soldagem pode ser vista na Figura 3.6. E a imagem capturada pode ser vista na Figura 3.7. Apesar da pequena perda na qualidade na imagem ocasionada pelos espelhos, a estrutura final possibilitou a obtenção de imagens da poça de fusão adequadas ao processamento.

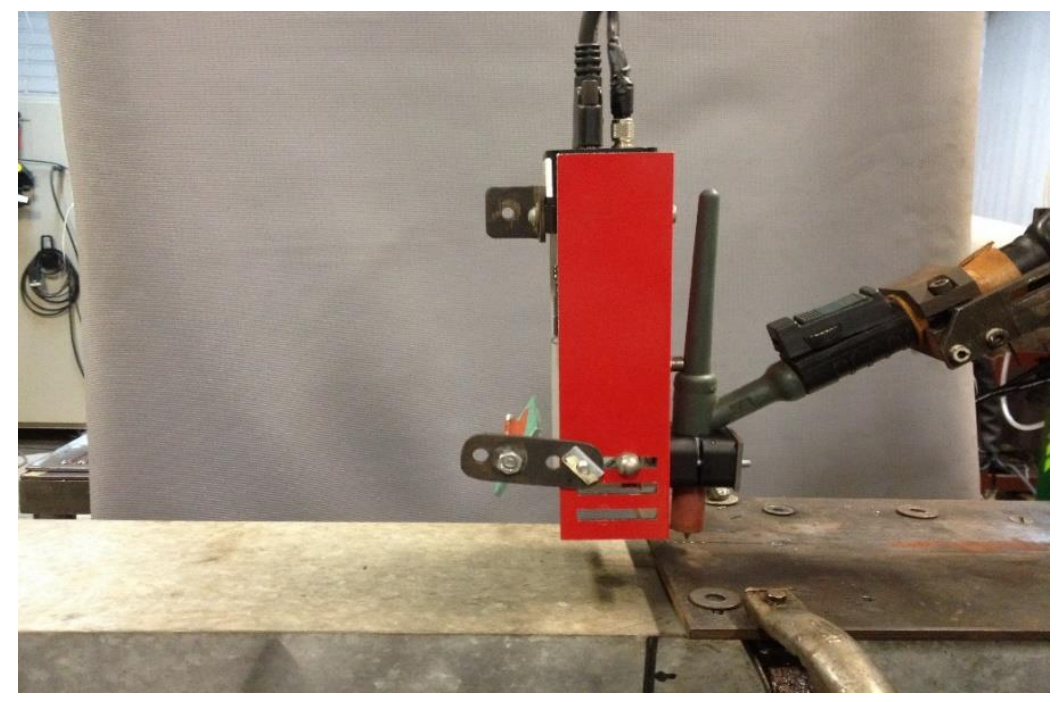

Figura 3.6 - Estrutura de fixação da Câmera, filtros e espelhos. 


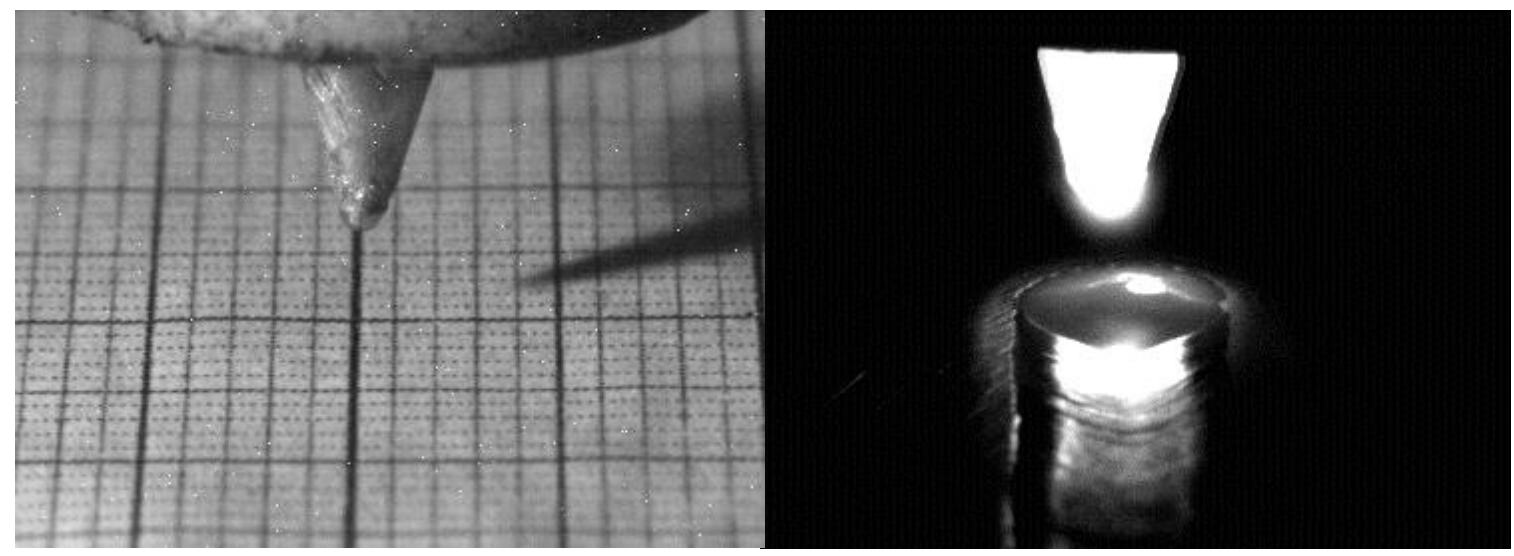

Figura 3.7 - Imagem capturada pela câmera

Duarte [1], afirma que as imagens obtidas podem ser melhoradas verificando as seguintes condições: (a) o ajuste do foco da lente objetiva, (b) ajuste do diafragma para maior ou menor entrada de luz, (c) utilização de uma lente de macro a fim de aumentar a imagem (sem deformá-la), (d) uso de filtros ópticos que capturam somente alguns comprimentos de onda (exemplo o infravermelho gerado pela poça fundida) e (e) ajuste da posição da câmera.

\subsubsection{MESA LINEAR}

Para realizar os experimentos que envolvem a captura da imagem da poça de soldagem GTAW é necessário manter fixa a distância da câmera e o ponto de formação da poça de soldagem, que está no mesmo plano perpendicular do eletrodo. Esses dados são obtidos com a calibração da câmera manualmente ou de forma automática. A utilização inicial da mesa linear vem do fato que se deve evitar ao máximo vibrações causadas pelo movimento da tocha ao adquirir uma imagem, pois vibrações afetam na qualidade das imagens adquiridas, e dificultam a detecção de um ponto de borda, devido ao efeito de borramento ocasionado pela movimentação do alvo durante o tempo de exposição do sensor. No caso real esse efeito poderia ser reduzido utilizando um tempo de exposição menor. 
Afim de evitar essa vibração, a tocha de soldagem e a câmera se manteriam fixas e somente a peça a ser soldada estaria em movimento. Para isso foi utilizada uma mesa linear com eixo livre acoplado a um motor de passo, disponível no laboratório do GRACO e mostrada na Figura 3.8.

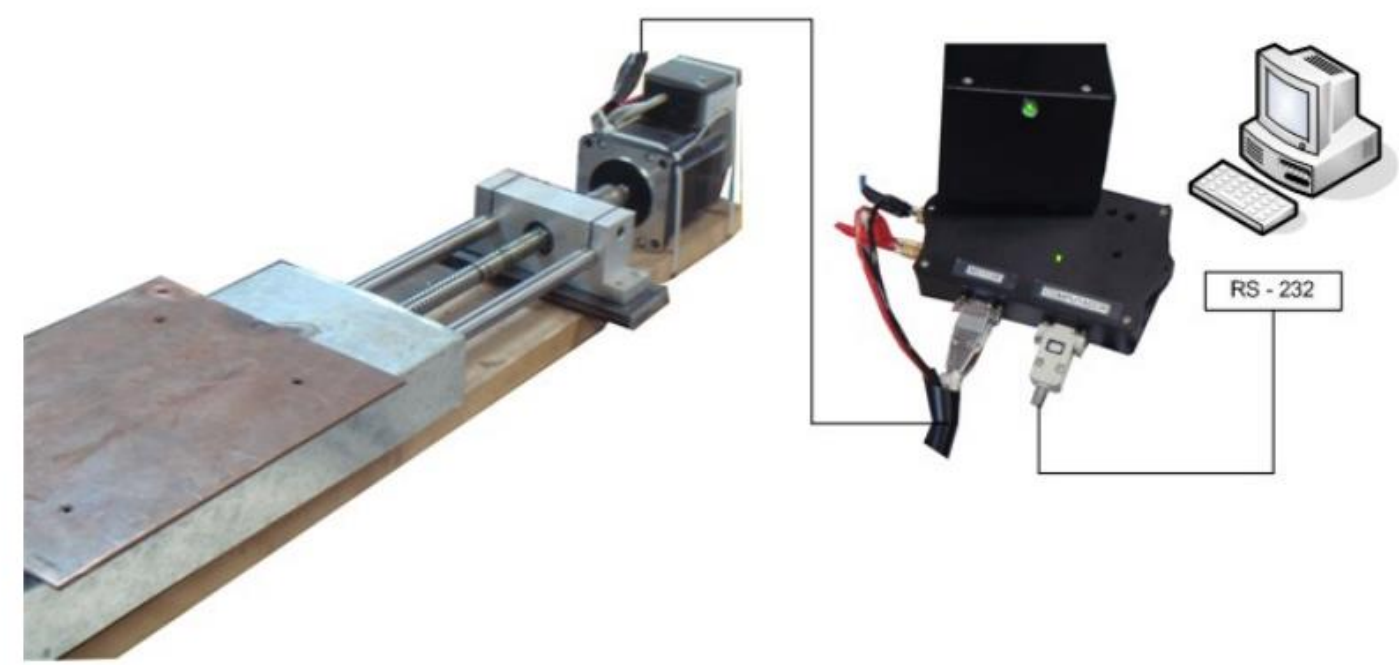

Figura 3.8 - Diagrama de montagem da mesa linear [1]

A mesa linear suporta com segurança uma carga de até $15 \mathrm{~kg}$. O motor de passo utilizado nessa mesa é do fabricante BERGER LAHR modelo ICIA IDS91 capaz de ser controlado diretamente por meio de pulsos, a configuração utilizada é de 200 pulsos por volta. O microcontrolador utilizado para controlar o motor de passo é do fabricante MICROCHIP modelo PIC16C63A.

Na soldagem GTAW pulsada, uma variável importante para qualidade do cordão soldado é a velocidade de deslocamento da tocha de soldagem. A mesa linear é capaz de deslocar-se em duas direções, com uma velocidade constante e ajustável, característica que permite uma soldagem fina e de boa qualidade.

O motor de passo é controlado por uma placa que possui: (a) um microcontrolador com um clock de 4MHz; (b) três conectores: um para alimentar a placa de controle e o motor de passo com tensão de $24 \mathrm{~V}$, um para controlar o sentido e a velocidade do motor, e o outro para receber indicações de falhas do motor; (c) dois botões para posicionar manualmente a mesa linear; (d) e um botão de reset para casos que seja necessário a parada de emergência. 
A placa de controle da mesa linear trabalha em conjunto com um computador, pois recebe comandos como sentido, velocidade e tempo de execução ou distância via porta serial e responde confirmando a recepção desses comandos e aguarda a ordem de execução. A vantagem de se utilizar a porta serial é a possibilidade de usar programas desenvolvidos em $\mathrm{C}, \mathrm{C}++$, MATLAB, ou mesmo outro microcontrolador para controlar a mesa com uma precisão adequada ao processo de soldagem.

\subsubsection{FONTE DE SOLDAGEM}

O equipamento de soldagem, fabricante Migatrônic, modelo BDH 320, foi utilizado para fabricação da solda. A fonte BDH é uma máquina baseada em inversores, e possui as seguintes vantagens [46]:

- Propriedades programáveis de soldagem, causando melhoria nas características da solda;

- Redução na perda de potência;

- Aumento no ciclo de trabalho;

O inversor, assim como todos os outros componentes das máquinas, é controlado por um microprocessador central, o que faz com que seja possível alcançar controle de soldagem avançado.

Como mencionado acima, a BDH é uma máquina baseada em inversores, ou seja, a fonte de alimentação (módulo de potência) é construída de acordo com o princípio de comutação. O módulo de potência BDH comuta com frequência de $100 \mathrm{kHz}$, e o princípio envolvido é ilustrado na Figura 3.9.

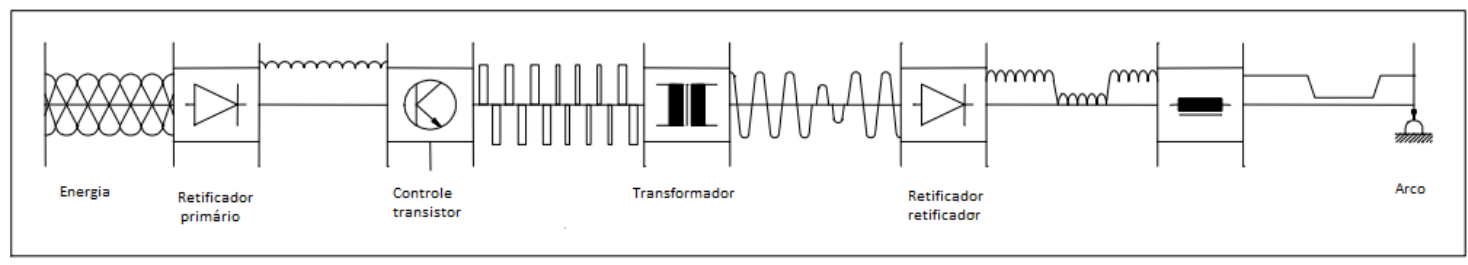

Figura 3.9 - Diagrama de bloco fonte BDH 320 [46]

O microprocessador se encarrega dos ciclos de medições de corrente e tensão da soldagem realizada. Outra função do microprocessador é o controle e coleta de dados nos módulos da máquina. 
O modo de operação utilizado foi o de corrente contínua com eletrodo na polaridade negativa (CCEN), ou seja, a maior parte do calor está na peça soldada (70\%), enquanto uma menor quantidade é concentrada no eletrodo (30\%). O eletrodo é resfriado por agua em um circuito fechado, já existente na fonte BDH. O gás utilizado foi Argônio puro. O equipamento pode ser visto na Figura 3.10:

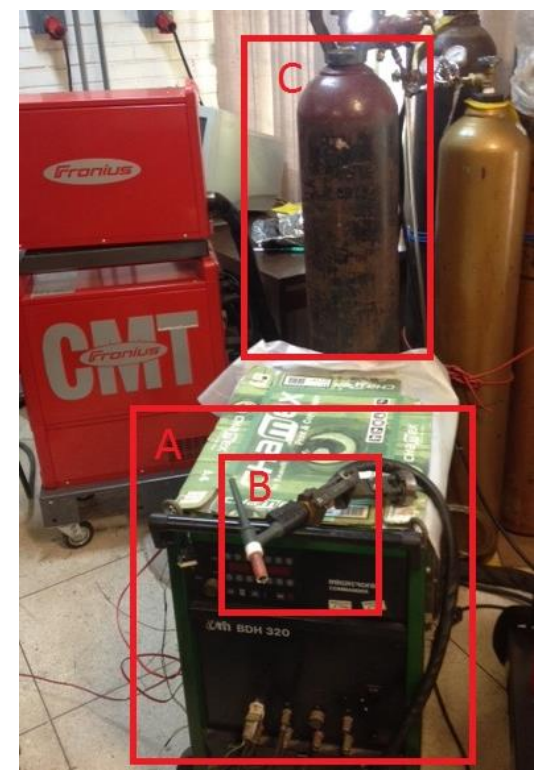

Figura 3.10 - (A) é a fonte de soldagem Migatrônic BDH 320; (B) Tocha do equipamento com eletrodo de tungstênio; $(C)$ tanque de gás argônio para proteção.

O tipo de processo utilizado foi o GTAW pulsado, sem adição de arame, e os dados para experimento seguem na Tabela 2:

Tabela 2 - Parâmetros do processo de soldagem TIG pulsado

\begin{tabular}{|c|c|}
\hline Tipo de Parâmetro & Valor do parâmetro \\
\hline Frequência de pulso $(H z)$ & 20,00 \\
\hline Corrente de Pico Ip (A) & 120,00 \\
\hline Corrente de Base Ib (A) & 50,00 \\
\hline Velocidade de Soldagem $(\mathrm{mm} / \mathrm{s})$ & 1,00 \\
\hline Diâmetro Eletrodo $\varphi(\mathrm{mm})$ & 3,00 \\
\hline Fluxo do gás (l/min) & 10,00 \\
\hline$G A P(\mathrm{~mm})$ & 3,00 \\
\hline
\end{tabular}




\subsection{PROCEDIMENTO EXPERIMENTAL}

Em resumo, a bancada experimental constitui-se por uma fonte de soldagem Migatrônic BDH 320, ajustada para o processo GTAW pulsado, uma mesa linear para movimento contínuo mantendo a tocha fixa, uma câmera DALSA modelo DS21 1M150SA para aquisição da imagem e integração com software de processamento por meio de comunicação serial (padrão CameraLink) com o computador, conjunto de filtros ópticos passa alta e neutro e dois espelhos planos. Um esquema básico da bancada pode ser visto na Figura 3.111.

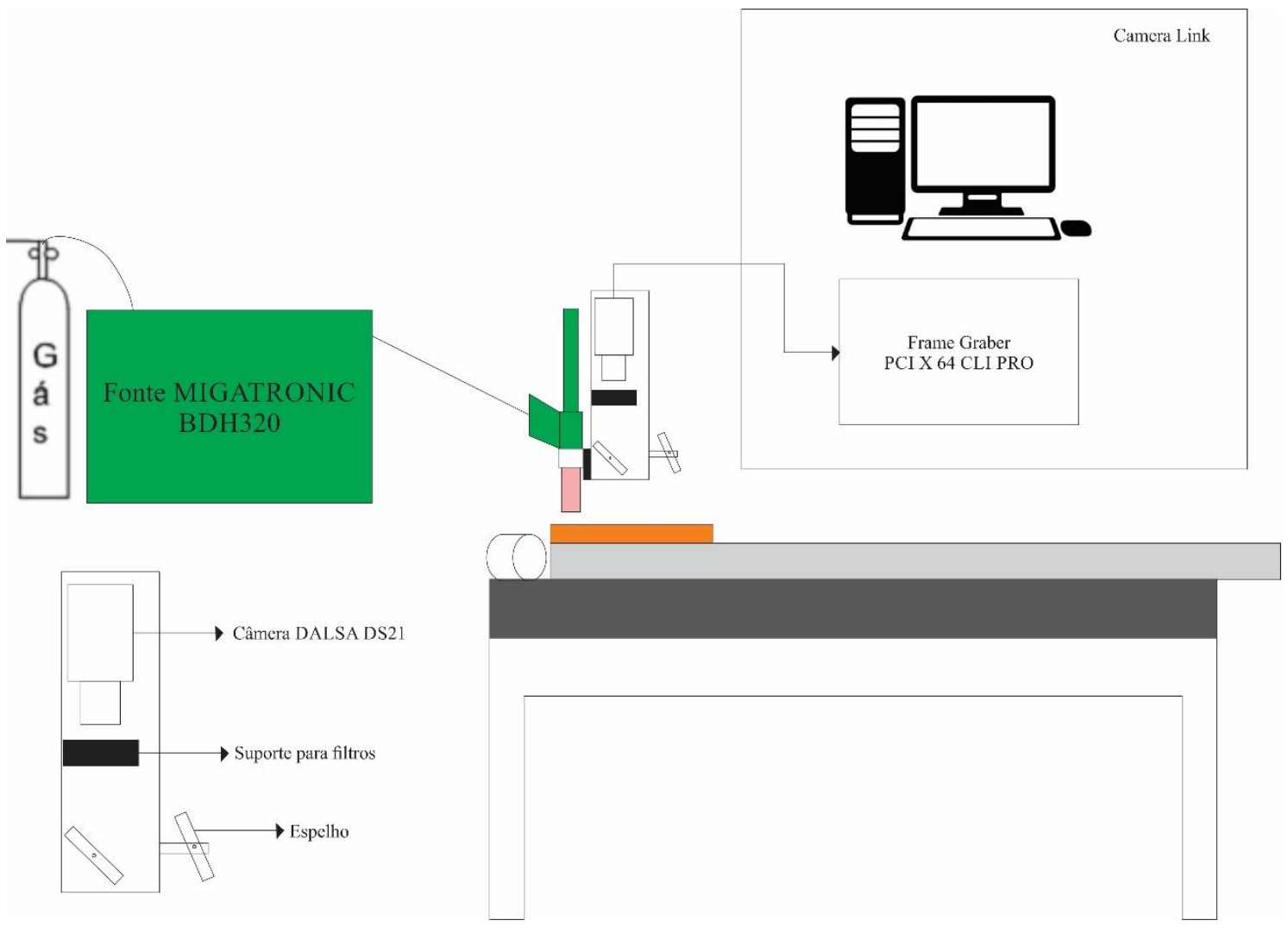

Figura 3.11 - Esquemático da bancada experimental 
Inicialmente foram capturadas imagens utilizando o programa CamExpert, a fim de ajustar o foco e alterar a taxa de amostragem sem iniciar o processo de soldagem. Ao aumentar a taxa de amostragem, mais escuro fica o objeto em foco pois menos luz é captada pelo sensor de imagem. Um exemplo disso pode ser visto na Figura 3.12. Outro ponto a se observar é a profundidade de foco na imagem. A profundidade em foco está relacionada a abertura da lente: quanto menor é a abertura maior é a profundidade em foco, porém menor é a quantidade de luz que chega ao sensor diminuindo a sensibilidade do conjunto. O tempo de exposição da câmera utilizado no experimento foi de $200 \mu \mathrm{s}$.

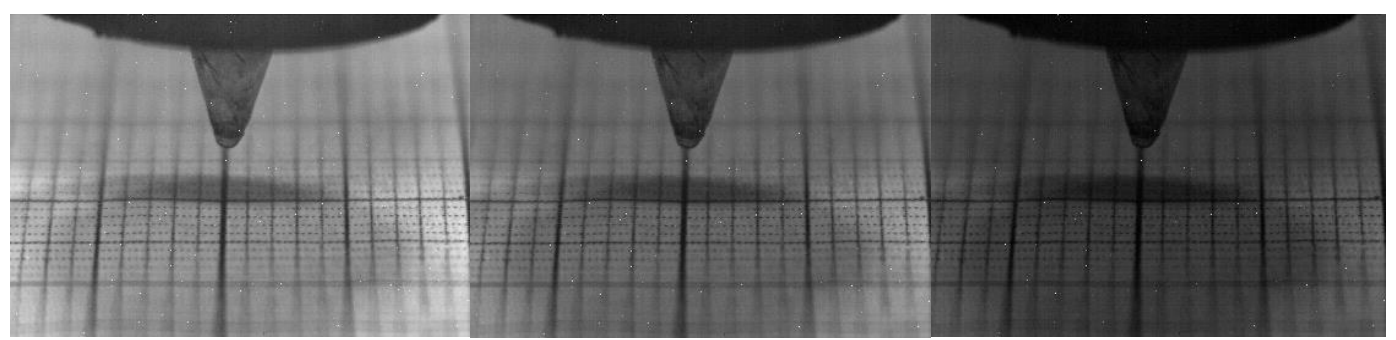

Figura 3.12 - Efeito da mudança na taxa de amostragem

O filtro utilizado foi de $900 \mathrm{~nm}$ passa alta (long wave pass filter), na região do infravermelho próximo (NIR) e a taxa de aquisição foi de 100 frames por segundo ( $p s$ ). A direção de visualização foi ajustada à captura tanto da poça como do cordão soldado. Os parâmetros de soldagem utilizados são explicitados na Tabela 2.

\subsection{PROCESSAMENTO DA IMAGEM}

As técnicas voltadas para a análise de dados multidimensionais, adquiridos por diversos tipos de sensores recebem o nome de processamento digital de imagens, ou seja, é a manipulação de uma imagem por computador onde a entrada e a saída do processo são imagens [39]. Existem inúmeras tipos de linguagem voltados para o processamento de imagens (Phyton, Java, MatLab, Visual Basic, $\mathrm{C} / \mathrm{C}++$ e etc.). Em particular, uma biblioteca bem conhecida e com inúmeros recursos tem sido empregada em programas com linguagem $\mathrm{C} / \mathrm{C}++$, Phyton e Visual Basic, trata-se da biblioteca OpenCV (Open Source Computer Vision Library).

Originalmente desenvolvida pela Intel, em 2000, é uma biblioteca multiplataforma, totalmente livre ao uso acadêmico e comercial, para desenvolvimento de aplicativos na área de visão computacional, bastando seguir o modelo de licença BSD 
Intel. O OpenCV possui módulos de processamento de imagens e vídeo, estrutura de dados, álgebra linear, GUI (Interface Gráfica de Usuário) básica com sistema de janelas independentes, controle de mouse e teclado, além de mais de 350 algoritmos de visão computacional como: Filtros de imagem, calibração de câmera, reconhecimento de objetos, análise estrutural e outros. O seu processamento é em tempo real de imagem [39].

Pela diversidade de material à disposição e o tempo de resposta ao processamento, optou-se pela utilização desta biblioteca para processamento das imagens adquirida pelo sensor em conjunto com o Microsoft Visual Studio, software especialmente dedicado ao NET Framework, e às linguagens Visual Basic, C/C++, C\# (C Sharp). Neste trabalho, utilizou-se a biblioteca com a linguagem $\mathrm{C}++$.

Os resultados do processamento das imagens foram plotados em gráficos utilizando o programa MatLab. Trata-se de uma ferramenta matemática abreviada de MATrix LABoratory, com ambiente de programação de alto nível, possuindo características de aplicativo (facilidade para o usuário) e de linguagem de programação (flexibilidade).

O MATLAB apresenta uma série de funções matemáticas já implementadas, que são úteis para a manipulação dos dados adquiridos com o processamento, possibilitando a análise e comparação dos dados através de gráficos interativos e funções feitas por meio de rotinas construídas pelo usuário.

\subsubsection{INTEGRAL DA IMAGEM}

A metodologia escolhida para sincronização das imagens com a menor interferência do arco provém de uma rotina de programação conhecida como integral da imagem [39], ou soma bits, técnica muito útil na visão computacional pois permite fazer diversos cálculos em sub-regiões de uma imagem. Geralmente a seleção da imagem é baseada na sincronização da câmera com os dados instantâneos de corrente e tensão do processo de soldagem [1], ou seja, nos momentos em que a corrente ou a tensão é mínima no processo, ocorre a captura da imagem para processamento. $\mathrm{O}$ brilho do arco relacionase principalmente ao nível de corrente enquanto a tensão está relacionada ao comprimento do arco, no caso definido pela distância entre os eletrodos. O objetivo da metodologia 
proposta, é utilizar o nível de brilho da imagem para descobrir se o processamento das características da poça é possível de ser realizado. Em uma aquisição livre do processo de soldagem, o programa deve separar as imagens em que a interferência do arco é mínima para processamento, descartando as imagens restantes.

A técnica funciona da seguinte maneira [39]: dada uma imagem $N x M$, pode-se criar uma imagem integral somando para cada pixel da imagem, o valor de cada pixel à esquerda e acima do pixel dado. Em termos matemáticos, para cada ponto $(x, y)$, atribuíse o valor da soma de todos os pixels $\left(x^{\prime}, y^{\prime}\right)$ tais que $x^{\prime}<x$ e $y^{\prime}<y$.

$$
I(x, y)=\sum i\left(x^{\prime}, y^{\prime}\right)
$$

Por motivos computacionais, a imagem integral possui dimensões $N+1 \times M+1$ com a primeira linha e a primeira coluna com valores zero. Para exemplificar a ideia, a Figura 3.13 representa uma imagem $N x M=5 x 5 \mathrm{com}$ as indicações das coordenadas adotadas, na imagem da direita tem-se a imagem integral correspondente.

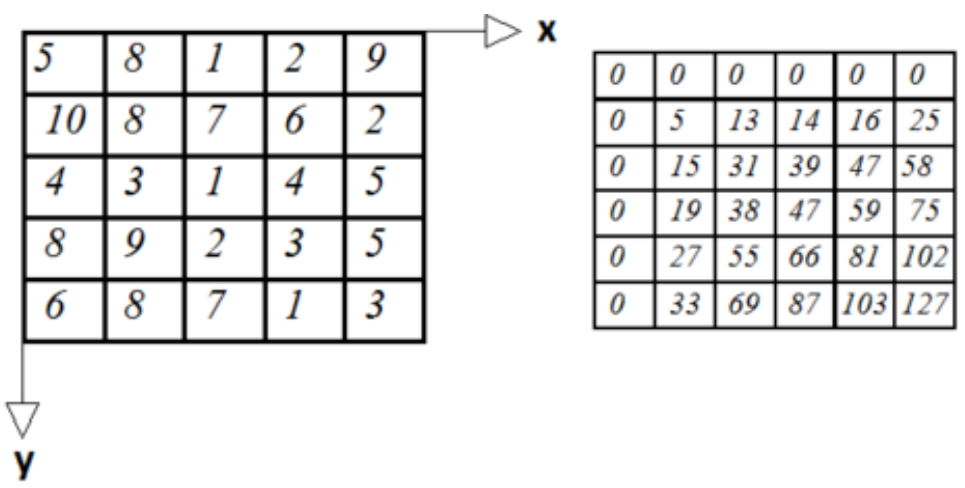

Figura 3.13 - Exemplificação da imagem integral

Possuindo os dados da imagem integral, é possível calcular o valor da soma dos pixels em qualquer região da imagem. O Cálculo se resume no acesso de somente quatros pontos. Ao adotar a nomenclatura da Figura 3.14, o cálculo se resumiria em:

$$
\text { Soma }=A+C-(B+D)
$$




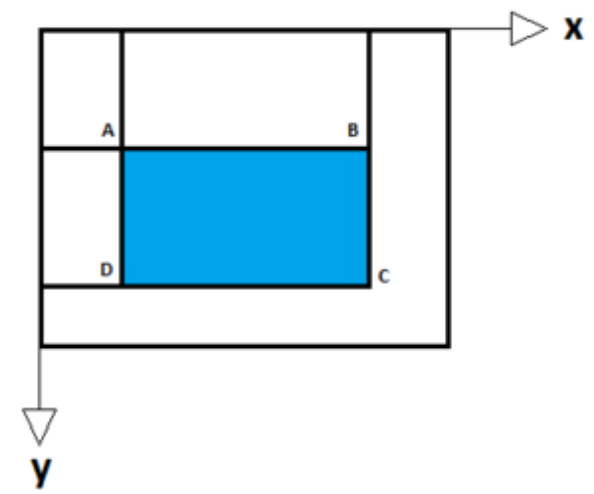

Figura 3.14 - Pontos da imagem, região de interesse.

Analisando os valores da imagem integral, percebe-se que o seu cálculo pode ser feito em uma única passagem pela imagem. Para cada pixel $(x, y)$ da imagem tem-se que:

$$
I(x, y)=i(x, y)+I(x-1, y)+I(x, y-1)-I(x-1, y-1)
$$

Em que I refere-se a matriz imagem. Se a coluna e a linha de zero não fossem adicionadas, não seria possível iniciar esse cálculo. Então o valor de $I(x, y)$ corresponde ao valor da integral da imagem.

\subsubsection{ANALISE E SINCRONIZAÇÃO DA IMAGEMO}

O propósito inicial do algoritmo integral da imagem é somar os valores dos pixels em uma região da imagem. Para formular o problema, a primeira coisa a se fazer é determinar uma região onde o arco, no tempo de pico, $t p$, em que é aplicado o pulso de corrente de pico Ip, estará interferindo na visualização da poça, o arco elétrico nesse ponto satura a região na imagem impedindo qualquer tipo de análise e compreensão de suas características, Figura 3.15.

\begin{tabular}{|c|c|c|c|c|c|c|}
255 & 255 & 255 & 255 & $\ldots$ & 255 \\
\hline 255 & 255 & 255 & 255 & $\ldots$ & 255 \\
\hline 255 & 255 & 255 & 255 & $\ldots$ & 255 \\
\hline 255 & 255 & 255 & 255 & $\ldots$ & 255 \\
\hline$\ldots$ & $\ldots$ & $\ldots$ & $\ldots$ & $\ldots$ & 255 \\
\hline 255 & 255 & 255 & 255 & 255 & 255 \\
\hline
\end{tabular}

Figura 3.15 - Característica da imagem saturada pela interferência do arco 
Os testes iniciais de processamento, concentraram-se em entender o comportamento do algoritmo integral da imagem, citado no tópico anterior. Os dados gráficos adquiridos neste ensaio podem ser vistos na Figura 3.16.

Para melhor compreensão do resultado, dividiu-se o gráfico da Figura 3.16 em três regiões, sendo elas: (A) Região de abertura do arco; (B) Transição da área de abertura do arco para área de estabilidade do processo; e (C) área de estabilidade do processo. O gráfico mostra o resultado da soma dos pixels (ordenada) para cada frame ao longo do processo de soldagem (abcissas).

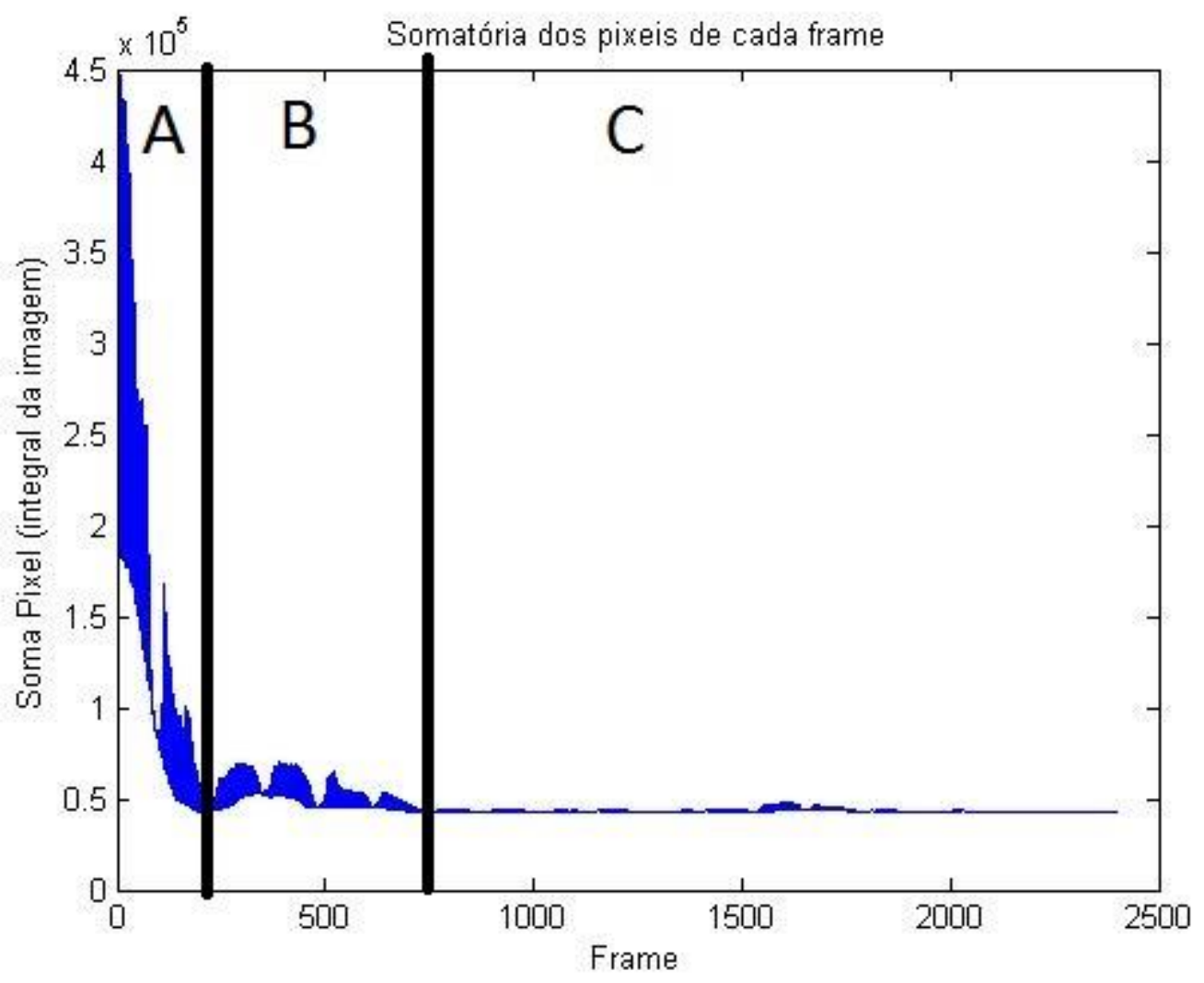

Figura 3.16 - Resultado do algoritmo "integral da imagem"

O fabricante da fonte utilizada no projeto recomenda que a abertura do arco seja feita por alta frequência, pois evita contaminação do eletrodo. Porém, equipamentos eletrônicos são sensíveis a alta frequência e sua utilização no processo implicaria em perda parcial ou total dos equipamentos periféricos utilizados (computador, câmera). Em alguns testes, com abertura por alta frequência a câmera desarmava e o computador apresentava problemas na tela de vídeo. Para contornar esse problema, a solução foi abrir o arco de maneira manual, utilizando uma lã de aço para curto-circuitar os polos da fonte. Isso implica em instabilidade no início do processo e novos componentes dos espectros 
emitidos. Essa característica pode ser vista na parte "A" da Figura 3.16. Os detalhes do comportamento da parte inicial do gráfico podem ser vistos na Figura 3.17:
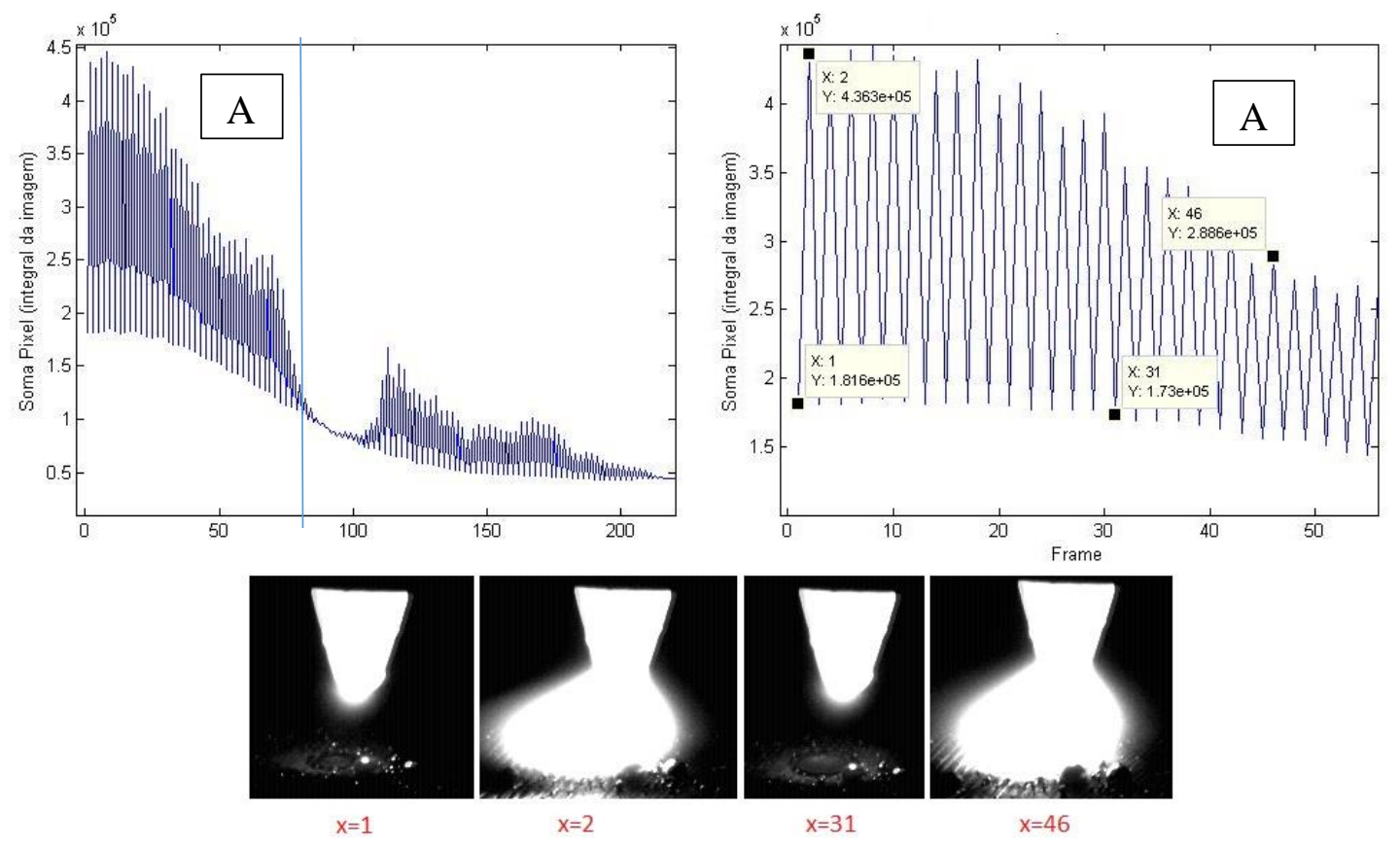

Figura 3.17 - Parte A do gráfico sobre integral da imagem

Analisando o gráfico da Figura 3.17, fica evidente que os pontos de pico são caracterizados por interferência do arco. Uma observação importante a ser ressaltada relaciona-se à abertura e estabilização do arco. Devido ao fato de se utilizarem equipamento sensíveis nas proximidades da tocha, evitou-se a utilização de pulsos de alta tensão e alta frequência para abertura do arco. Para essa finalidade utilizou-se lã aço utilizada para produzir o curto circuito inicial, de modo a simular uma abertura de arco similar à resultante do toque do eletrodo na peça. Durante a abertura a lã de aço se funde e, no início do cordão, deixa resquícios de metal incandescente que geram ruídos no cálculo da integral das imagens respectivas, conforme mostram as figuras e o gráfico (Figura 3.17).

A região B mostrado no gráfico da Figura 3.16 é caracterizada pela transição da região de abertura do arco onde há instabilidade para uma região de estabilidade. Os detalhes do comportamento dessa região podem ser vistos na Figura 3.18. Note que a poça começa a tomar forma.

A última parte do gráfico da Figura 3.16 é caracterizada por estabilidade no processo. Nessa parte é possível fazer a comparação entre a característica do gráfico 
gerado com o formato do gráfico da corrente do TIG pulsado (Figura 2.6), onde ficam evidentes os pontos de corrente de pico e corrente de base. A Figura 3.19 apresenta a característica da região.

Analisando os gráficos, conclui-se que os pontos de pico são caracterizados pela presença do arco, ou seja, nestes pontos não é possível realizar o processamento das imagens e extrair as características geométricas da poça de solda, pois a luz do arco satura a maior parte da imagem, encobrindo a poça. Outra conclusão é quanto à frequência de pulsação da fonte de soldagem, que nos pontos de corrente de pico (Ip), são caracterizados por uma sequência cíclica de alta e baixa corrente (isso a uma taxa de aquisição de 100fps), caso que não ocorre na região de corrente de base ( $I b)$. Essa pulsação é relevante, pois quanto mais imagens sem a interferência do arco forem capturadas durante o processo, maior será a frequência de realimentação para um controle futuro.
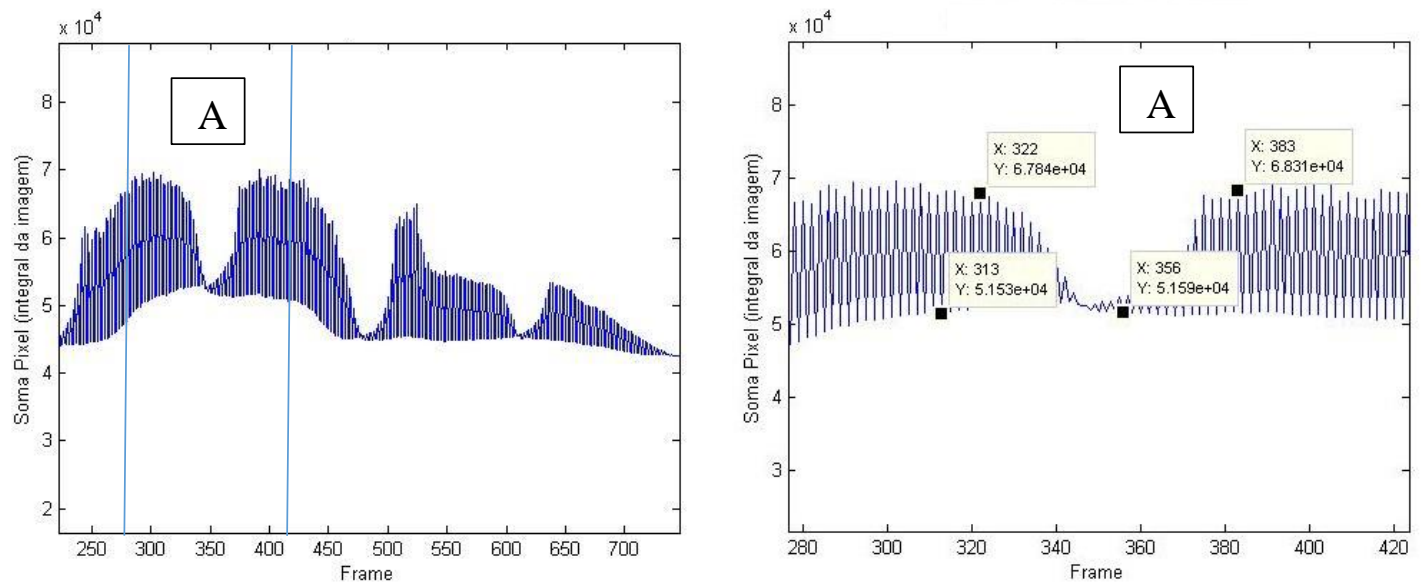

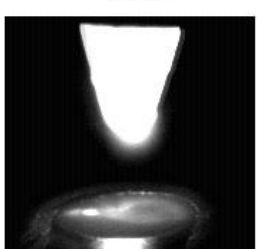

$X=313$

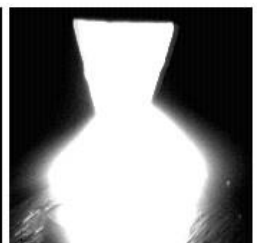

$X=322$

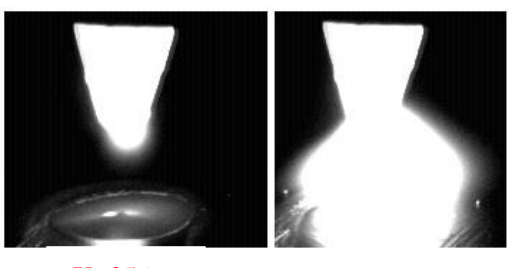

$X=356$
$X=383$

Figura 3.18 - Parte B sobre o resultado da integral da imagem 

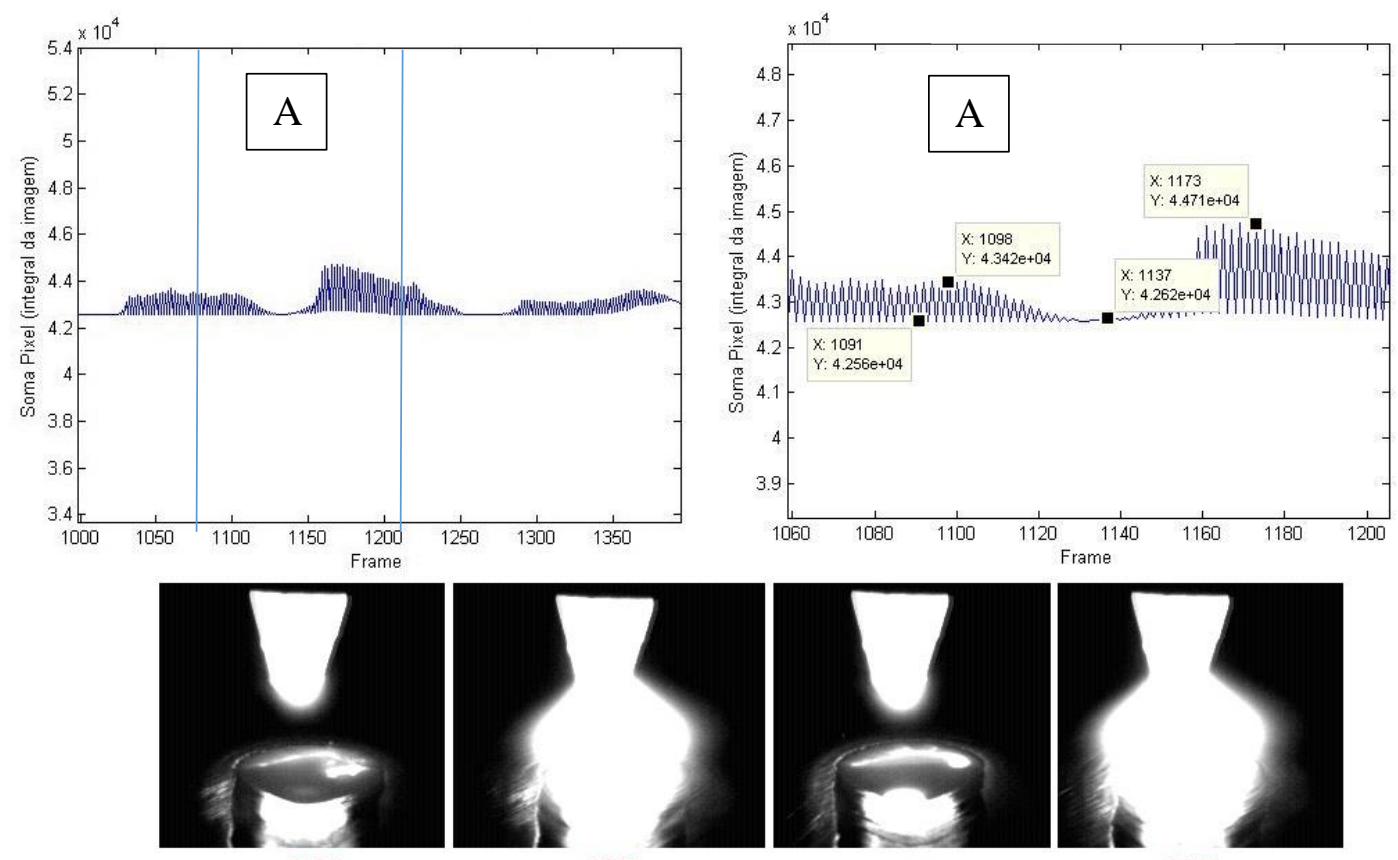

$x=1131$

$x=1173$

Figura 3.19 - Parte C sobre o resultado da integral da imagem

O conhecimento do funcionamento do algoritmo integral da imagem é essencial para projetar um método de sincronismo eficiente, neste contexto duas maneiras de sincronização podem ser aplicadas, sendo elas:

- Sincronização feita estabelecendo um limiar: Forma não tão eficiente pois dependeria de inúmeros experimentos com parâmetros diferentes para achar um limiar que conseguisse ao máximo separar as imagens com forte interferência do arco. Neste método, a região A do gráfico da Figura 3.16 não seria possível aplicar o algoritmo de detecção de borda, pois a região A é caracterizada por instabilidade devido a abertura manual do arco.

- Sincronização feita com identificação dos pontos de pico do gráfico integral da imagem: A ideia é identificar todos os pontos que são caracterizados por presença do arco, ou seja, os picos no cálculo da soma dos pixels de cada frame. Toda vez que for detectada presença de pico, ou uma subida abrupta na soma da sub-região escolhida da imagem, esta deve ser marcada como imagem com interferência luminosa, incapaz de ser 
processada. Dessa maneira apenas a região de corrente baixa seria processada para extração das bordas da poça.

As duas formas de sincronização foram implementadas, porém neste trabalho apenas será tratada da sincronização por identificação dos pontos de pico, pois foi a que melhor se aplicou ao processo, devido ao fato de não perder imagens que são possíveis de serem processadas. Para melhor compreensão, o método compara a imagem atual, com a imediatamente anterior a ela e, por meio de análise matemática, verifica se houve um aumento expressivo na somatória dos pixels. Caso essa informação seja verdadeira a imagem atual é descartada para posterior processamento. Estes dados podem ser vistos na Figura 3.20. Note que a quantidade de frames que são possíveis de serem processados diminui quase pela metade.

O resultado adquirido possui o mesmo formato dos pontos de mínimo mostrados no gráfico da Figura 3.16. Para ficar mais claro, foram duplicados os valores e plotados no mesmo gráfico da integral da imagem do processo, o resultado pode ser visto na Figura 3.21. Note que a linha vermelha percorre todos os pontos de mínimo, resultando em um método eficiente para sincronização de imagens em processos de soldagem. Este método

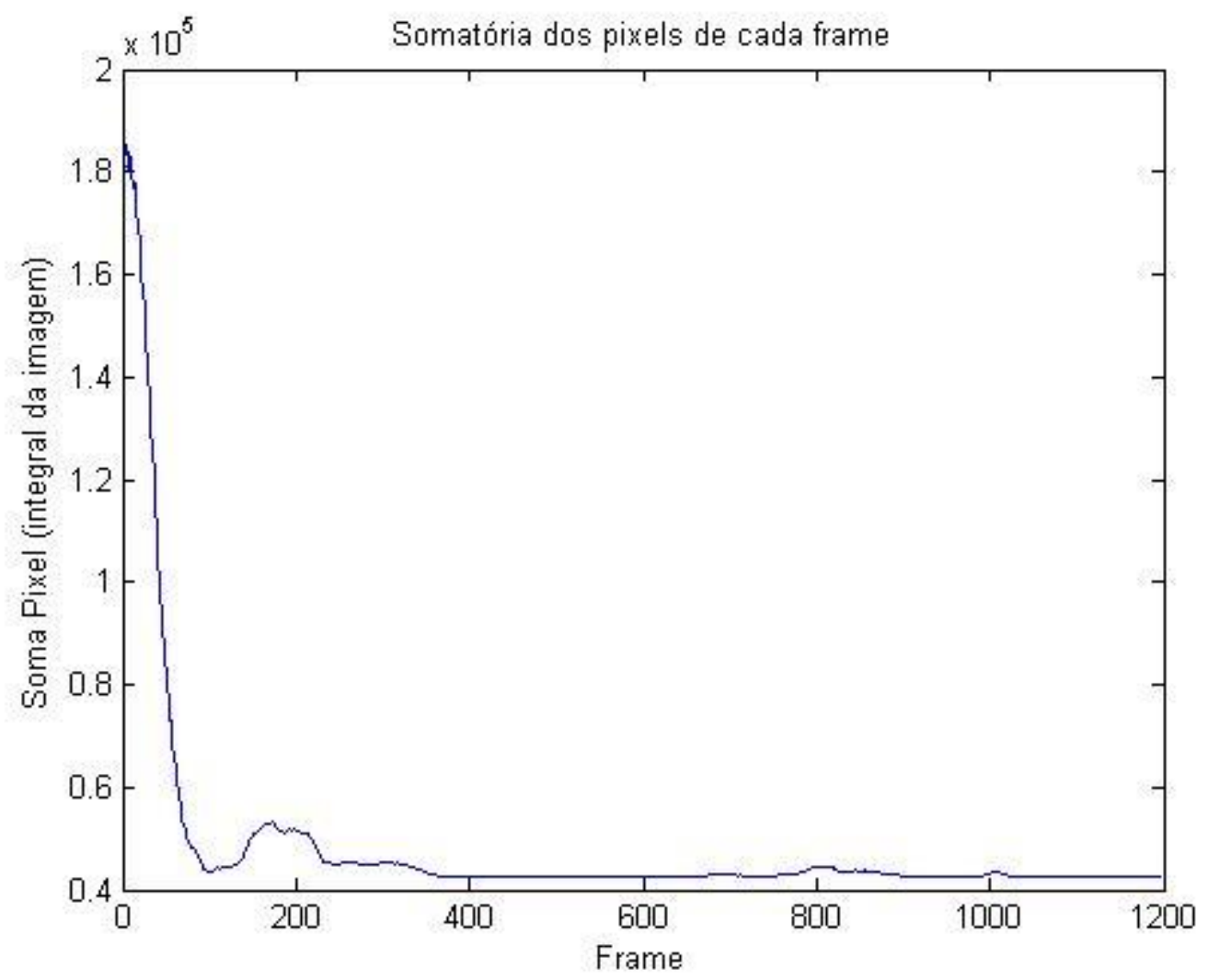

Figura 3.20 - Resultado da sincronização 
pode ser aplicado também em outros tipos de soldagem, como o GMAW. Sua vantagem em relação ao convencional utilizado é a retirada de um circuito de hardware extra do processo, pois baseia-se apenas em métodos computacionais de análise de imagens.
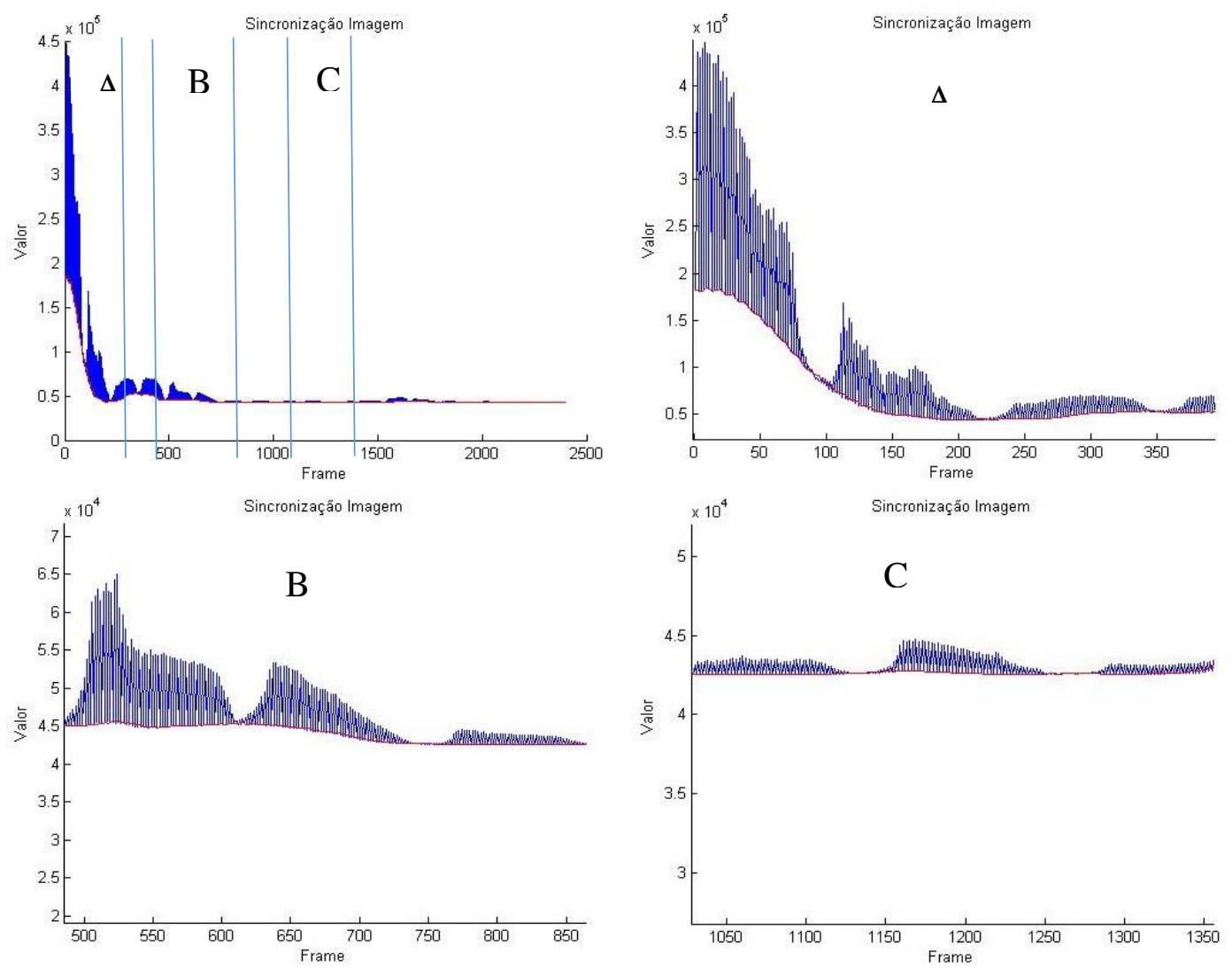

Figura 3.21 - Gráfico da sincronização por meio de análise dos pontos de pico

O resultado final do projeto de sincronização foi um sistema computacional eficiente para seleção das imagens aptas à extração das características da poça de solda. 
Para fins de comparação a Tabela 3 apresenta uma comparação com sincronização via métodos computacionais:

Tabela 3 - Tabela Comparativa de Sincronizações

$\begin{array}{lcccc} & \text { Hardware } & \begin{array}{c}\text { Taxa de } \\ \text { Captura }\end{array} & \begin{array}{c}\text { Fonte } \\ \text { sincronização }\end{array} & \begin{array}{c}\text { Vantagem/ } \\ \text { Desvantagem }\end{array} \\ \begin{array}{l}\text { Sincronização } \\ \text { via sinais }\end{array} & \text { Necessita } & \text { ao ciclo do } & \text { Sinais elétricos } & \text { Condicionada/ } \\ \text { elétricos } & & \text { processo } & & \text { Eficiência } \\ \text { Sincronização } & \text { Não } & \text { Condicionada } & \text { Cálculo } & \text { Alimentação } \\ \text { via Métodos } & \text { necessita } & \text { ao ciclo do } & \text { integral da sub- } & \text { controle/Tempo } \\ \text { Computacionais } & & \text { processo } & \text { região do arco } & \text { processamento }\end{array}$

\subsubsection{DETECTORES DE BORDA PARA MEDIÇÃO DA LARGURA DA POÇA DE SOLDA}

Como foi mencionado na revisão bibliográfica, a poça de fusão possui informações relevantes para o processo de soldagem. Sua análise pode evitar futuras rupturas por trincas, levantar dados das propriedades mecânicas, ou informações sobre a penetração total na junta. Desta forma, o emprego de técnicas para medição de parâmetros geométricos da poça tem sido amplamente estudado. Porém, sua aplicação não é tão simples, pois se trata de um processo altamente ruidoso com forte interferência luminosa. Neste tópico serão demostrados os métodos utilizados para eliminar os ruídos da imagem proveniente da aquisição e sincronização e, posteriormente, serão apresentados os resultados da medição da poça de solda por meio do operador SOBEL.

Os métodos de filtragem espacial operam diretamente sobre a matriz de pixels (imagem digitalizada), e geralmente utilizam operações de convolução entre a imagem original e uma máscara especialmente construída. As máscaras são chamadas de filtros espaciais. No domínio da frequência, as máscaras podem implementar filtros para 
suavizar a imagem, realçar as bordas e remover frequências baixas ou altas. $\mathrm{O}$ filtro Gaussiano possui o efeito de suavizar a imagem, porém preserva os contornos da imagem, sendo ideal para posterior aplicação dos operadores SOBEL e LAPLACIANO.

O operador Sobel é um operador de diferenciação discreta. Ele calcula uma aproximação do gradiente da função de intensidade da imagem e combina a diferenciação com a suavização gaussiana. $\mathrm{O}$ operador Laplaciano trabalha de forma semelhante ao Sobel, porém utiliza métodos derivativos de segunda ordem. Em geral o programa para detecção de borda deve seguir os seguintes passos.

- Carregar uma imagem;

- Remover o ruído aplicando um filtro Gaussiano (passa-baixa);

- Converter para escala de cinza (a câmera já fornece imagens na escala de cinza);

- Aplicar o operador Sobel ou Laplaciano para a imagem em tons de cinza, e armazená-la como imagem de saída;

- Apresentar os resultados em forma de gráficos.

A largura da poça de solda geralmente é medida na intersecção do plano perpendicular à trajetória do eletrodo, em que este está contido, e o cordão de solda. Admite-se que a poça tem sua maior largura, considerando os ângulos de ataque e de trabalho fixados em $90^{\circ}$ (tópico 2.1.3). Para definir a posição da interseção desse plano com o plano de deposição, um papel milimetrado foi posicionado sobre a superfície do corpo de prova com as linhas da grade orientadas de forma alinhada e perpendicular à direção de soldagem. Em seguida tocou-se o ponta do eletrodo na folha de papel, em uma região onde a linha cortava o plano. Através desse procedimento, pode-se informar ao programa em qual linha de pixels se encontra o plano de medição e de aplicação dos operadores. Esta é uma forma simples de calibração da câmera, calibração manual, em que apenas se informa em que linha de pixels deve ser aplicado o operador. A Figura 3.22 mostra a linha de varredura. 
Com base na linha de varredura determinada, foi possível encontrar os primeiros resultados sobre a aplicação dos operadores derivativos. A primeira análise é quanto ao seu funcionamento: consiste em executar o programa em apenas uma imagem e verificar as respostas obtidas na aplicação da derivada de primeira e de segunda ordens. Para isso, inicialmente foi determinada uma região de interesse. A resposta ao operador pode ser vista na Figura 3.23.

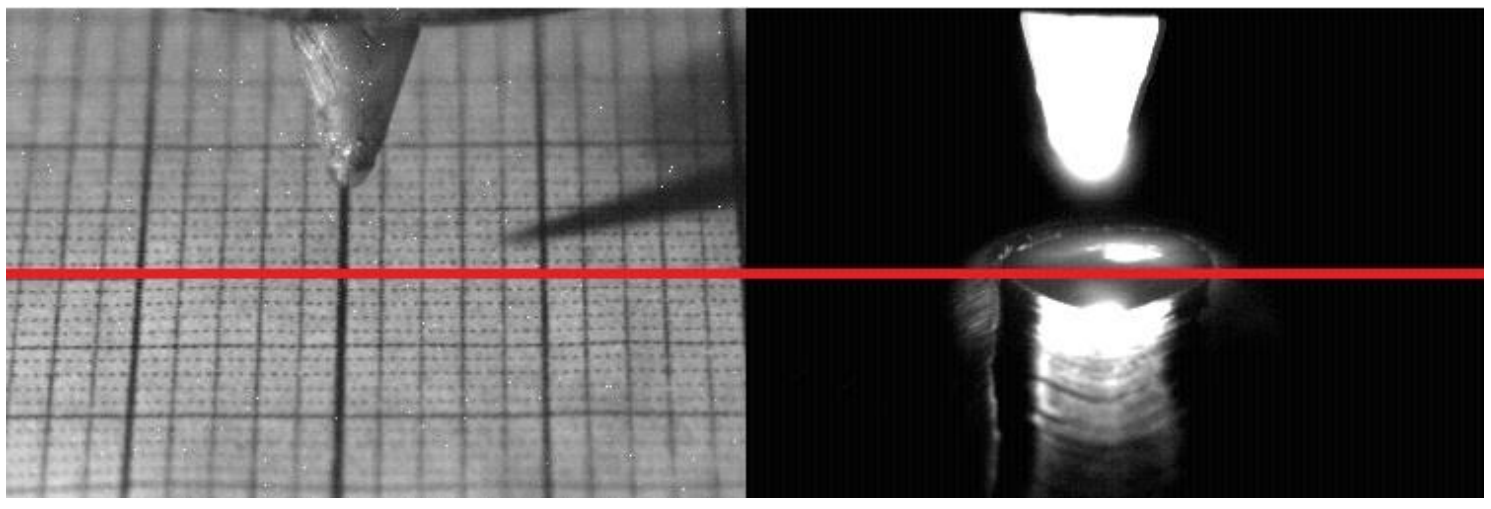

Figura 3.22 - Linha de varredura da imagem
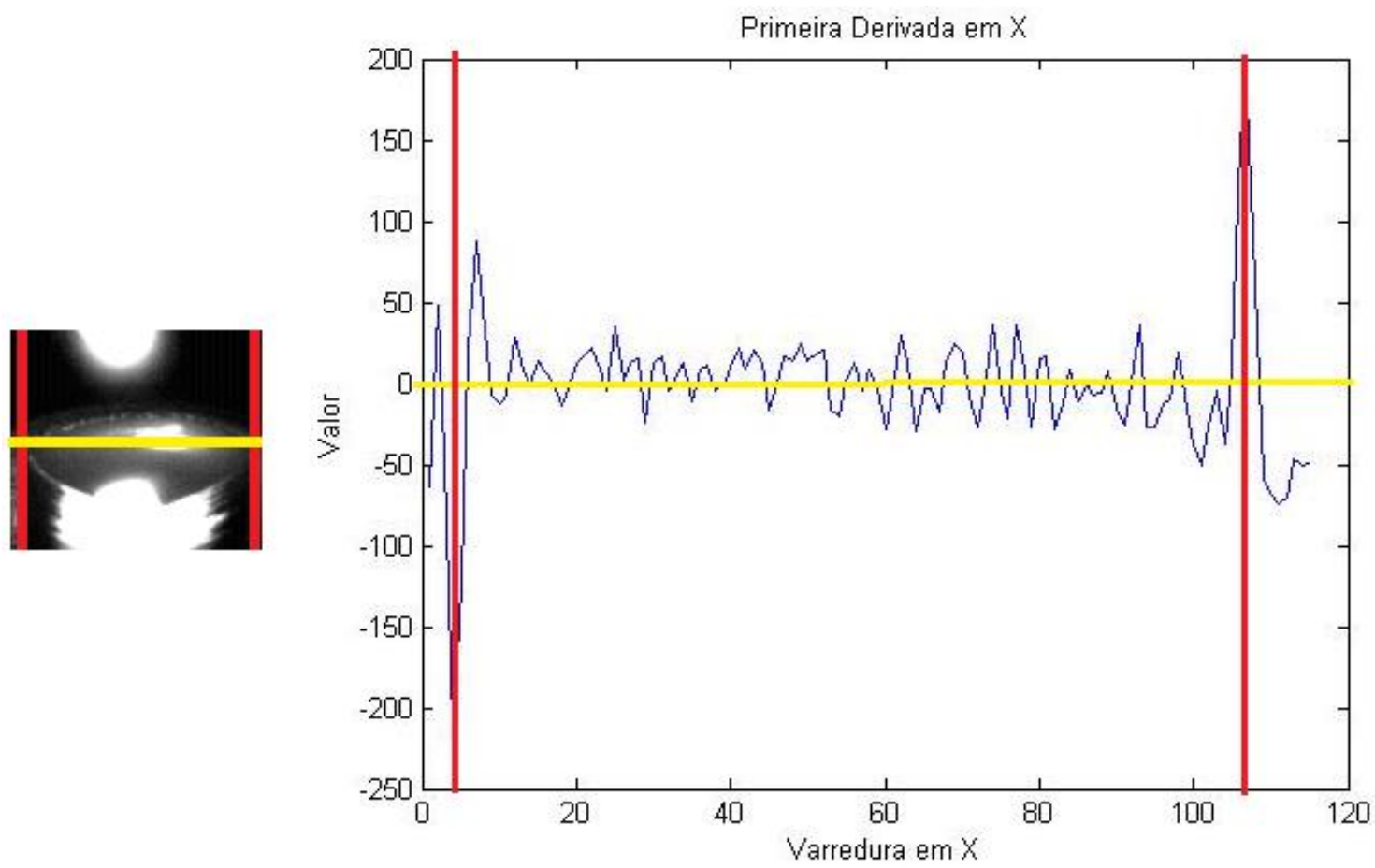

Figura 3.23 - Aplicação da primeira derivada na linha de pixel determinada 
Algumas conclusões podem ser tiradas com base na Figura 3.23. A primeira é quanto ao nível de ruído na região entre as linhas vermelhas, porém esse aspecto já era esperado. Suas causas são diversas e podem estar ligadas diretamente ao processo de aquisição da câmera, ao nível de brilho ainda existente, e à aplicação do operador derivativo. No entanto considera-se que o ruído observado não prejudique o desempenho do programa, pois, como visto, houve uma mudança no vetor gradiente da função devido à magnitude da primeira derivada nos pontos de borda da poça de solda, ou seja, um pico local na primeira derivada.

O gráfico da Figura 3.24 mostra a resposta à aplicação do operador Laplaciano, ou a segunda derivada em um ponto da imagem. Para comparação do comportamento da segunda derivada em relação à primeira, plotaram-se as duas repostas no mesmo gráfico. Como já mencionado na revisão bibliográfica, o Laplaciano é muito sensível a ruídos, e geralmente é usado para detectar se um pixel está do lado claro ou escuro da borda. Apesar de ter sido implementado, sua aplicação ao processo de soldagem não é recomendável, sendo apenas útil para comparação com os dados encontrados na aplicação do operador SOBEL. Desta forma, para cálculo da largura da poça de solda apenas as respostas à primeira derivada foram utilizadas.

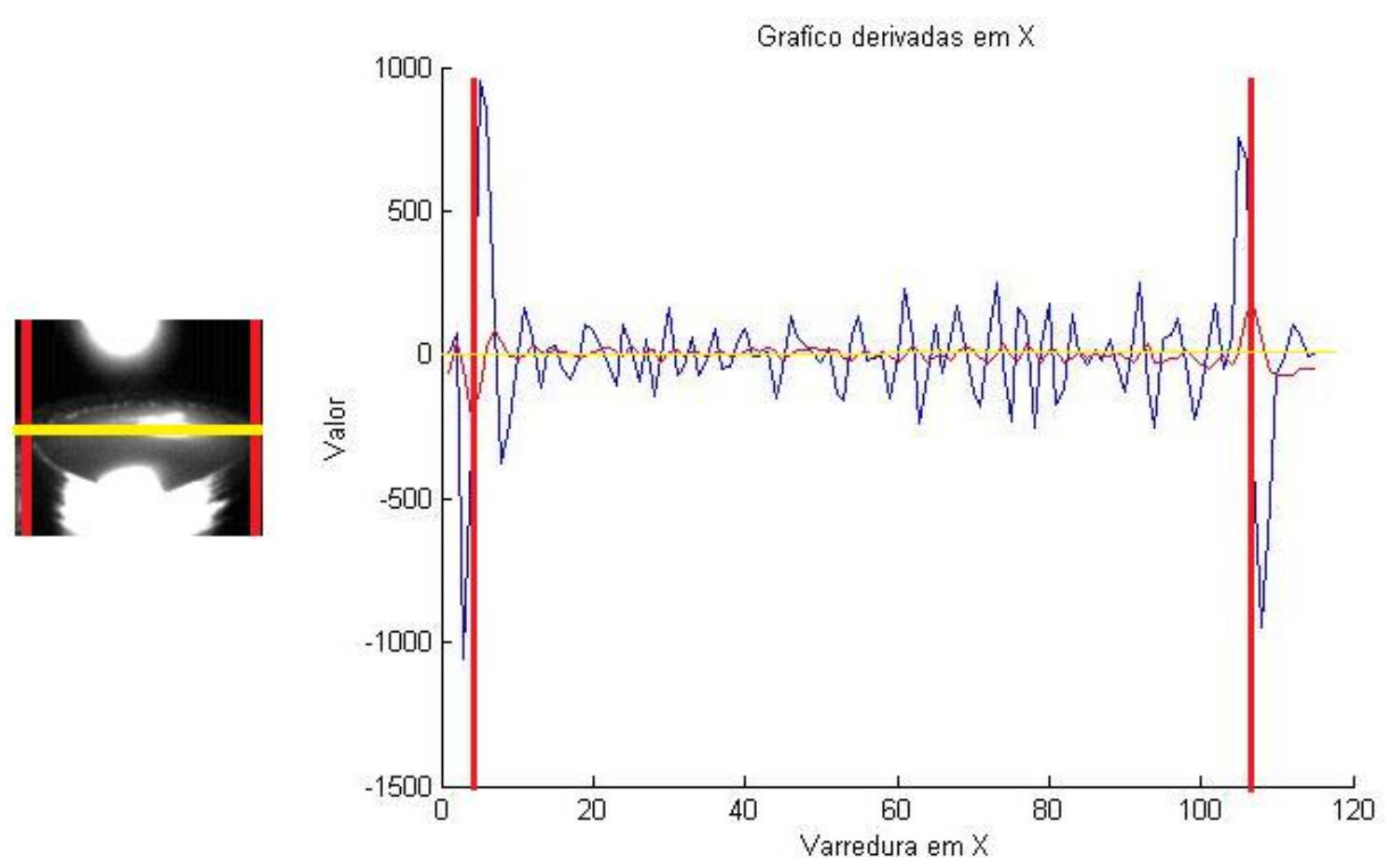

Figura 3.24 - Aplicação da primeira derivada na linha de pixel determinada 
O cálculo da largura da poça de solda é feito pela contagem dos pixels que estão entre uma borda e outra. Para essa última parte do programa, é preciso determinar uma região de interesse, ou seja, a área da imagem caracterizada pela imagem da poça. Quanto mais precisa for a definição dessa região, melhor será para o processamento, pois implica em menor tempo de processamento. Essa região pode ser encontrada com base nas respostas encontradas no cálculo da largura da poça, ou seja, toda vez que for determinada uma borda, aquela posição de pixel de borda é marcada. Para as bordas da esquerda da imagem, esse ponto na matriz coluna de pixel encontrado é subtraído a um valor simbólico, para as bordas da direita, esse ponto é somado, encontrando a região ao longo do eixo X. Esses valores de região são atualizados a cada frame, pois a poça tende a aumentar de tamanho até um ponto de estabilidade. Essa mesma rotina pode ser feita para calcular a região ao longo do eixo Y. A Figura 3.25 mostra a representação da região de interesse encontrada em cada Frame:

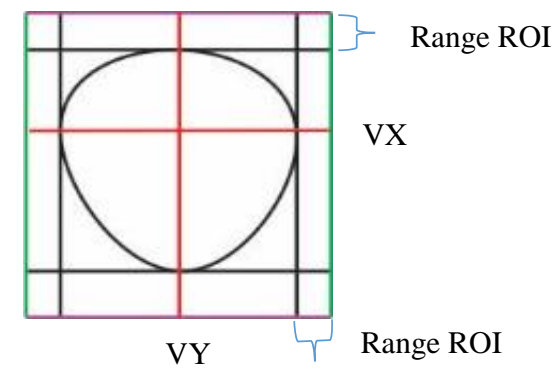

Figura 3.25 - Cálculo da região de interesse

Em que " $V X$ " representa a varredura ao longo do eixo $X$, " $V Y$ " a varredura ao longo do eixo Y. A poça encontra-se determinada pela região interna das linhas pretas, o "Range ROI" representa o valor a mais de colunas ou linhas de pixels a ser somado ou subtraído da região de interesse inicial.

Com a região de interesse encontrada, a última parte é o cálculo da largura da poça de solda. Os resultados obtidos pós processamento seguem na Figura 3.27. Neste gráfico a largura é dada em quantidade de pixels. Para transformar os valores em milímetros, basta multiplicar a soma encontrada em cada frame por um dado conhecido, ou seja, cada pixel equivale a uma quantidade de milímetros no mundo físico. Para encontrar o valor de cada pixel em milímetro, utilizou-se um papel milimetrado, bastando fazer a conversão depois de contados quantos pixels equivalem a um milímetro, isso só vale na linha da intersecção entre um plano vertical transversal ao cordão passando pela projeção da ponta 
do eletrodo na peça, conforme explicado anteriormente. Outros pontos para frente ou para traz dessa linha apresentam distorção de perspectiva.

Durante o processo de soldagem, algumas imagens se tornaram inviáveis para processamento mesmo sem a presença de arco. Nessas imagens, falsas bordas ou bordas duplas foram detectadas devido à preparação do corpo de prova (esmerilhamento), ou pela região interna da poça de solda com excesso de brilho. Para contornar esse problema, um limiar foi declarado no programa (limiar encontrado com base em experimentos), a partir do qual apenas valores de pixel acima do limiar determinado sobre uma região de interesse seria declarado como borda de poça. Esses mesmos dados da poça não entrariam como parâmetro para detecção da região de interesse, descartando aquele frame no processo. Também, uma função de realce no contraste da imagem foi adicionada ao algoritmo final, com intuito de tentar minimizar o efeito do brilho da poça. Essa função é dividida em duas etapas: (a) diminuir o brilho da imagem; (b) e aumentar o contraste, a Figura 3.26 mostras as etapas. Note que o ruído de fundo é eliminado da imagem.

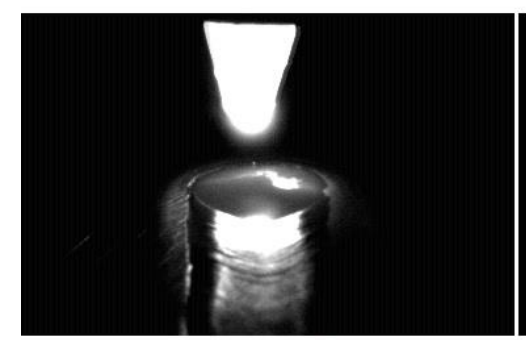

Imagem Normal

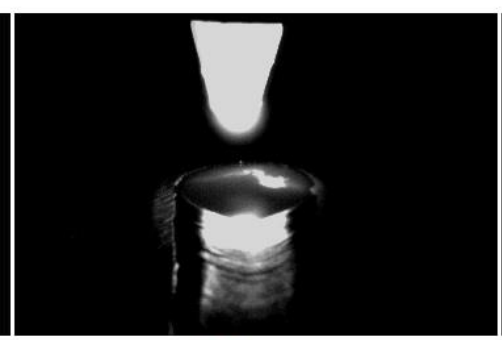

Brilho

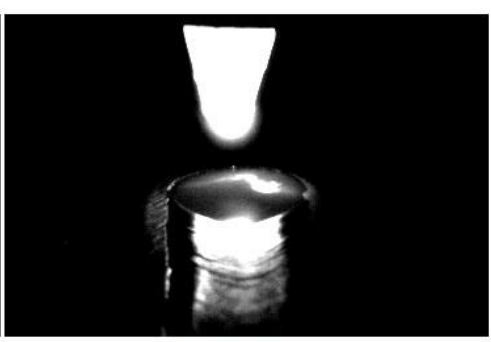

Contraste

Figura 3.26 - Realce no contraste da imagem 


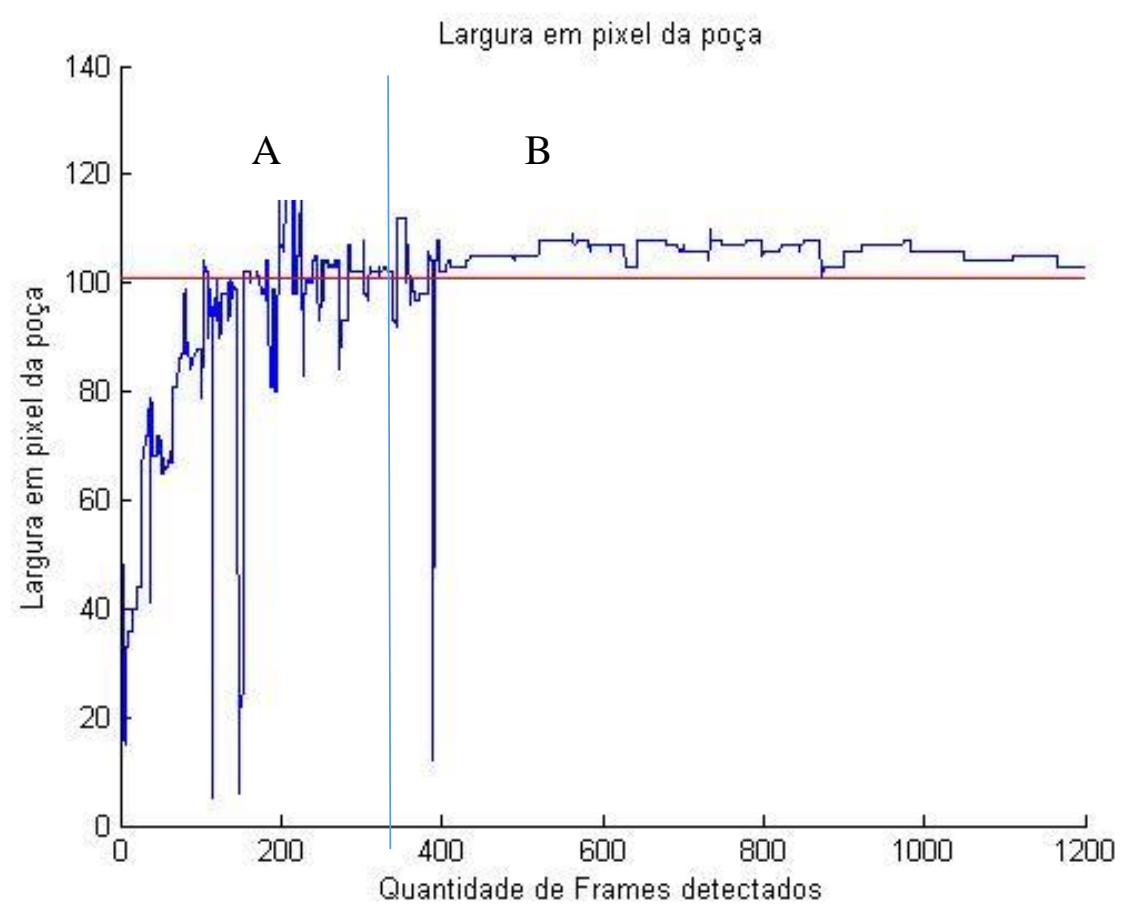

Figura 3.27 - Largura da poça em pixel encontrada durante experimento

Para tornar mais claro, o gráfico da Figura 3.27 foi dividido em duas regiões, sendo elas: (A) Início do processo de soldagem, em que a poça de solda ainda não possui uma geometria fixa (poça em crescimento), região caracterizada por instabilidade do arco e por bordas falsas, Figura 3.29; (B) estabilidade na largura da poça de solda, em que os valores ficam em torno de uma média Figura 3.30 e Figura 3.31. A linha vermelha representa a média da poça de solda que seria 101 pixels, cada pixel equivale cerca de 0,058mm, valor obtido contando os pixels na região de um milímetro do papel milimetrado com as características adotadas no ensaio, sendo que transformando os valores de pixels em milímetros daria uma poça com média de 5,86mm, valor que se aproxima ao obtido na medição no corpo de prova (Figura 3.28).

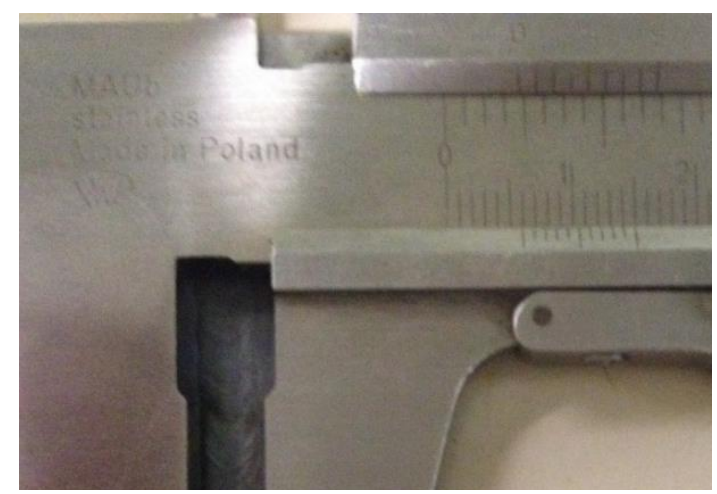

Figura 3.28 - Medidas no corpo de prova 

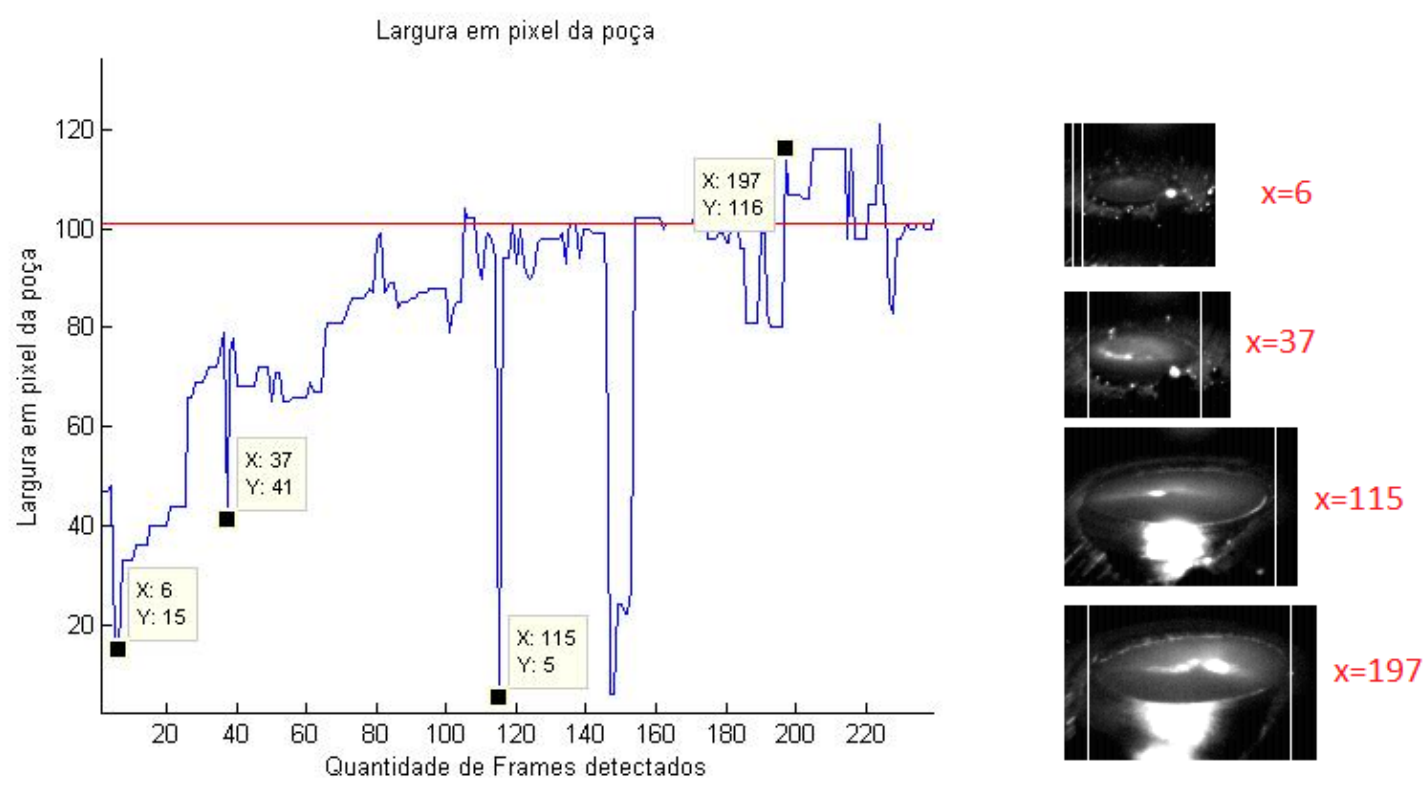

Figura 3.29 - Largura da poça em pixel parte A
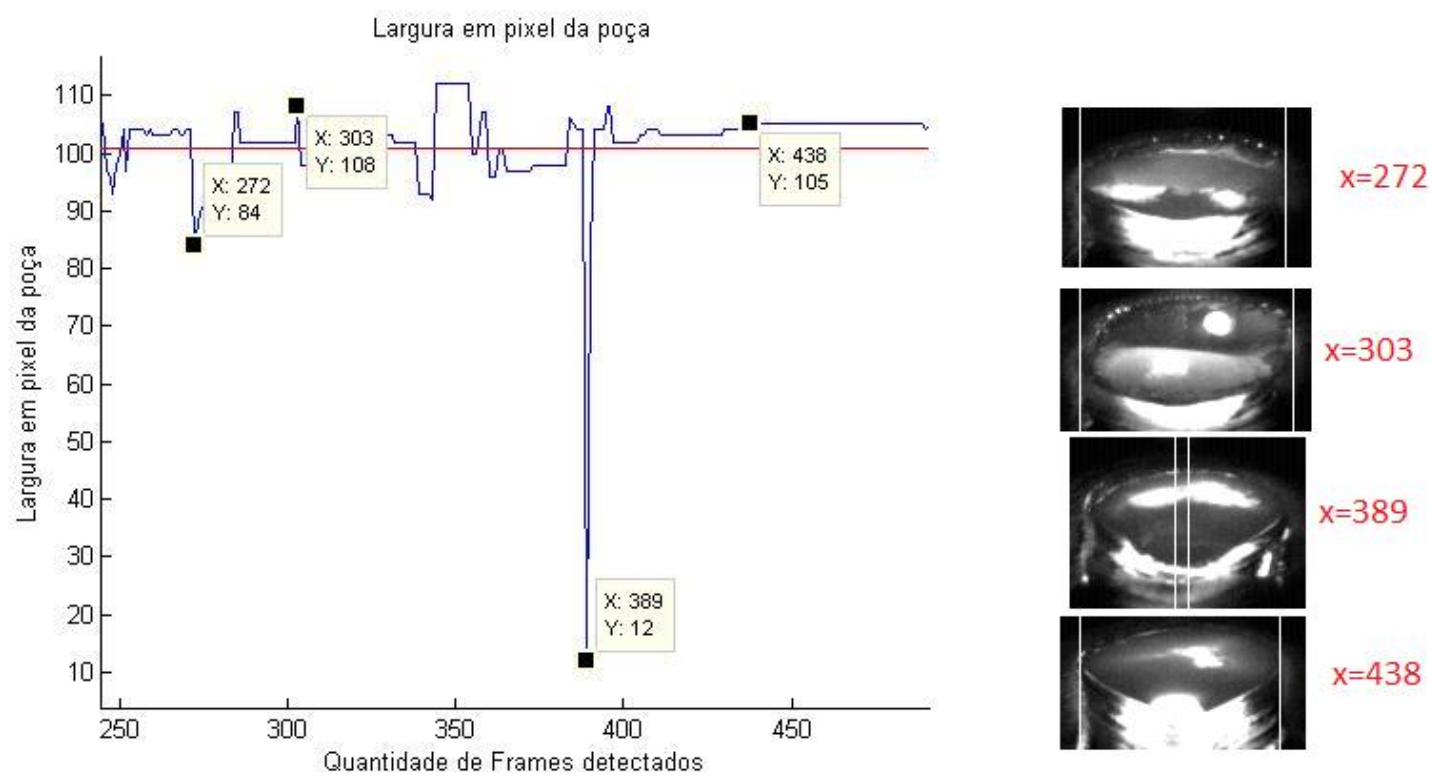

Figura 3.30 - Largura da poça em pixel na região B 


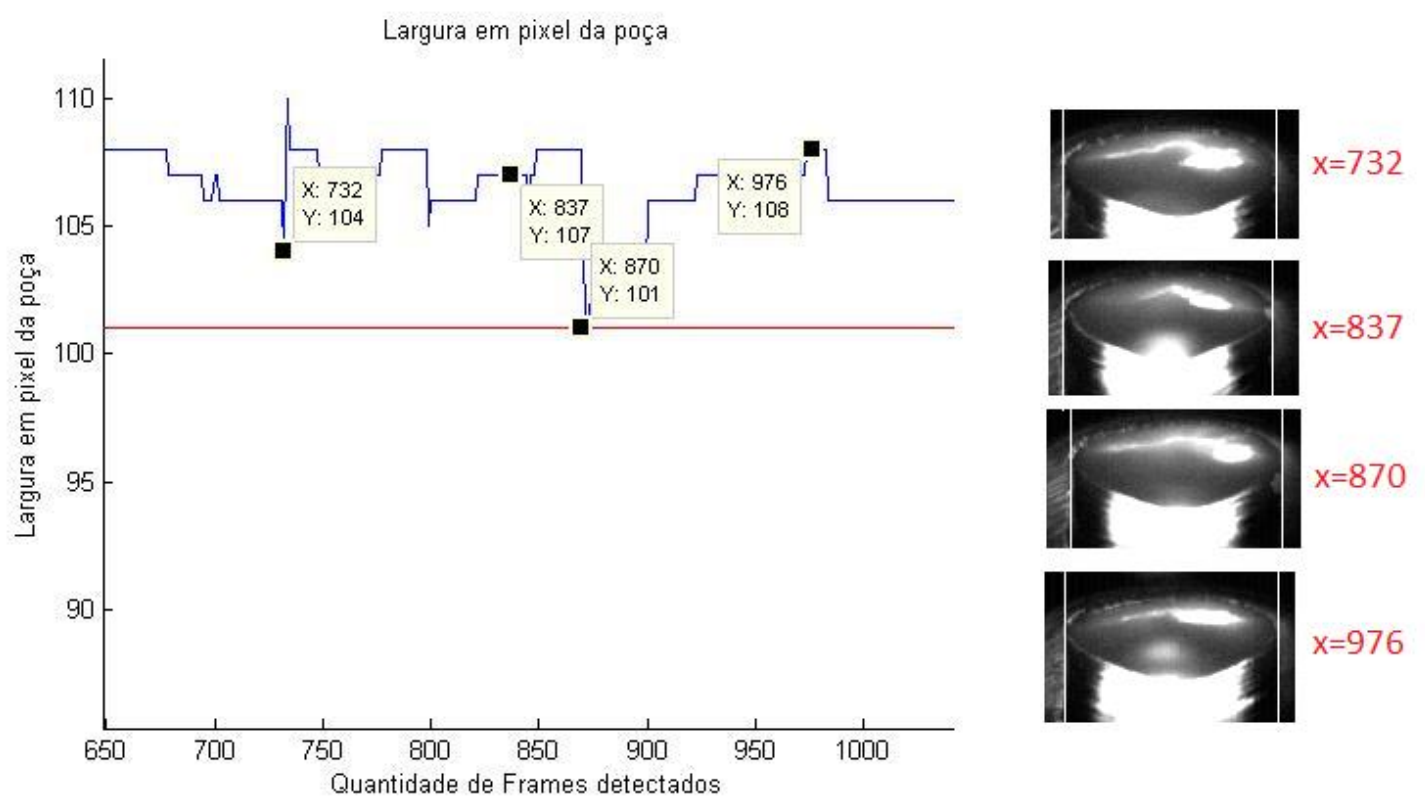

Figura 3.31 - Largura da poça em pixel em outra parte da região B

As variações da borda direita e esquerda das imagens podem ser vistas na Figura 3.32:

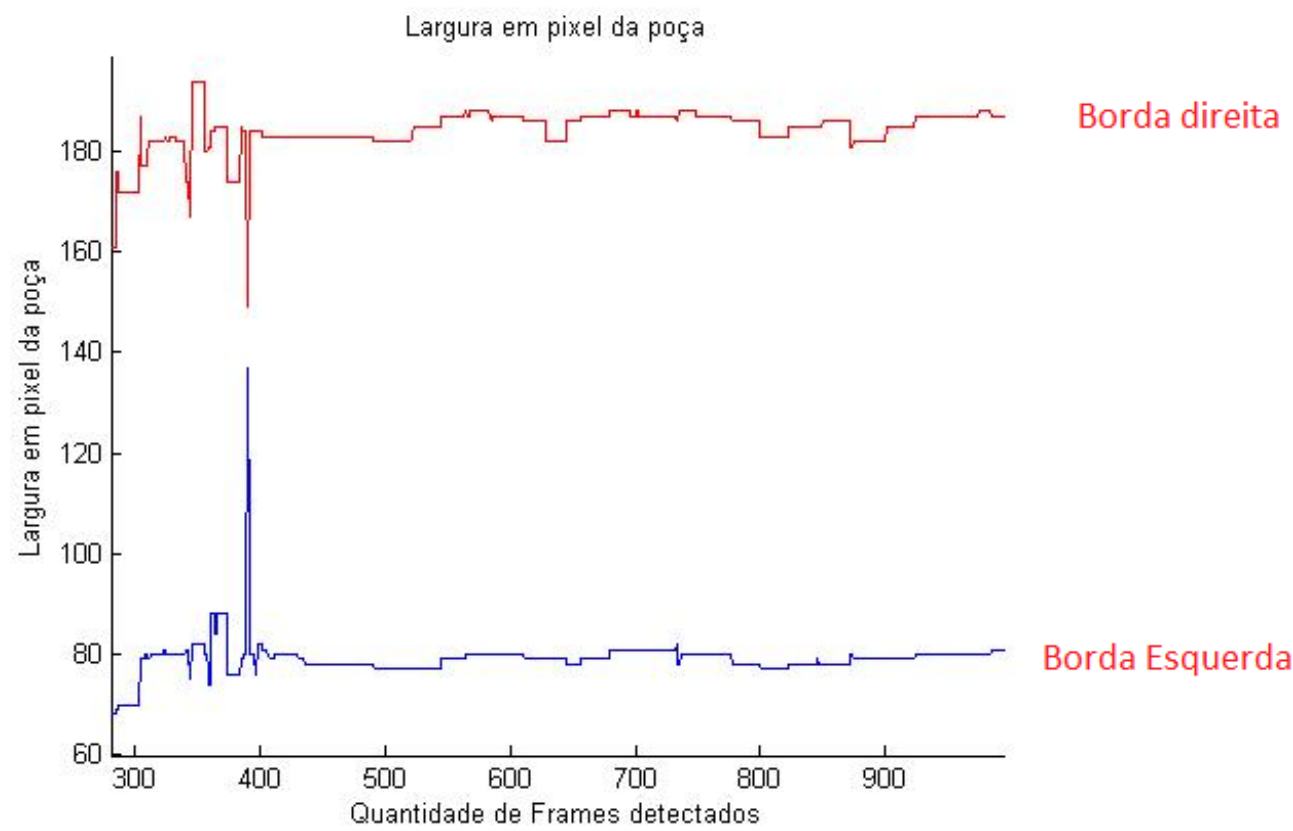

Figura 3.32 - Variação da borda 


\section{DISCUSSÃO DOS RESULTADOS}

Este trabalho propôs a criação de um sistema de monitoramento no processo GTAW pulsado sem alimentação de arame, baseado na aquisição de imagens da poça de fusão e da análise da intensidade luminosa de cada frame. A aquisição das imagens foi livre, sem sincronização por meio de monitoramento de sinais elétricos, porém foi desenvolvido um método computacional da análise luminosa de cada frame adquirido, a fim de selecionar as imagens em que a interferência do arco é pequena, ou seja, em que o brilho do arco não impede a visualização da poça fundida, possibilitando o desenvolvimento de um algoritmo de processamento e medição das características geométricas da poça.

A primeira parte do projeto baseou-se no desenvolvimento de um aparato experimental complexo, composto pelos seguintes itens: (a) uma mesa de movimentação linear e o entendimento dos respectivos sistemas de controle; (b) programação de parâmetros na fonte de soldagem para obtenção de um processo de soldagem pulsado; (c) escolha da câmera com características que tornariam possível a aquisição de imagens de qualidade da poça; (d) projeto de uma estrutura de fixação dos aparatos utilizados para monitoração na tocha de soldagem; (e) um conjunto de software para captura e análise da imagem. O conjunto de todos esses elementos constituiu-se um trabalho penoso, devido à complexidade de ajuste da cada parte e a interação entre todas elas, tendo como base que o mal funcionamento ou dimensionamento de uma das partes acarretaria em um problema que poderia ser difícil de ser identificado, pois os diversos equipamentos envolvidos e dispersos entre si, tornam-se potenciais pontos de falhas.

Uma dificuldade encontrada foi com respeito ao funcionamento da fonte de soldagem TIG. Para um cordão de qualidade, recomenda-se a abertura do arco utilizando alta frequência, porém equipamentos eletrônicos são sensíveis à interferência eletromagnética produzida pelo sistema de alta frequência. Desta forma, durante os testes iniciais, alguns equipamentos eletrônicos foram danificados, causando atraso na obtenção dos primeiros resultados. Com o intuito de contornar esse problema, inicialmente foi proposta a construção de um tipo de gaiola de Faraday, porém os resultados eram os mesmos, como exemplo, desarme da câmera e aquecimento do computador conectado a ela. Sendo assim optou-se pela abertura do arco de forma manual, utilizando pedaços de 
lã de aço para fechar contato entre o eletrodo e o corpo de prova. Esse procedimento causou mudanças no comportamento inicial do arco, ocasionando instabilidade em parte do processo, porém nada que prejudicasse um cordão final de qualidade e boas imagens da poça de soldagem.

Por se tratar de um projeto voltado para a aplicação de técnicas de visão computacional para monitorar aspectos geométricos da poça de soldagem, a escolha da câmera é uma etapa importante. Inicialmente o projeto consistia em utilizar uma câmera de pequena proporção, optando por utilizar um endoscópio CMOS USB 2.0 com capacidade de 30fps e uma resolução de 640x480 pixels. A escolha da câmera estava ligada ao projeto da estrutura que a fixaria na tocha de soldagem, pois como comentado, quanto maior o aparato colocado sobre a tocha de soldagem, maior a perda de liberdade de orientação da tocha num processo robotizado. Entretanto, por se tratar de um equipamento barato e de baixa qualidade, os testes feitos não trouxeram respostas desejáveis, principalmente pela saturação da imagem causada pelo brilho do arco e pela pequena distância focal. Desta forma, foi utilizada uma câmera de alta velocidade disponível no laboratório do GRACO. Para não alterar o escopo do projeto, uma nova estrutura foi criada para atender os requisitos pré-estabelecidos inicialmente no trabalho.

A última parte, concernente à montagem experimental, consistia na elaboração de um projeto estrutural que fixaria a câmera, os filtros e os espelhos. Todo projeto deveria ser elaborado para que, no final, pudesse ser montado na tocha de soldagem, e implantada em um processo de soldagem robotizado. A escolha do local de montagem teve como base alguns trabalhos que descreviam que o efeito das vibrações ocasionadas pelo o movimento do robô é menor próximo à ferramenta de trabalho. Nenhum teste para validar essa informação foi feito. Como mencionado, o monitoramento da solda utilizando câmeras é bem restrito e pouco utilizado, devido a perda de orientação ocasionada pela instalação do mesmo, dessa forma, estudos recentes estão elaborando técnicas de visualização da solda por filmagem indireta, o que acarretaria em uma menor estrutura. Essa técnica é baseada no caminho da luz e em reflexões ocasionadas pelos espelhos como já comentado no tópico 2.3.1. Assim projetos com pequenas proporções poderiam ser elaborados. A estrutura mostrou eficiente para filmagem da poça de solda, e pode ser utilizada também para outros projetos, pois possibilita, dependendo da configuração dos espelhos, diferentes cenas da poça de solda e do cordão formado. Outras cenas da poça poderiam reduzir o efeito do reflexo da ponta incandescente do eletrodo na superfície 
líquida da poça, por exemplo a visualização frontal. O cordão depositado não precisa ser diretamente visualizado, uma vez que sua largura final está fortemente relacionada com a largura da poça de fusão, podendo-se considerá-los como tendo as mesmas dimensões (largura).

O uso de visualização indireta, com base na reflexão da imagem por espelhos dá margem ao desenvolvimento de sensores capazes de recuperarem informações tridimensionais, por meio da utilização de espelhos oblíquos entre si, formando duas imagens da mesma cena a partir de vistas diferentes, de modo semelhante à visão estéreo.

Após a realização de testes de soldagem para verificar a correta performance do aparato experimental, realizou-se pesquisa sobre técnicas de monitoramento e de análise dos parâmetros de soldagem. Constatou-se que a maioria dos trabalhos envolvendo soldagem e visão computacional, sincronizava as imagens possíveis de processamento por meio de sistemas de monitoramento de sinais elétricos, onde a aquisição se dava nos instantes de corrente ou tensão baixa. Desta forma, um hardware de detecção desses pontos era acrescentado ao escopo do projeto. Buscando outra forma de sincronização, uma abordagem diferente foi implementada, em que a sincronização aconteceria por meio de técnicas computacionais e processamento de imagens em uma filmagem livre. A técnica consistia em analisar a soma integral dos pixels de uma sub-região da imagem, geralmente onde o arco é predominante durante os picos de corrente (Ip). Verificou-se que durante esse tempo havia uma saturação da imagem na região do arco. A ideia, então, foi comparar a imagem de aquisição atual com a imediatamente anterior e, caso houvesse um pico negativo na intensidade luminosa, catalogá-la-ia como imagem sem arco. O método se tornou eficiente como técnica de sincronização, que pode ser utilizado em outros processos de soldagem onde há uma faixa cíclica de corrente e tensão de alta e baixa intensidade. Para bom funcionamento do algoritmo integral da imagem, são necessários estudos sobre os comprimentos de onda emitidos pelas composições químicas do gás utilizado, a fim de especificar filtros de atenuação (neutros ou seletivos) compatíveis com o processo.

O desenvolvimento do algoritmo de processamento de imagens da poça foi baseado em uma sequência de passos. Primeiramente, uma seleção das imagens sem interferência do arco foi feita pelo algoritmo integral da imagem. As imagens selecionadas devem ser processadas por um algoritmo de detecção de bordas, segundo 
passo, desenvolvidos no ambiente e programação $\mathrm{C}++$, utilizando a biblioteca OpenCV. O objetivo era extrair das imagens a largura da poça e salvá-las em um arquivo final de programa para plotagem dos gráficos. Os gráficos foram desenvolvidos no ambiente MATLAB, pela facilidade de interação com os resultados através de criação de rotinas matemáticas. Esses passos visavam validar a eficiência computacional e a capacidade de generalização do algoritmo proposto com todas as imagens do experimento. Inicialmente grande parte das imagens processadas portavam bordas duplas, o que prejudicava a contagem dos pixels e consequentemente, não era possível extrair os valores reais da largura a poça. Para solucionar esse problema bastou apenas mudar o aparato de filtros ópticos, pois se constatou que grande parte dessas bordas duplas eram ocasionadas por uma região de intenso brilho em volta da poça fundida.

Com essas mudanças, o algoritmo se mostrou adequado na medição da largura da poça de solda, comprovando a capacidade de utilizar o operador SOBEL nos processos de soldagem para detecção das bordas. Uma melhoria no algoritmo seria a implementação de outros filtros para eliminação dos ruídos e realce das bordas (caso não abordado no escopo do trabalho), ou seja, filtros computacionais passa-alta direcionais, neste caso as bordas seriam realçadas segundo a direção preferencial de interesse, definidas pelas mascaras utilizadas, produzindo resultados que poderiam melhorar a eficiência final do algoritmo. 


\section{CONCLUSÃO}

O objetivo do trabalho foi desenvolver um sistema de visão computacional utilizando técnicas de processamento para sincronização das imagens da poça sem o brilho ocasionados pelo arco de soldagem, para então analisar alguns parâmetros da poça fundida como a largura a poça e sua posição média.

Os resultados do experimento permitiram concluir que:

- É possível desenvolver um sensor de visão não intrusivo para monitorar um processo de soldagem GTAW pulsado;

- A técnica de sincronização das imagens por meio de técnicas computacionais em uma filmagem livre é eficiente na seleção das imagens com mínima interferência do arco, tornando-se uma possível solução para quem não optar por sincronizar a captura baseado nos sinais elétricos;

- Filtros ópticos passa alta, reduzem o brilho do arco elétrico evidenciando a poça de fusão em um processo de soldagem;

- A visualização da poça fundida pode ser feita através da reflexão utilizando espelhos planos, e sua utilização não acarreta perda expressiva na qualidade da imagem, contanto que o objeto filmado esteja dentro da distância focal da câmera;

- Utilizar espelhos para monitoração da poça permite a instalação da estrutura do sensor próximo à tocha o que reduz sua interferência no conjunto;

- O algoritmo de medição apresentado neste trabalho é eficiente na medição da poça a uma alta taxa de captura, porém sensível a ruídos ocasionados pela presença do arco, por sua reflexão na poça ou por reflexões da ponta incandescente do eletrodo na poça ou, ainda, por imagens fora de foco, isoladamente ou em associação com os fatores citados.

O projeto deste trabalho abre uma gama de possibilidades da implantação de sensores de visão nos processos de soldagem robotizados, com a intenção de melhorias continuas na qualidade do cordão produzido e monitoração de novos parâmetros que não seriam possíveis de serem medidos apenas utilizando dados elétricos como corrente e tensão. 


\subsection{TRABALHOS FUTUROS}

Como trabalhos futuros pode-se citar inicialmente a implantação do sensor de visão em robô de soldagem, como o IRB2000 disponível no GRACO, levantando as vantagens e desvantagens da estrutura fixada na tocha de soldagem no monitoramento de dados da soldagem e na orientação da tocha. Outro projeto seria a implementação de um controle de malha fechada utilizando os dados da largura da poça obtidas pelo algoritmo como realimentação aliando aos sinais elétricos. Utilizar o algoritmo no processo de soldagem GMAW, e verificar sua eficiência em outros tipos de soldagem.

Outro projeto está relacionado a melhorias do trabalho proposto, entre as quais se destacam: (a) calibração automática para início da aquisição das imagens; (b) detecção das bordas baseado em inteligência artificial, para melhoria na eficiência, evitando bordas duplas e outros dados que não são importantes para o processo; (c) utilização de espelhos oblíquos entre si, mapeando cenas diferente da poça, para reconstrução tridimensional do cordão soldado; (d) implementar o software em um ambiente FPGA. 


\section{BIBLIOGRAFIA}

[1] Duarte, L. (2007) "Sincronização, Captura e Análise de Imagens de Poça de Soldagem no Processo GMAW Convencional, no Modo de Transferência Metálica por Curto-Circuito.," 2007 - Dissertação Mestrado - UnB.

[2] Absi, S; Carvalho, C. (2003) "Monitoração da poça de Fusão," Soldagem $e$ Inspeção, vol. 8, no. 1, pp. 23-29, 2003.

[3] Kong, M; Chen, S. (2009) "Al alloy weld pool control of welding robot with passive vision," Sens. Rev., vol. 29, no. 1, pp. 28-37, 2009.

[4] Chen, S; Zhang, T. (2003) "Robotic Welding Systems with Vision-Sensing and Self-learning Neuron Control of Arc Welding Dynamic Process," - Journal of Intelligent and Robotic Systems - pp. 191-208, 2003.

[5] Wu, L; Wang, Q. (2000) "Intelligent Methodology for Sensing, Modeling and Control of Pulsed GTAW : Part l"- Welding Research Supplement - pp. 151-163, 2000.

[6] Mota, C; Machado,Vilarinho, L. (2013) "Sistema de visão por infravermelho próximo para monitoramento de processos de soldagem a arco," Soldagem e Inspeção, vol. 18, no. 1, pp. 19-30, Mar. 2013.

[7] Frolov, V; Pipa, V; Kozakov, R. (2014) "Influence of the arc plasma parameters on the weld pool profile in TIG welding," J. Phys. Conf. Ser., vol. 550, 2014.

[8] Modenesi, J. (2007) "Introdução à Física do Arco Elétrico e sua Aplicação na Soldagem dos Metais," - Departamento de Mecânica - p. 146, 2007 UFMG.

[9] Teixeira, G. (2011) "Análise da influência dos parâmetros de soldagem sobre a geometria do cordão de solda depositado pelo processo de soldagem TIG - MAG em Tandem," - Vetor - v. 22 Porto Alegre, 2011.

[10] A. R. Apolina, I. M. Pereira, P. J. Modenesi, "TIG welding with single-component fluxes,” J. Mater. Process. Technol., vol. 99, pp. 260-265, 2000.

[11] P. J. Modenesi, "A química da formação do cordão na soldagem TIG," Soldag. $e$ Insp., vol. 18, pp. 287-300, 2013.

[12] Machado, I. (2007) Soldagem em técnicas conexas, UFRGS. Porto Alegegre, 2007.

[13] Delgado, L. (2000) "Estudo e Desenvolvimento do Processo Tig com alimentação automática de arame," 2000 - Dissertação de Mestrado UFSC.

[14] Cunha, T. (2008) "Desenvolvimento de equipamento e de metodologia de parametrização para a soldagem orbital TIG," 2008 Dissertação de Mestrado UFSC.

[15] Dutra, J; Quites, A. (1979) "Tecnologia de Soldagem a Arco Voltaico", Edição pró. Florianopolis, 1979.

[16] Júnior, R. (2002) "Novos métodos de controle da soldagem MIG/MAG," 2002 Tese Doutorado UFSC.

[17] Liu, Y; Zhang, W; (2015) "Nonlinear Modeling for 3D Weld Pool Characteristic Parameters in GTAW," Weld. Res., no. Julho, pp. 231-240, 2015.

[18] Liu, Y; Zhang, W. (2014) "Model-Based Predictive Control of Weld Penetration in Gas Tungsten Arc Welding," Weld Res., vol. 22, no. 3, pp. 955-966, 2014.

[19] Mota, C; Machado,Vilarinho, L. (2011), "Estudo da emissão de raios infravermelho próximo em processos de soldagem a arco," Soldag. e Insp., vol. 16, no. 1, pp. 44-52, 2011.

[20] Liu, Y; Zhang, W. (2012). "Characterization of Three-Dimensional Weld Pool Surface in GTAW,” Weld. J., vol. 91, no. Julho, pp. 195-203, 2012.

[21] Carvalho, G. "An Adaptive Control System For Off-Line Programming in Robotic 
Gas Metal Arc Welding," Cranfield University, 1997 Tese.

[22] Koike, C; Barros, M. (1999). "Monitoração da Poça de Fusão no Processo GMAW". COBEM - Novembro de 1999.

[23] Lippiello, V; Siciliano, B; (2005) "Eye-in-Hand/Eye-to-Hand Multi-Camera Visual Servoing," Proc. 44th IEEE Conf. Decis. Control, pp. 5354-5359, 2005.

[24] Węglowski, M. S. (2007) "Investigation on the arc light spectrum in GTA welding," Manuf. Eng., vol. 20, pp. 519-522, 2007.

[25] Bebiano, D. F. V. (2008) "Monitoração e Localização de Defeitos na Soldagem TIG Utilizando Técnicas De Espectrometria," Universidade de Brasília, 2008.

[26] Bálsamo, B; Scotti, L; Vilarinho, L. (2000) "Development of an experimental technique for studying metal transfer in welding: Synchronized shadowgraphy," Int. J. Join. Mater., vol. 12, no. 2, pp. 48-59, 2000.

[27] Wang, J; Lin, T; Chen, S. (2005) "Obtaining weld pool vision information during aluminium alloy TIG welding," Int. J. Adv. Manuf. Technol., vol. 26, no. 3, pp. 219-227, 2005.

[28] Shi, F; Huang, X; Duan, Y; Chen. (2010) "Part-based model for visual detection and localization of gas tungsten arc weld pool," Int. J. Adv. Manuf. Technol., vol. 47, no. 9-12, pp. 1097-1104, 2010.

[29] Madsen, O; Sorensen, C; Larsen, R; Overgaard, L; Jacobsen, J (2002) "A system for complex robotic welding," Ind. Robot An Int. J., vol. 29, no. 2, pp. 127-131, 2002.

[30] Gu, W; Xiong, Z. (2003) "Autonomous seam acquisition and tracking system for multi-pass welding based on vision sensor," Int. J. Adv. Manuf. Technol., vol. 69, no. 1-4, pp. 451-460, Maio 2013.

[31] Wang, X (2014) "Three-dimensional vision-based sensing of GTAW: a review," Int. J. Adv. Manuf. Technol., vol. 72, no. 1-4, pp. 333-345, 2014.

[32] Maroudis, A. (2011) "Compact Vision System For Monitoring Of 3d Weld Pool Surface In Pipe Welding," - University of Kentucky - 2011 Tese.

[33] Smith, G (2009). "The invention and early history of the CCD," Nucl. Instruments Methods Phys. Res. Sect. A Accel. Spectrometers, Detect. Assoc. Equip., vol. 607, no. 1, pp. 1-6, 2009.

[34] Litwiller, C. (2001) "CCD vs. CMOS," Photonics Spectra, vol. 35, no. 1, pp. 154 $158,2001$.

[35] SCHOTT Advanced Optics. 2015.

[36] Gonzalez, R; Woods, R (2000) “Processamento de imagens digitais." p. 509, 2000.

[37] Li, Y (1996) "Monitoring of Weld Joint Penetration Based on Weld Pool Geometrical Appearance.” Welding Research Supplement pp. 317 - 329.1996

[38] Canny, J. (1986) "A computational approach to edge detection.," IEEE Trans. Pattern Anal. Mach. Intell., vol. 8, no. 6, pp. 679-698, 1986.

[39] Bradski, G; Kaehler, A (2008) "Learning OpenCV - Computer Vision With the OpenCV Library", vol. 1. 2008.

[40] Mota, C. (2011) "Sistema de visão por infravermelho próximo para monitoramento de processos de soldagem a arco," 2011. Dissertação Mestrado UnB

[41] Lopera, J. Ramos, E; Carvalho, G; Alfaro, S. (2011) "Uso da Técnica de Perfilografia Para Visualização dos Modos de Transferência Metálica no Processo de Soldagem GMAW Usando uma Câmera CMOS de Alta Velociada," in $A B C M$, 2011, no. 2006.

[42] Sagrario, M; Escofet, J; Pérez, E. (2004) "Óptica Geométrica" 2004.

[43] NIST Atomic Spectra Database Lines, Disponível em: 〈www.nist.gov〉. Acesso dia 14 de outubro de 2015 
[44] Manual de Instruções câmera DALSA

[45] IEEE Acquired Engineering 360, Disponível em: <http://www.globalspec.com>. Acesso 12 de outubro de 2015

[46] Manual de Instrução Migatronic BDH 320; Versão E - Migatronics A/S.

[47] Chen, S.B; Wu, J. (2009). "Visual Sensing Systems for Arc Welding Process". Springer- Verlag Berlin Heidelberg.

[48] Koike, C; Barros, M. (1999). "Monitoração da Poça de Fusão no Processo GMAW". COBEM - Novembro de 1999.

[49] Bauchspiess, A.; Absi Alfaro (2001). "Predective Sensor Guided Robotic Manipulators in Automated welding cells". Jounal of Materials Processing Technology, Vol 109, pp. 13-17.

[50] Ramos, E; Lopera, J. (2011). "Uso de Técnica de Perfilografia para Visualização dos Modos de Transferência Metálica no Processo de Soldagem GMAW Usando uma Câmera de Alta Velocidade" COBEF - Abril de 2011.

[51] Adolfsson, S. "On line Quality Monitoring in Short-Circuit Gas Metal Arc Welding". Welding Journal 78(2), pp. 50-73 (1999). 


\title{
7 APÊNDICE
}

\subsection{OPERADOR SOBEL IMAGEM OFFLINE}

\author{
\#include "stdafx.h" \\ \#include "opencv2/imgproc/imgproc.hpp" \\ \#include "opencv2/highgui/highgui.hpp" \\ \#include <opencv2/opencv.hpp> \\ \#include <iostream> \\ \#include <fstream > \\ \#include <string> \\ \#include <cstdlib>
}

using namespace cv;

using namespace std;

int main( int $\operatorname{argc}$, const char** $\operatorname{argv}$ )

\{

Mat img = imread("Img1683.bmp", CV_LOAD_IMAGE_UNCHANGED); //ler os dados de imagem no arquivo "MyPic.JPG" e armazená-lo em 'img'

//__ Variaveis

Mat frame;

Mat gray;

Mat dst;

Mat src, src_gray;

Mat grad;

char* window_name = "Sobel Demo - Simple Edge Detector";

int scale $=1$;

int delta $=0$;

int ddepth $=$ CV_16S ; 
//__ Região de interesse e soma de pixels

//Definição da região de interesse

int $\mathrm{xo}=125$, yo=150;

int width=115, height=1; //imagem sem arco

Mat roi(img,cv::Rect(xo,yo, width,height));

//Calculo soma sem arco

//Retorna um escalar para trabalhar com imagens multi-canal

Scalar sum $=$ cv::sum $($ roi $)$;

// Calculo da integral da imagem

Mat integralImage;

integral(img,integralImage,CV_32S);

//Obter soma sobre uma área usando três adições / subtrações

//sem arco

int sumInt $=$ integralImage at $<$ int $>($ yo+height, xo+width $)$

-integralImage.at $<$ int $>($ yo+height,xo $)$

-integralImage.at $<$ int $>$ (yo,xo+width)

+integralImage.at $<$ int $>($ yo,xo $)$;

$/ /$ FILTRO

//FIltro mediano

frame=img;

//medianBlur(frame,dst,3); //Aplicar filtro mediano

//cvtColor(dst, src_gray, CV_BGR2GRAY);

//Transformar para escala de cinza 
//Filtro Gaussiana e escala de cinza

//GaussianBlur( frame, dst, Size(3,3), 0, 0, BORDER_DEFAULT );

//Aplicação do filtro Gaussiano

//cvtColor(dst, src_gray, CV_BGR2GRAY);

//Transformar para escala de cinza

//Filtro Bilateral

bilateralFilter( frame, dst, 3, 75, 75 );

//__ SOBEL e cálculo de derivadas

//Cálculo das derivadas na direção X e Y

Mat grad_x, grad_y, grad_x1, grad_y1;

Mat abs_grad_x, abs_grad_y;

/// Gradiente X

Sobel( roi, grad_x, ddepth, 1, 0, 3, scale, delta, BORDER_DEFAULT );

///Segunda derivada em $\mathrm{X}$

Sobel(grad_x, grad_x1, ddepth, 1, 0, 3, scale, delta, BORDER_DEFAULT );

/// Gradiente Y

Sobel( roi, grad_y, ddepth, 0, 1, 3, scale, delta, BORDER_DEFAULT );

///Segunda derivada em $\mathrm{Y}$

Sobel(grad_y, grad_y1, ddepth, 1, 0, 3, scale, delta, BORDER_DEFAULT );

//Convertemos nossos resultados parciais de volta para CV_8U:

convertScaleAbs(grad_x, abs_grad_x ); 
convertScaleAbs(grad_y, abs_grad_y );

//Finalmente, tentamos aproximar o gradiente adicionando ambos os gradientes direcionais

addWeighted( abs_grad_x, 0.5, abs_grad_y, 0.5, 0, grad );

cout $<<$ "Integral da imagem : " $<<$ sumInt $<<$ endl;

//__ Cálculo poça a parti do gradiente $\mathrm{x}$

double minVal; double maxVal; Point minLoc; Point maxLoc;

Point matchLoc;

$\operatorname{minMaxLoc}\left(\operatorname{grad} \_x, \& \min V a l, \& \max V a l, \& \operatorname{minL} L o c, \& \max L o c, M a t()\right)$;

cout<<"Borda Inicial: "<<minVal<<endl; //Borda inicial

cout $<<$ "Borda Final: "<<maxVal<<endl; //Borda Final

cout<<"Pos ibor: "<<minLoc<<endl; //Posição Inicial

cout $<<$ "Pos fbor: "<<maxLoc<<endl; $\quad$ //Posição final

cout<<"Poca: "<<maxLoc-minLoc<<endl; //poça

//__ Guardar resultado em txt

//Salvar valor da poça

ofstream borda;

borda.open("Poça.txt", ios::out | ios::app);

borda $<<$ maxLoc-minLoc $<<$ endl;

borda.close(); 
//Salvar primeira derivada

ofstream gradienteX;

gradienteX.open("DerivadaX.txt", ios::out | ios::app);

gradienteX $<<$ grad_x $<<$ endl;

gradienteX.close();

//Salvar valor da integral da imagem

ofstream escreve;

escreve.open("Brilho.txt", ios::out | ios::app);

escreve $<<$ sumInt $<<$ endl;

escreve.close();

//______ Caso a imagem não abra

if (img.empty()) //verificar se a imagem é carregada ou não

\{

cout $<<$ "Error : Imagem não pode ser carregada!!" < < endl;

//system("pause"); //esperar apertar uma tecla

return -1 ;

\}

namedWindow("MyWindow", CV_WINDOW_AUTOSIZE);

//Criar uma janela com o nome "MyWindow"

imshow("MyWindow", roi);

//apresentar a imagem que é armazenado no "img" na janela "MyWindow"

waitKey(0); //tempo de espera infinita para uma tecla 
destroyWindow("MyWindow"); //destruir a imagem com o nome, "MyWindow"

return 0 ;

\}

\subsection{OPERADOR SOBER CAPTURA LIVRE}

\#include "stdafx.h"

\#include "opencv2/imgproc/imgproc.hpp"

\#include "opencv2/highgui/highgui.hpp"

\#include <opencv2/opencv.hpp>

\#include <iostream>

\#include <fstream>

\#include <string>

\#include <cstdlib>

\#include <iomanip>

using namespace cv;

using namespace std;

//__ Rotina para abrir o vídeo

int main(int $\operatorname{argc}$, char* $\operatorname{argv}[])$

\{

VideoCapture cap("videoaqui"); // Abrir o Video na pasta local ou câmera

if ( !cap.isOpened() ) // Se não obtiver sucesso, fechar o programa

\{

cout $<<$ "Esse video nao carrega" $<<$ endl;

return -1 ; 
$/ /$ Dados do vídeo

//cap.set(CV_CAP_PROP_POS_MSEC, 300); //Começar o vídeo após 300ms

double fps $=$ cap.get(CV_CAP_PROP_FPS $)$; //Capturar FPS do vídeo

cout $<<$ "Frame por segundo : " $<$ fps $<<$ endl;

namedWindow("MyVideo",CV_WINDOW_AUTOSIZE); //Criar uma janela chamada "MyVideo"

namedWindow("MyVideo1",CV_WINDOW_AUTOSIZE); //Criar uma janela chamada "MyVideo"
int frameAnterior $=0$;
int frameAtual $=0$;
int ePrimeiroFrame $=1$;
int diferenca $=0$;

while(1)

\{

//Variaveis

Mat frame;

Mat gray;

Mat dst;

Mat src, src_gray;

Mat grad;

char* window_name = "Sobel Demo - Simple Edge Detector"; 
int scale $=1 ;$
int delta $=0 ;$
int ddepth $=$ CV_16S;

bool bSuccess = cap.read(frame); // Ler um novo frame do vídeo

if(!bSuccess $)$

\{

break;

\}

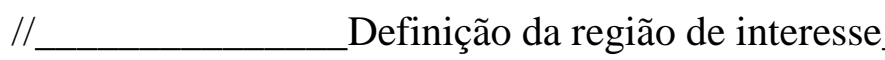

//Definição da região de interesse

int $\mathrm{xo}=95, \mathrm{yo}=125$;

int width $=150$, height $=45 ;$;

Mat roi(frame,cv::Rect(xo,yo, width,height));

/I Calculo integral da Imagem

//Calculo soma sem arco

//Retorna um escalar para trabalhar com imagens multi-canal

Scalar sum= cv::sum(roi);

// Calculo da integral da imagem

Mat integralImage;

integral(frame,integralImage,CV_32S);

//Obter soma sobre uma área usando três adições / subtrações 


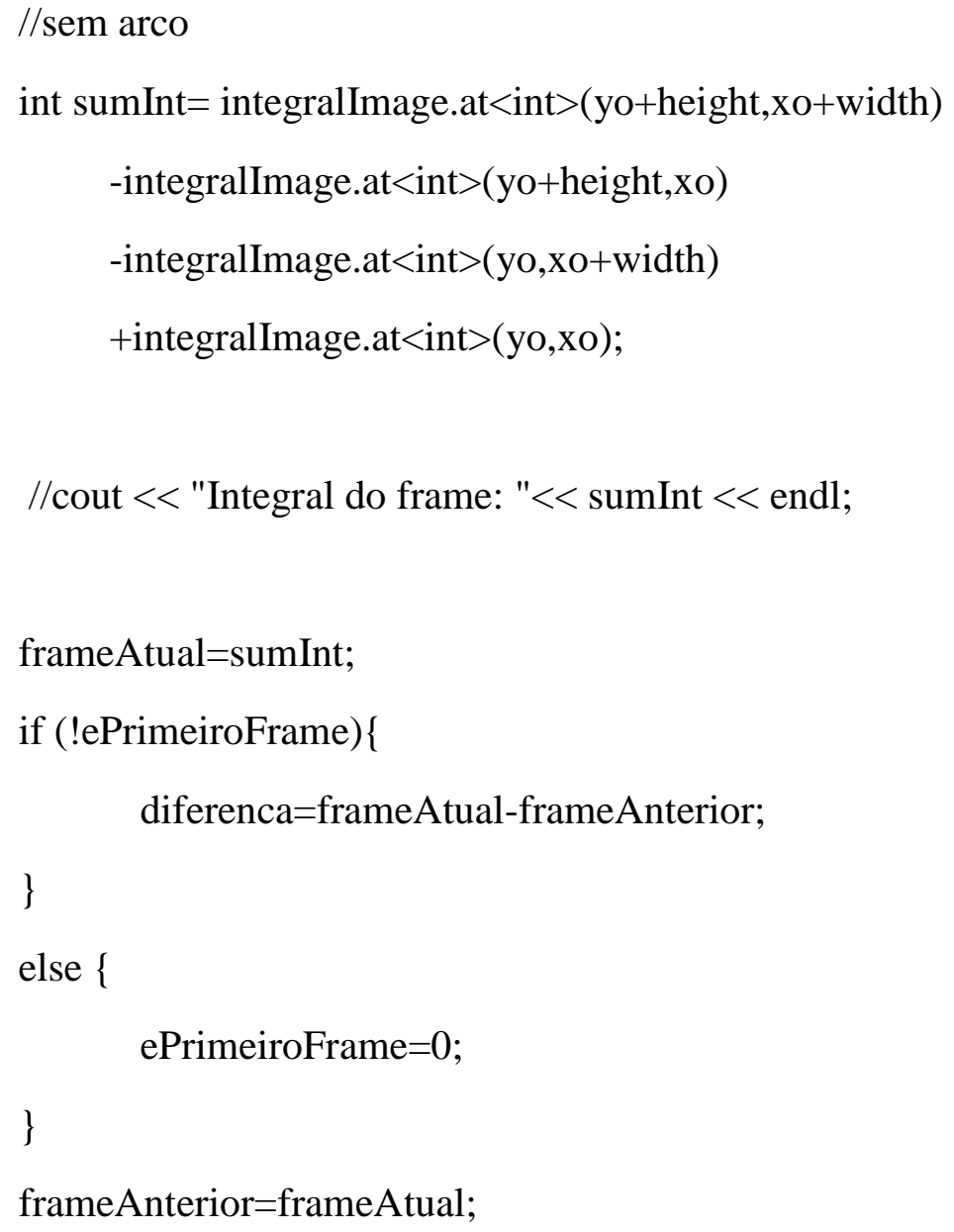

cout $<<$ diferenca $<<$ endl;

//__ Separando Imagem com arco

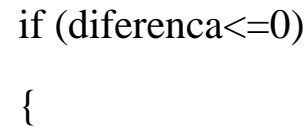


// Filtros

//Filtro Gaussiana e escala de cinza

GaussianBlur( roin, dst, Size(3,3), 0, 0, BORDER_DEFAULT );

//Aplicação do filtro Gaussiano

cvtColor(dst, src_gray, CV_BGR2GRAY);

//Transformar para escala de cinza

//FIltro mediano

//medianBlur(roi,dst,3); //Aplicar filtro mediano

//cvtColor(dst, src_gray, CV_BGR2GRAY);

//Transformar para escala de cinza

//Filtro Bilateral

//bilateralFilter( frame, dst, 3, 75, 75 );

// SOBEL

//Cálculo das derivadas na direção X e Y

Mat grad_x,grad_y, grad_x1, grad_y1;

Mat abs_grad_x, abs_grad_y;

/// Gradiente X

Sobel( dst, grad_x, ddepth, 1, 0,3, scale, delta, BORDER_DEFAULT );

//Segunda derivada em X

Sobel(grad_x,grad_x1, ddepth, 1, 0,3, scale, delta, BORDER_DEFAULT );

/// Gradiente Y

Sobel( dst, grad_y, ddepth, 0, 1, 3, scale, delta, BORDER_DEFAULT ); 
///Segunda derivada em Y

Sobel(grad_y, grad_y1, ddepth, 1, 0, 3, scale, delta, BORDER_DEFAULT );

//cout $<<$ "Mat: "< grad_x $<<$ endl;

//Convertemos nossos resultados parciais de volta para CV_8U:

convertScaleAbs(grad_x, abs_grad_x );

convertScaleAbs( grad_y, abs_grad_y );

//Finalmente, tentamos aproximar o gradiente adicionando ambos os gradientes direcionais

addWeighted( abs_grad_x, 0.5, abs_grad_y, 0.5, 0, grad );

//___ Cálculo poça a parti do gradiente $\mathrm{x}$

double minVal; double maxVal; Point minLoc; Point maxLoc;

//Point matchLoc;

$\operatorname{minMaxLoc}\left(\operatorname{grad} \_x, \& \operatorname{minVal}, \& \max V a l, \& \operatorname{minLoc}, \& \max L o c\right.$, Mat() );

cout $<<$ "Borda Inicial: "<<minVal<<endl; //Borda inicial

cout $<<$ "Borda Final: "<<maxVal<<endl; //Borda Final

cout $<<$ "Pos ibor: "<<minLoc<<endl; //Posição Inicial

cout<<"Pos fbor: "<<maxLoc<<endl; //Posição final

cout $<<$ "Poca: "<<maxLoc-minLoc<<endl; //poça

//__ Guardar resultado em txt

// Salvar valor da poça 
ofstream borda;

borda.open("Poça.txt", ios::out | ios::app);

borda $<<$ maxLoc-minLoc $<<$ endl;

borda.close();

Salvar primeira derivada

ofstream gradienteX;

gradienteX.open("DerivadaX.txt", ios::out | ios::app);

gradienteX $<<$ grad_x $<<$ endl;

gradienteX.close();

//__ Mostrar vídeo

Mostrar as imagens sem arco

Filtro - dst

Filtro em escala de cinza - scr_gray

Sobel - grad

imshow("MyVideo1", dst);

\}

ofstream escreve;

escreve.open("Brilho.txt", ios::out | ios::app);

escreve $<<$ sumInt $<<$ endl;

escreve.close();

//__ C C C C _ _ _ Caso não abra o Vídeo (Fim) 
if (!bSuccess) //Caso contrário, fechar o loop

\{

cout $<<$ "Não lido o Frame do vídeo" < < endl;

break;

\}

imshow("MyVideo", frame); //Mostrar o Frame em minha janela

if(waitKey(30)==27) //wait for 'esc' key press for $30 \mathrm{~ms}$. If 'esc' key is pressed, break loop

\{

cout $<<$ "Tecla esc foi apertada pelo usuário" < e endl;

break;

\}

destroyWindow("Myvideo");

\}

return 0 ;

\} 


\section{ANEXOS}

\subsection{PROJETO INICIAL COM UM ENDOSCÓPIO CMOS}

A proposta inicial deste trabalho consistia na utilização de um endoscópio CMOS com interface USB para visualização da poça de solda. A ideia veio da necessidade de construir um aparato de fixação com pequenas proporções, visando aproveitar ao máximo os graus de orientação da tocha. Os dados do endoscópio utilizado são:

- Diâmetro da encapsulamento: $7 \mathrm{~mm}$;

- Resolução: 640x480 pixels;

- Taxa de Frames: $30 \mathrm{fps}$;

- Campo de visão: 67 graus;

- Distância focal: 25-35mm;

- Arquivo final: JPEG ou AVI.

Para atender à necessidade do processo, o sensor deveria ser apto a filmar com nitidez a poça de solda com o mínimo de interferência luminosa ocasionada pelo arco. A primeira etapa concentrou-se em construir um aparato de fixação para os filtros ópticos, espelhos e endoscópio para instalação na tocha de soldagem. O resultado do projeto pode ser visto na Figura 8.1:
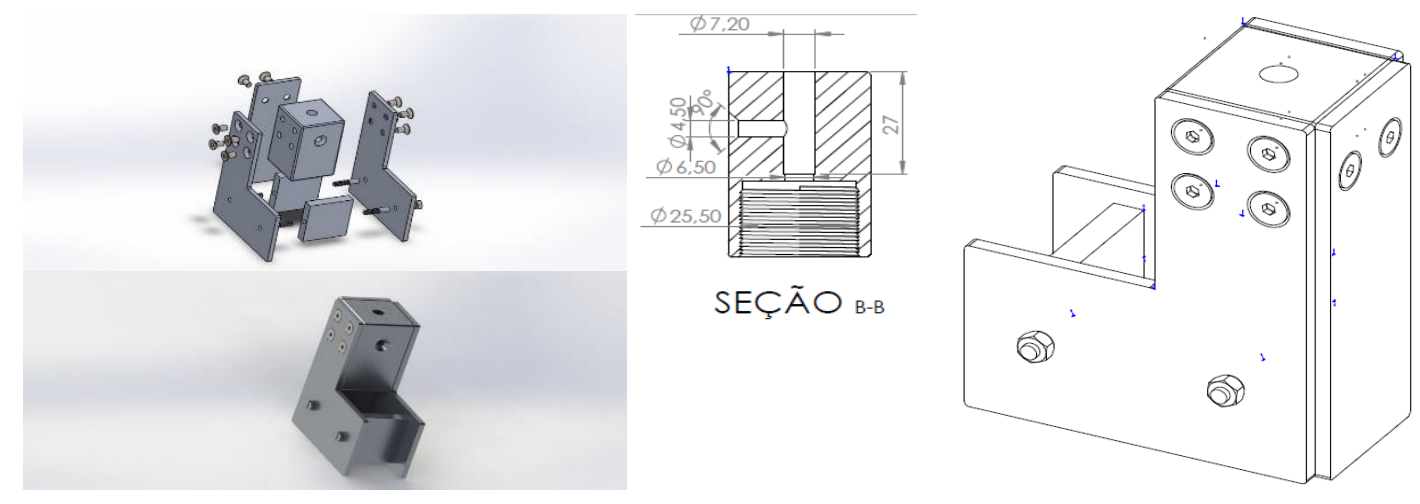

Figura 8.1 - Aparato para suporte dos periféricos do sensor

Na realização dos testes para validação da estrutura verificou-se a necessidade de aumentar a distância focal da câmera devido à perda expressiva na qualidade da imagem. Sendo uma câmera de foco fixo, a solução encontrada para solucionar o problema foi acrescentar ao projeto uma lente com finalidade de aumentar a distância focal. 
Toda estrutura foi montada no robô IRB2000 e os testes para calibração da câmera foram feitos de forma manual. O resultado da montagem da estrutura na tocha pode ser visto na Figura 8.2.

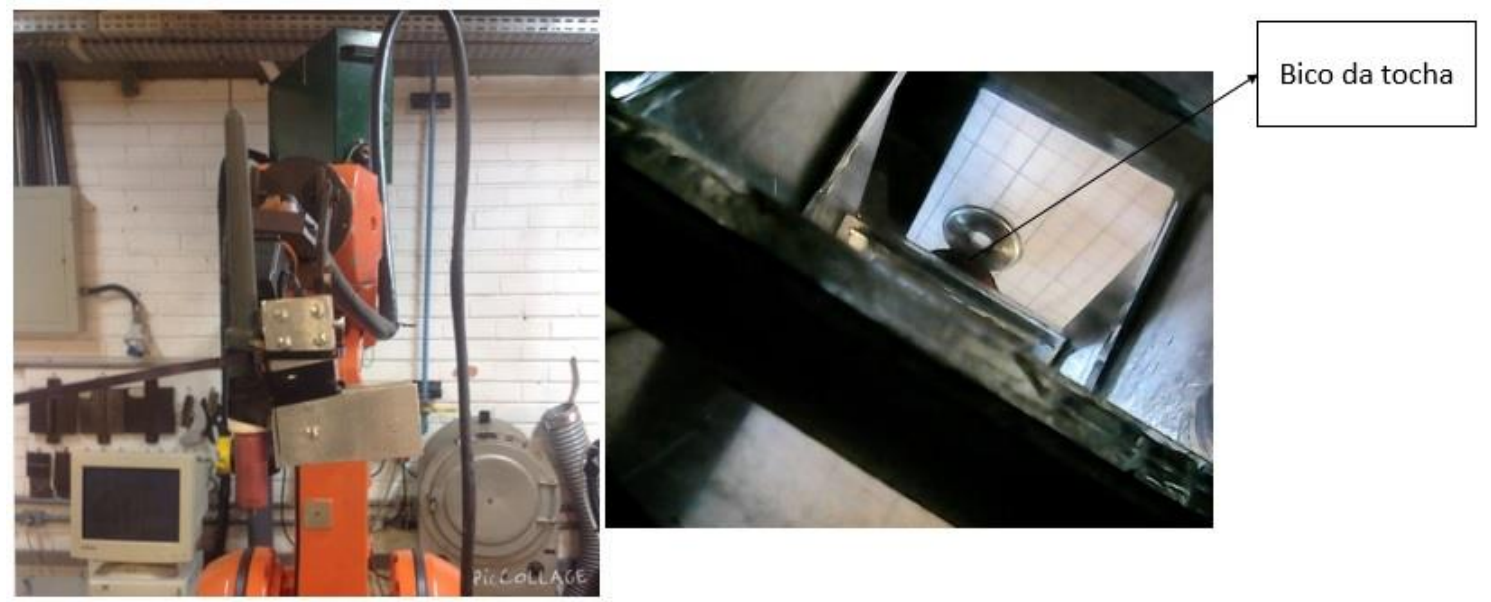

Figura 8.2 - Montagem da estrutura no robô IRB2000

Os primeiros testes com soldagem foram executados com o propósito de selecionar um conjunto de filtros ópticos que melhor se adaptassem ao processo de filmagem. Porem todos se tornaram ineficientes ao projeto. Os filtros foram selecionados com base no tópico 3.4.1. Como exemplo pode-se ver a Figura 8.3, que mostra parte da filmagem feita em um dos testes. Mesmo com os filtros de atenuação a aquisição é prejudicada pela influência do arco.

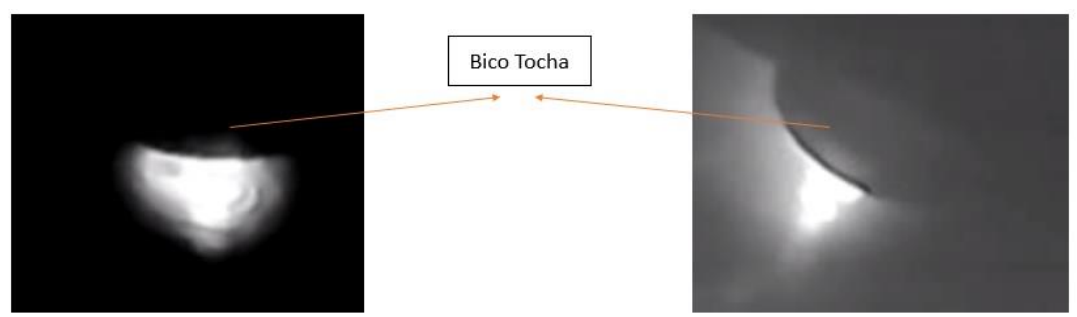

Figura 8.3 - Imagem adquirida utilizando um Endoscópio

O último teste feito consistiu em alterar o tempo de exposição da câmera, com propósito de diminuir a intensidade luminosa que chega no sensor. No entanto as imagens ainda eram fortemente influenciadas. Os testes feitos para ajuste da distância focal, seleção do conjunto de filtros ópticos e alteração no tempo de exposição da câmera propiciaram as seguintes conclusões: 
- A lente utilizada aumentou da distância focal da câmera, porém ainda havia uma perda razoável na qualidade da imagem;

- Mesmo utilizando filtros ópticos na faixa continua do espectro do arco, as imagens continuavam fortemente interferidas pelo brilho do mesmo;

- O tempo de exposição não alterou com expressão a influência do arco no sensor, para o endoscópio usado foi possível alterar o tempo de exposição para 1/60s, com esta configuração houve uma perda significativa na qualidade da imagem.

Outro ponto relevante para ineficiência do projeto é a taxa de aquisição da câmera, que para projetos onde o arco está continuamente aberto, a câmera não consegue sincronizar os tempos de baixa corrente e tensão onde o nível de brilho é alterado ciclicamente. Com isso, para atender ao escopo do projeto, fez-se necessário alterar a câmera e consequentemente todo projeto estrutural para fixação na tocha de soldagem. 